\author{
UNIVERSIDADE DE SÃO PAULO \\ INSTITUTO DE FÍSICA DE SÃO CARLOS
}

DEPARTAMENTO DE FÍSICA E CIÊNCIA DOS MATERIAIS

\title{
Correlação entre Polarização da \\ Luminescência e Orientação Molecular em Polímeros Conjugados
}

Francisco Carlos Barbosa Maia

Dissertação apresentada ao Instituto de Física de São Carlos, da Universidade de São Paulo, como parte dos requisitos à obtenção do título de Mestre em Física Aplicada.

Orientador: Prof. Dr. Francisco E. G. Guimarães

São Carlos

2006 


\section{COMISSÃO JULGADORA}

(Substituir pela folha a ser fornecida pela CPG) 


\section{FOLHA DE APROVAÇÃO}

Membros da Comissão Julgadora da Dissertação de Mestrado de Francisco Carlos Barbosa Maia, apresentada ao Instituto de Física de São Carlos, da Universidade de São Paulo, em /2006.

Comissão Julgadora:

Prof. Dr. Francisco Eduardo Gontijo Guimarães - Orientador (IFSC/USP) 


\section{DEDICATÓRIA}

Dedico esta dissertação à minha mãe, Sílvia Maria Barbosa Maia, ao meu pai, Carlos Roberto Maia, à minha querida irmã, Juliana Barbosa Maia, aos meus avós e em memória de meu avô, João Barbosa. 


\section{AGRADECIMENTOS}

Sou eternamente grato a Deus. E a todas as pessoas que me ajudaram, em especial, àquelas citadas, segredo meus agradecimentos:

\section{Ao Professor:}

Prof. Dr. Francisco Eduardo Gontijo Guimarães pela oportunidade, confiança, transmissão de conhecimento e valiosa orientação e Célio Aécio Borges;

Aos amigos de casa, pela convivência, sobrevivência e amizade:

Bruno H. N. Ometto

Higor R. Favarim

Waldir Avansi Júnior

A todos meus imprescindíveis amigos de Andradas (seus nomes estão em um apêndice em preparação)

\section{Ao Pessoal Técnico do IFSC:}

Ademir Soares - Técnico do Grupo de Polímero;

Carlos A. A. Camargo (Carlinhos) e Técnicos da Oficina Mecânica;

Débora T. Balogh, Dr. Técnico do Grupo de Polímero;

Haroldo Arakaki - Técnico Grupo de Semicondutores MBE;

José R. Betho - Técnico do Grupo de Polímero;

Níbio J. Mangerona - Técnico do Grupo de Polímero;

Rosângela M. M. de Oliveira - Secretária do Grupo de Polímero; 
Aos Professores do IFSC:

Francisco E. G. Guimarães (Chico);

Osvaldo Novais de O. Jr (Chu);

\section{Aos Amigos do Grupo:}

Ângelo C. Perinotto;

Antônio Carvalho (Tony);

Célio A. Borges

Clarissa A. Olivatti;

Edivaldo L. Queiroz;

Fábio A. Bonk;

Felippe José Pavinatto;

Lucas F. Santos;

Silmar A. Travain;

Thiago Cazati;

Valtencir Zucolotto. (Xuxa)

Vicente Galber F. Viana;

Jose Roberto (Júnior)

Caio Oliveira Haysaka

Thiers Massami Uemara 


\section{À Instituição:}

À Fundação de Amparo à Pesquisa do Estado de São Paulo, FAPESP, pela concessão da bolsa de doutorado e pelo apoio financeiro para a realização deste trabalho.

Sinceramente grato. 
Sentado ao cais, homem vê as vagas, Não só elas, também o fim do mar... Quieto pensa: O que há de lá estar, Atrás do sol, do invisível, insólitas plagas?

Só avisos, em curtas cartas de cuja caligrafia é rara. Vindas, talvez de lá, em garrafas e garrafas de vinho raro. Sem endereço, sem pistas, apenas cheiro, e só o faro, De que usam os gênios, é que as desvendara.

Sentado ao cais, homem só divaga.

Em tudo vê o que quer saber a mais...

Diminui-se, é o mar que e faz, É o céu, o invisível, desintegra-se e se apaga... 


\section{Sumário}

1. Introdução..................................................................................

2. Processos Fotofísicos em Polímeros Conjugados .................6

2.1. Polímeros e Moléculas Orgânicas Conjugadas ..........................................7

2.2. Distribuição de segmentos conjugados ..................................................9

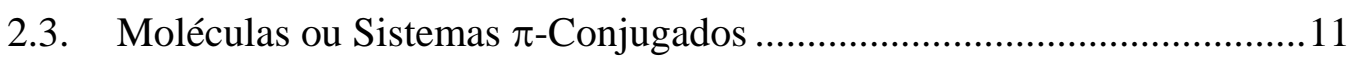

2.4. Estrutura Eletrônica de Polímeros Conjugados........................................13

2.5. Espectros de Absorbância e Luminescência ...............................................16

2.6. Dinâmica do estado excitado eletrônico em sistemas poliméricos: efeito da organização molecular e concentração

2.7. Processos de relaxação da excitação eletrônica em sistemas poliméricos 21

2.8. Transferência de energia 24

2.9. Excitação de um sistema molecular contendo uma distribuição angular de segmentos conjugados: efeito da organização molecular.

2.10. Absorção em um sistema molecular contendo uma distribuição angular de segmentos conjugados: efeito da organização molecular.... .35

3. Materiais e Métodos............................................................39

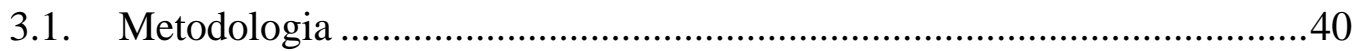

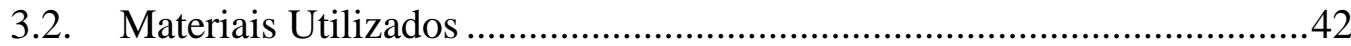

3.3. Síntese do PTHT (precursor do PPV) …...................................................43

3.4. Processo alternativo para formação de filmes de PPV ............................46

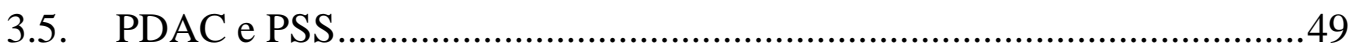

3.6. Limpeza e tratamento dos substratos ....................................................50

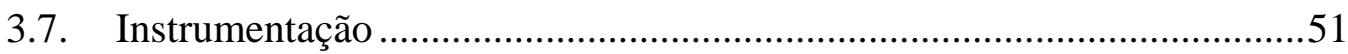

3.8. Absorbância UV-VIS e infravermelho....................................................52

3.9. Sistema óptico de um espectrofotômetro .................................................53

3.10. Fotoluminescência Independente do Tempo (PL) ...............................55

3.11. Aparato experimental para obtenção das medidas de fotoluminescência 55

3.12. Sistema de medidas da anisotropia molecular .................................58

3.13. Método de adsorção de filmes automontados .....................................59 
3.14. Estrutura Molecular dos Filmes LbL estudados ................................62

3.15. Preparação dos filmes sobre Teflon ...................................................63

4. Fotofísica de filmes poliméricos conjugados sem

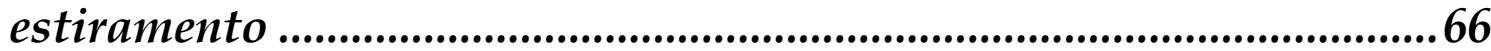

4.1. Propriedades ópticas do PPV sobre filme de Teflon...............................69

4.2. Processos fotofísicos em filmes não estirados ..........................................70

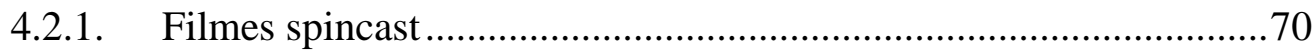

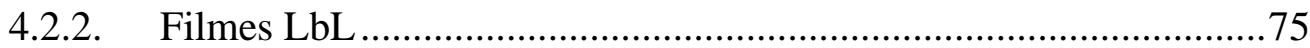

4.3. Propriedades ópticas de filmes com pequeno grau de estiramento: orientação axial das cadeias 80

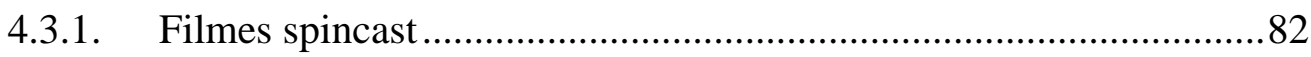

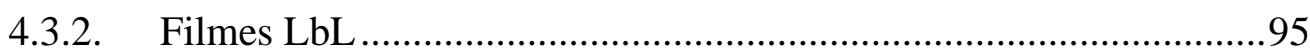

5. Migração das excitações eletrônicas em polímeros conjugados luminescentes diluídos em uma matriz inerte ...............101

5.1. Efeito da separação entre cadeias..........................................................106

5.2. Efeito da separação ao longo da cadeia...............................................118

5.3. Separações Simultâneas Intracadeia e Intercadeia................................126

5.4. Efeito da separação molecular na polarização da emissão.....................132

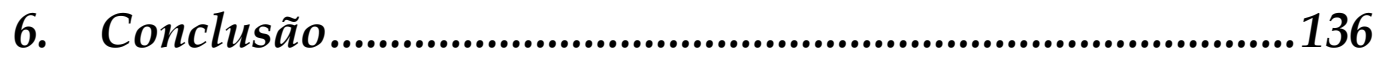

7. Referências Bibliográficas......................................................140 


\section{Lista de Figuras}

Figura 2.1.1 Plano da molécula com os orbitais hibridizados $s p 2,2 s, 2 p_{x}$ e $2 p_{y}$. O orbital $2 p_{z}$ é perpendicular ao plano da molécula.

Figura 2.2.1 -.Segmentos conjugados separados, cilindros cinzas, separados por segmentos não conjugados, linhas pretas, designando a distribuição estatística dos segmentos conjugados na cadeia do copolímero, conseqüentemente a distribuição média de segmentos no filme.

Figura 2.2.2 Ilustração do modelo físico envolvendo segmentos conjugados de PPV (estados não localizados dependentes de $n$ ) de diferentes tamanhos separados por segmentos não conjugados (estados localizados independentes de $n$ )

Figura 2.2.3 Distribuição de segmentos conjugados seguindo a forma de uma Gaussiana ...... 11

Figura 2.3.1 Molécula de poli(acetileno) com $\mathrm{n}$ igual ao comprimento de conjugação ................ 11

Figura 2.3.2 Molécula conjugada de butadieno, nuvens eletrônicas de probabilidade das ligações a) $\sigma$, no plano da molécula; e b) $\pi$, perpendicular ao plano da molécula. ........... 12

Figura 2.4.1 Curva de dispersão de energia para o PPV. As letras d indicam os estados localizados e não localizados, $\pi$ e $\pi^{*}$......

Figura 2.5.1 Espectros característicos de absorbância e de emissão de um filme SA de PPV sobre quartzo. ............................................................................................... 17

Figura 2.5.2 Diagrama de Jablonski[12] ilustrando possíveis processos de recombinação intramolecular após excitação. ABS - absorção , RV - relaxação vibracional, Cl conversão interna, F - fluorescência , FOS - fosforescência, CIS - cruzamento intersistema, $S_{0}$ - estado singleto fundamental, $S_{1}$ e $T_{1}-$ primeiros estados de singleto e tripleto excitados. As setas onduladas são os processos que envolvem a geração de fônons ou multifônons enquanto que as setas lineares envolvem fótons...... 19

Figura 2.9.1- Ângulos especificando a orientação do eixo molecular (OA), do vetor campo elétrico da luz incidente (OP1) e a componente polarizada da luz emitida (OP2)............ 31

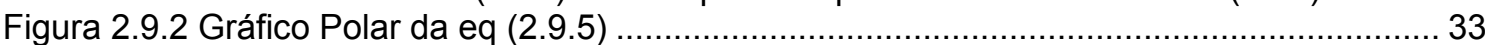

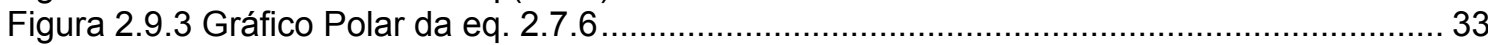

Figura 2.9.4 Razão de I// (eq. 6.4) por $\mathrm{I} \perp$ (eq. 6.3) em função da elongação $\mathrm{L} / \mathrm{L} 0$. .................... 34

Figura 2.10.1 A reta é a simulação de $A_{/ /} / A_{\perp}$ utilizando as equações 2.10.7 e 2.10.8. $A_{/ /}$e $A \perp$ são respectivamente a posição do analisador paralela e perpendicular ao eixo de estiramento.

Figura 3.3.1 Estrutura química do copolímero PTHT-PPV. Na figura, podemos separar o polímero conjugado PPV, a), cujo segmento possui $r$ repetições da estrutura entre colchetes, e o polietrólito PTHT, b), cujo comprimento da cadeia é de n repetições da estrutura fora dos colchetes.

Figura 3.3.2 Esquema mostrando desde e reação química de polimerização do PTHT, passando pela formação dos filmes, até o tratamento térmico e obtenção do PPV ......... 45

Figura 3.4.1 - a) procedimento convencional, em que a conversão PTHT em PPV ocorre pela eliminação térmica do grupo de saída sulfônico (tiofeno)[11]. b) procedimento alternativo de formação do copolímero PPV-PTHT, através da substituição do contra íon $\mathrm{Cl}$ - pelo íon de cadeia longa DBS. Esse procedimento tem a vantagem de requer menor tempo e temperatura mais baixa do que o convencional.

Figura 3.5.1 Moléculas de PDAC e PSS, policátion e poliânion, usados na formação de filmes orgânicos automontados.

Figura 3.9.1 Sistema óptico do espectrofotômetro Hitachi 2001 para medida de absorbância.

Figura 3.11.1 - Diagrama esquemático do arranjo experimental para medida do espectro de luminescência (Sistema A) e excitação seletiva (Sistema B) pela técnica de detecção pelo "Lock-in".

Figura 3.12.1 - Esquema do aparato experimental montado para determinar as propriedades da polarização da luminescência.

Figura 3.13.1 - Esquema que ilustra a adsorção das bicamadas catiônica/aniônica de polieletrólitos sobre o substrato tratado. 
Figura 3.13.2- Esta figura simula a seqüência das imersões do filme (B), nas soluções aniônica e catiônica, entremeadas pela secagem e retirada do excesso de material (A) através da rotação do filme em formação.

Figura 3.15.1 Filme de PPV sobre Teflon montado pela técnica de Spin-Coat. ........................ 65

Figura 4.1.1 Mostra que a absorção do Teflon e do Quartzo não interferem nas medidas de Absorbância e Emissão do PPV

Figura 4.2.1 Medidas de polarização da absorbância (a) e fotoluminescência (b) à temperatura ambiente para o filme spincast-PPV sobre teflon.

Figura 4.2.2 Dependência da intensidade da luminescência normalizada de um filme de PPV 'spin' para as polarizações paralela e perpendicular da excitação.

Figura 4.2.3 Medidas de polarização: (a) absorbância e (b) fotoluminescência à temperatura ambiente para o filme LbL-PPV sobre teflon.

Figura 4.2.4 Dependência da intensidade da luminescência normalizada de um filme de LbL-PPV para as polarizações paralela e perpendicular da excitação. A curva contínua corresponde à calculada de acordo com capítulo 2 .

Figura 4.3.1 Medidas de absorbância ( $300 \mathrm{~K}$ ) para filmes 'spincast' de PPV sobre teflon para valores de estiramento iguais a $L / L o=1$ e $L / L o=1.67$ considerando os casos da

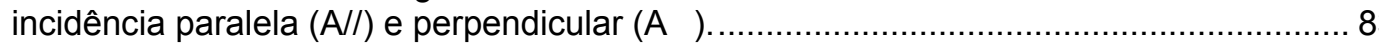

Figura 4.3.2 Grau de polarização da absorbância, $A / /$ / $A \perp$, medida para o comprimento de onda de $487 \mathrm{~nm}$ em função do grau de estiramento...

Figura 4.3.3 Espectros de fotoluminescência polarizada $(300 \mathrm{~K})$ para diferentes configurações da polarização da luz de excitação (lazer de excitação de $\mathrm{HeCd}$ em $441 \mathrm{~nm}$ ) e emissão paralela e perpendicular ao estiramento de filmes 'spincast' de PPV sobre teflon para valores de estiramento a) $L / L o=1$ e b) $L / L o=1.67$..

Figura 4.3.4 Orientação média (eq. 2.9.4) da rede estatística de segmentos conjugados em relação ao eixo de estiramento, em função do grau de estiramento $\lambda=\mathrm{L} / \mathrm{L}_{0} \ldots \ldots \ldots \ldots \ldots \ldots . . . . . . .88$

Figura 4.3.5 Intensidade integrada da luminescência de um filme 'spincast' de PPV sobre teflon em função do ângulo do analisador para graus de estiramentos (L/Lo) variando de $2 \%$ no intervalo de 0 a $72 \%$. A direção da excitação utilizadas foram a) paralelã A $/ /$ e b) perpendicular $A \perp$. $O$ ângulo zero corresponde à direção de polarização paralela ao eixo de estiramento.

Figura 4.3.6 Intensidade normalizada da luminescência em função do ângulo do analisador para graus de estiramento extremamente pequenos variando na região de $1 \leq \mathrm{L} / \mathrm{L} 0 \leq 1.14$ para o caso de excitação perpendicular ao estiramento.

Figura 4.3.7(a) Intensidade da luminescência em função do estiramento para os casos de excitação paralela e emissão paralela e perpendicular à direção de estiramento. (b) curva de pontos, dados experimentais do grau de polarização da luminescência, $\mathrm{P}_{/ /} / \mathrm{P}_{\perp}$, em função do estiramento para polarização da excitação paralela ao estiramento; as curvas contínuas são simulações a partir das equações de distribuição molecular mostrada na seção 2.8-2.

Figura 4.3.8 Espectros de absorbância medidos para diferentes configurações da polarização da luz de excitação paralela $\mathrm{A} / /$ e perpendicular $\mathrm{A} \perp$, ao estiramento de um filme $\mathrm{LbL}$ para temperaturas de a) $300 \mathrm{~K}$ e de b) $4 \mathrm{~K}$ para estiramentos L/Lo=1 e $\mathrm{L} / \mathrm{Lo}=1,68)$.

Figura 4.3.9 Intensidade integrada da luminescência de um filme LbL de PPV sobre teflon em função do ângulo do analisador (tomando-se o ângulo zero a direção de estiramento como referência) para graus de estiramentos L/Lo variando de $2 \%$ no intervalo de 0 a $25 \%$. A direção da excitação utilizadas foram a) paralela $A / /$ e b) perpendicular $\mathrm{A} \perp$ ao estiramento....

Figura 4.3.10 Grau de polarização calculado a partir das Figuras x.x.2a e b para amostra LbL de PPV sobre Teflon. As linhas contínuas servem com guia para os olhos...

Figura 5.1.1 Taxa de deposição do PTHT/PDAC, solução catiônica, e DBS, solução aniônica

Figura 5.1.2 a) Logaritmo da absorbância e (b) luminescência em função da fração $x$ de PDAC na mistura (PPV) 1 - $(\text { PDAC })_{x}$.

Figura 5.1.3 a) Intensidade da absorbância no comprimento de onda do laser de $\mathrm{He}-\mathrm{Cd}$ de excitação $(441 \mathrm{~nm})$ e a eficiência de emissão do PPV, definida como a razão da intensidade integrada da luminescência pelo valor da absorbância em 441 nm, em 
função da fração $x$ de PDAC em filmes de PPV. b) A mesma dependência para a posição e largura da linha de fônon zero da emissão do PPV.

Figura 5.1.4. Espectros de a) PLE e b) absorbância em função da fração x de PDAC. $O$ espectro de absorção do PPV, sem diluição $(x=0)$ (círculos abertos), é mostrado na figura a) para efeito de comparação.

Figura 5.1.5. Diferença entre o espectro de excitação (PLE da Figura 5.1.4a) e o espectro de absorbância Figura 5.1.4b) para as amostras contendo diferentes frações de PDAC.

Figura 5.1.6 Intensidade integrada da luminescência (normalizada em $4 \mathrm{~K}$ para melhor visualização) de filmes contendo 10, 20 e 100 \% de PPV.

Figura 5.2.1. (a) Absorbância e (b) espectros de luminescência em função do volume de DBS em solução de do polieletrólito precursor do PPV, PTHT.

Figura 5.2.2. Eficiência Integrada da PL em função do volume de DBS na solução de PTHT.121

Figura 5.2.3. (a) PLE normalizada e (b) diferença entre o espectro de excitação (PLE da figura a) e o espectro de absorbância (da figura 5.2-1a), em função do volume de DBS em solução de do polieletrólito precursor do PPV, PTHT. O espectro de absorbância (círculos) de uma amostra preparada com $150 \mu \mathrm{l}$ de DBS é mostrado para efeito de comparação.

Figura 5.2.4 Fotoluminescência integrada em função da temperatura para os volumes de DBS na solução de PTHT de $0 \mu \mathrm{L}$ e de $150 \mu \mathrm{L}$.

Figura 5.3.1 Ganho de eficiência da PL ao se atenuarem os processos de transferência de energia inter e intracadeia. As amostras de que extraímos os dados têm como solução aniônica: PSS, e catiônica: PTHT/DBS/PDAC, ambas aquosas.

Figura 5.3.2 a) Lunimescência normalizada em função das separações dos segmentos de PPV, através do separador PDAC e pela seleção do comprimento da molécula conjugada mediante incorporação de DBS. b) triângulo de cores, em que se tem o grau de pureza da cor, apresentamos o deslocamento da banda de emissão conforme se separam as cadeias.

Figura 5.4.1 Medidas de Polarização de filmes construídos pelos métodos de automontagem e spincasting, em função do posicionamento do analisador (polarizador) em relação a polarização da luz de excitação.

Figura 5.4.2 Razão $P_{/ /} / P_{\perp}$ da Intensidade da luz emitida paralelamente $\left(P_{/ /}\right)$e perpendicularmente $\left(P_{\perp}\right)$ à direção de polarização da luz do laser de excitação. 


\section{Resumo}

Nesta dissertação, visamos o entendimento de processos intermediários que regem a transferência de energia e determinam as propriedades ópticas de polímeros conjugados, a fim de encontrar meios para aumentar a eficiência de emissão e o tempo de vida dos 'LED's' orgânicos. Estudamos especificamente o polímero PPV, poli(p-fenileno vinilideno), sintetizado através de novo método desenvolvido no Grupo de Polímeros do Instituto de Física de São Carlos, por Marletta e colaboradores[1], na forma de filmes finos depositados pelas técnicas 'spincast' e de automontagem (LbL). Para o trabalho utilizamos técnicas espectroscópicas de luminescência, excitação seletiva e absorbância.

Por meio de técnicas de engenharia molecular e através do ordenamento induzido da rede polimérica, avaliamos o peso que têm os eventos intermediários à emissão.

Estiramos gradualmente filmes de PTHT/PPV depositados sobre Teflon, sob um eixo preferencial, e constatamos a dependência da polarização da luz emitida com processos de transferência de energia e com a anisotropia da matriz polimérica.

Realizamos a separação das cadeias do copolímero a fim de analisar separadamente a transferência de energia entre os segmentos conjugados pertencentes a cadeias distintas (processos intercadeia) ou ao longo da cadeia (processos intracadeia). Esta separação intercadeia e intracadeia resultaram em um significativo aumento da eficiência da emissão, assim como um deslocamento da banda de emissão para o azul, privilegiando a emissão de segmentos de menor conjugação e que participavam apenas nos processos de relaxação de energia e transferência da excitação e não dos estados emissivos finais. Separamos os segmentos conjugados dentro da própria cadeia do copolímero, regulando o comprimento de conjugação, através da incorporação de DBS. Aqui, verificamos, os processos de transferência intracadeia concorrem em igual peso com processos intracadeia na migração energética em polímeros conjugados. Concluímos que o processo limitante da eficiência de emissão em polímeros conjugados e dispositivos é a eficiente transferência de energia entre cadeias ou ao longo da cadeia para centros supressores de energia. 


\section{Abstract}

The main goal of this work is the understanding of intermediated energy relaxation processes that are governed by Energy Transfer. Such processes strongly affect the optical properties of conjugated polymers, reducing the emission efficiency and the life time of OLEDs. We study specifically the polymer poly( $p$-phenylene vinylene), PPV, synthesized through the new method developed by Marletta and co-workers [1]. The films were prepared by Spincast and self-assembly (Layer-by-Layer) techniques on different substrates. The optical characterization of the polymeric material was carried out by photoluminescence, selective excitation spectroscopy and UV-Vis absorbance measurements. With the use of molecular engineering techniques and by changing the polymeric order induced by uniaxial stretch of the films deposited on a flexible substrate, it was possible to infer the weight of intermediary events in final emission process.

A special issue of this work was the study of the optical properties of thin PPV films deposited on flexible Teflon substrates under very low deformation levels. Optical data of low stretched conjugated polymers on transparent substrates were not previously available in the literature. Continuous axial stretch was applied at room temperature to very thin PPV films enabling simultaneous luminescence and absorbance polarization measurements. The optical properties of polymeric light emitting devices are strongly dependent on the structural order of the polymer chains and the energy transport mechanism between the conjugated segments. We demonstrate that such low stretched films presents a very efficient isotropicto-polarized conversion regarding the fact we are dealing with energy transfer between luminescent chromophore of same species.

We also carried out chain separation of conjugated segments of a PPV copolymer in order to analyze two Energy Transfer kinds: one that occurs among PPV segments in different chains (interchain processes) and the other involving the Energy Transfer between PPV segments along the same PPV chain (intrachain processes). To account for the interchain separation of the PPV segments we diluted the PPV chain in an inert polymeric matrix. The novelty, however, lies in the precise control of the separation of PPV segments along the chain by using a copolymer with sequences of conjugated PPV and nonconjugated PTHT distributed randomly along the polymer chain. The efficiency increase together with the spectral blue shif with the segment separation show that inter- and intrachain exciton mobility is enhanced by low range Förster Energy Transfer. For the case of samples without chain separation, it is easier for excitons to move around by energy transfer process and find quenching defects before their radioactive decay. For diluted or low conjugated samples, excitons will not reach defects before recombination since Energy Transfer is suppressed. Thus, we verify, the Intrachain Energy Transfer process have the same influence as for Interchain process produced by the energy migration among conjugated polymers segments. From a more fundamental point of view, the establishment of a controlled ordering and separation of the polymeric chains may reduce effects such as the luminescence quenching that strongly reduce the emission efficiency in organic devices. 
Capitulo 1 -

1. Introdução 
Há poucas décadas, destacou-se uma nova classe de materiais, os semicondutores orgânicos emissores de luz que por acumularem características similares às dos semicondutores inorgânicos, abriram vasto campo de estudo às suas propriedades ópticas. Foram descobertos na década de 70, por Shirakawa, a partir de experimentos com o poliacetileno, que tem natureza condutora, mobilidade tanto de carga quanto da energia de excitação, explicada pelo caráter não localizado das ligações $\pi$, gerando as bandas de energia permitidas: HOMO - "Highest Occupied Molecular Orbital", considerada a banda de valência, e LUMO - "Lowest Unoccupied Molecular Orbital", a banda de condução.

O interesse, nestes materiais, reside tanto em suas possíveis aplicações tecnológicas[2] (dispositivos optoeletrônicos e eletrônicos) quanto nas áreas de física fundamental (estrutura eletrônica, excitações elementares, transferência de energia e formação de filmes finos). Particularmente, a sua processabilidade, na forma de filmes finos, mostra 
grande aplicação como painéis e dispositivos luminescentes flexíveis, além do que é possível modular a energia de emissão, destes materiais, através de variações tanto na estrutura molecular dos filmes quanto no processo de síntese polimérica.

A emissão de luz nos polímeros conjugados é resultado da recombinação de um elétron excitado, pertencente à banda LUMO, com um buraco na banda HOMO, o par elétron-buraco é também chamado de éxciton. Deste modo, a montagem esquemática, simplificada dos dispositivos orgânicos emissores de luz, OLED's, fundamenta-se um anodo e, na outra, um catodo que geram campo elétrico e provocam a movimentação dos portadores de cargas, elétrons e buracos, na fase condutora.

Os polímeros conjugados apresentam maior facilidade de condução de elétrons do que de buracos, por isto a desativação dos éxcitons, recombinação elétron-buraco, ocorre, majoritariamente, nas imediações da interface anodo/material orgânico. Imperfeições da rede polimérica, impurezas e defeitos variados, próximos a esta interface, reduzem a eficiência da emissão de luz, que constitui um dos fatores de maior interesse em otimização. Para sanar este problema, uma camada espaçadora, injetora de buracos é colocada[3], entre o anodo e o material orgânico, com o objetivo de aumentar a eficiência da emissão

Não obstante, grandes avanços tenham sido alcançados nas técnicas de fabricação de dispositivos, propriedades fundamentais dos polímeros conjugados requerem estudos mais aprofundados. Uma das importantes questões está no entendimento do caminho percorrido pela energia, desde a 
excitação do elétron $\pi$, à banda LUMO, até a emissão final ou a desativação da excitação por centros não radiativos. Vários processos intermediários concorrem, canalizando a energia para os estados finais, desta forma são responsáveis diretos pela eficiência da emissão.

No momento, o foco principal dos melhoramentos em OLED's está no aumento da eficiência da emissão de luz e no tempo de vida útil, estes dois pontos estão, intimamente, ligados aos eventos intermediários. Por exemplo, a eficiência é seriamente afetada por defeitos na rede polimérica, e pela emissão final ocorrer em segmentos longos, de menor energia. Sendo assim a excitação migra dos segmentos de tamanho de conjugação pequeno para os segmentos conjugados longos. Esta migração da excitação por meio de processos de transferência de energia é seguida de relaxação energética, sendo, portanto, chamada de difusão espectral. Neste meio tempo, a excitação pode ser aprisionada em armadilhas de desativação não radiativa, que além de tudo atingem termicamente o dispositivo reduzindo seu tempo de vida útil.

Interessados na melhoria da eficiência da emissão e no estudo analítico dos fatores naturais que controlam as transferências de energia, redirecionamos o estudo deste trabalho. A fim de isolarmos os efeitos de orientação molecular média na matriz polimérica, sistematizamos experimentos em que interferimos na estrutura do arranjo molecular, para que a resposta dos espectros de absorção, emissão e excitação seletiva nos trouxessem informações relevantes. Para tanto, provocamos, de forma controlada, o alinhamento médio dos segmentos conjugados através de estiramento externo pequeno, com intuito de analisar o efeito da anisotropia 
na emissão final. Além disso, impusemos a separação, no nível supramolecular, das cadeias poliméricas nos filmes finos: (i) separação dos segmentos conjugados, por meio de um polímero opticamente inativo, na região espectral em análise, traduzida em uma separação intercadeias , (ii) separação dos segmentos conjugados ao longo do esqueleto da cadeia, separação intracadeia e (iii) separação concomitante intra e intercadeia. Baseamos as três modalidades de separação, em técnicas de engenharia molecular, com a controlada alteração dos constituintes da cadeia, bem como, no uso das facilidades e do controle no nível de monocamada proporcionado pela técnica de preparação de filmes por automontagem.

A disposição textual desta dissertação de mestrado tem os seguintes capítulos: Capítulo 2 - Introdução Teórica, descrevemos parte da teoria sobre polímeros condutores, aplicamos um apanhado teórico da literatura no estudo de filmes estirados e qualitativamente, expomos uma teoria para os vários processos de transferência de energia; Capítulo 3 - Materiais e Métodos, exibimos todos passos para que a investigação, em cada experimento, das propriedades ópticas objetivadas; Capítulo 4 - Fotofísica de filmes poliméricos conjugados com baixo grau de estiramento; Capítulo 5 - Migração das excitações eletrônicas em polímeros conjugados luminescentes diluídos em uma matriz inerte Capítulo 6 - Conclusão e Capítulo 7 - Referências Bibliográficas, consta a literatura consultada. 
Capítulo 2

2. Processos Fotofísicos em Polímeros Conjugados 


\subsection{Polímeros e Moléculas Orgânicas Conjugadas}

Apresentaremos, neste capítulo, um modelo físico destinado ao entendimento dos processos fotofísicos presentes em polímeros conjugados. Essa classe de materiais abre interesse prático devido seu grande potencial como dispositivo eletroluminescente. Para isto é necessário conhecermos a natureza intrínseca dos fenômenos radiativos e não radiativos que concorrem diretamente para a eficiência da emissão de luz.

Os polímeros são moléculas orgânicas extensas organizadas pela repetição sistemática de moléculas idênticas menores. Em geral, os átomos de carbono, C, são a base da cadeia polimérica. A estrutura de um polímero é simplificadamente um esqueleto formado por átomos de $\mathbf{C}$ ligados entre si. A cada átomo de carbono restam duas ligações covalentes feitas com outros grupos ou átomos, chamados radicais, de modo a formar uma configuração 
molecular que se repete ao longo da cadeia. Essa estrutura que, pela repetição sistemática, representa o polímero, é chamada de monômero.

O caráter semicondutor dos polímeros advém do fato de seus monômeros serem moléculas conjugadas, ou seja, apresentam ligação $\pi$. A hibridização $\mathrm{sp}^{2}$ do átomo de $\mathbf{C}$ torna possível 3 ligações $\sigma$ e uma ligação $\pi$ por meio do orbital $p$ restante.

As ligações $\sigma$ são localizadas, responsáveis pela rigidez da molécula, compostas pelos orbitais $2 \mathrm{~s}, 2 \mathrm{p}_{\mathrm{x}}$ e $2 \mathrm{p}_{\mathrm{y}}$, ver Figura 2.1.1, com simetria axial ao eixo que passa pelos átomos ligantes. A ligação $\pi$ provém da superposição de dois orbitais $2 \mathrm{p}_{\mathrm{z}}$ de carbonos vizinhos, perpendicularmente ao plano das demais ligações $[4,5]$ Os elétrons $\pi$ não são localizados e suas ligações são fracas[5].

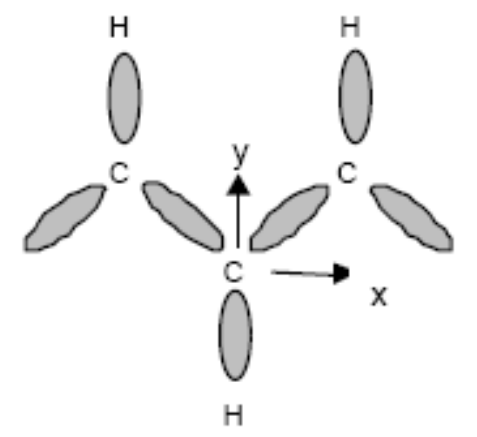

Figura 2.1.1 Plano da molécula com os orbitais hibridizados $s p 2,2 s, 2 p_{x}$ e $2 p_{y}$. 0 orbital $2 p_{z}$ é perpendicular ao plano da molécula. 


\subsection{Distribuição de segmentos conjugados}

O esqueleto de uma cadeia polimérica conjugada real estrutura-se em uma sucessão de segmentos conjugados e segmentos não conjugados, Figura 2.2.1. A quebra da conjugação está relacionada a defeitos estruturais incorporados durante o processo de polimerização e a conformações assumidas pela cadeia (enovelamento, torções e isomerização cis-trans, por exemplo), resultando em uma distribuição estatística de segmentos conjugados representada por gaussiana do número de segmentos em função dos comprimentos de conjugação, Figura 2.2.3,

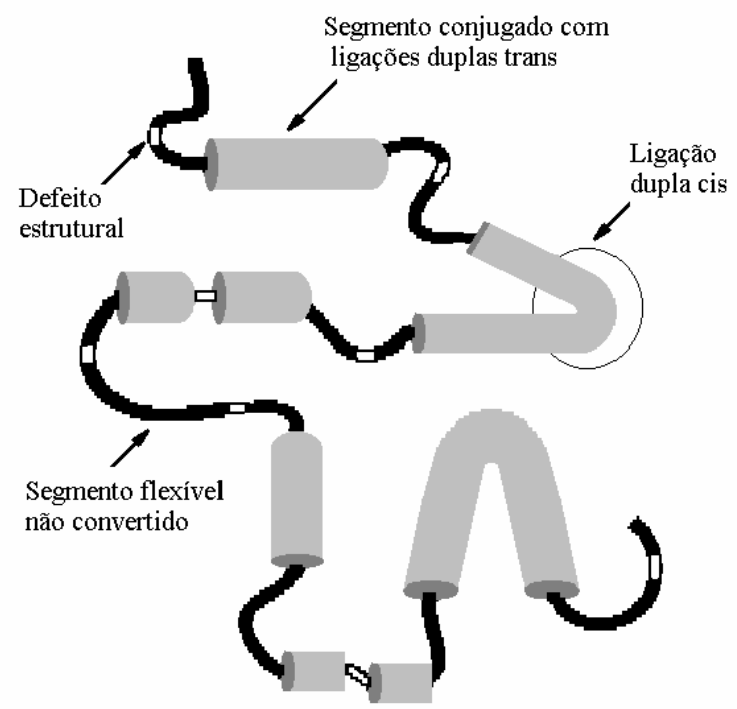

Figura 2.2.1 -.Segmentos conjugados separados, cilindros cinzas, separados por segmentos não conjugados, linhas pretas, designando a distribuição estatística dos segmentos conjugados na cadeia do copolímero, conseqüentemente a distribuição média de segmentos no filme.

A interrupção da conjugação, quer por defeitos variados quer por efeitos conformacionais, impõe um limite espacial, ao elétron $\pi$ não 
localizado, que vai do começo ao final da conjugação. Isto leva a uma distribuição estatística das energias associadas a cada segmento conjugado com respeito ao seu comprimento, Figura 2.2.2.

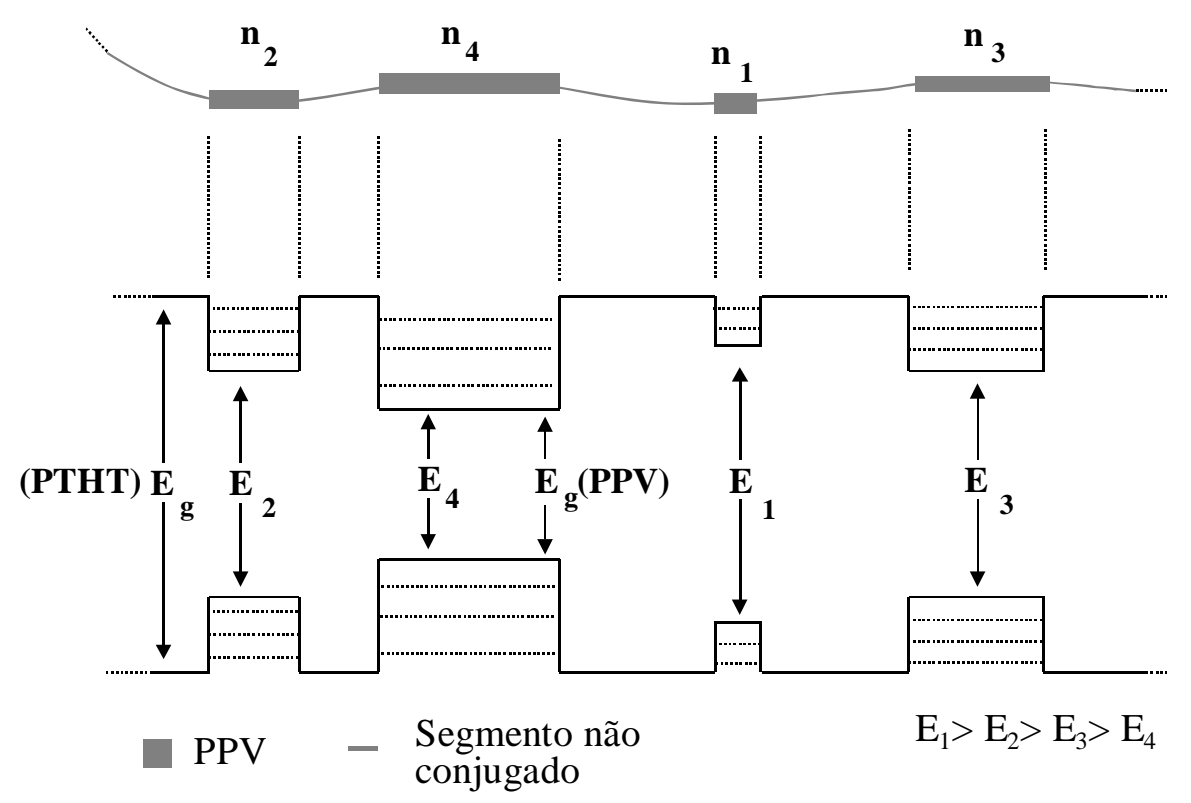

Figura 2.2.2 llustração do modelo físico envolvendo segmentos conjugados de PPV (estados não localizados dependentes de $n$ ) de diferentes tamanhos separados por segmentos não conjugados (estados localizados independentes de $n$ )

A função gaussiana é centrada em um comprimento de conjugação médio, $\mathbf{n}_{0}$ na Figura 2.2.3, que caracteriza as bandas de absorção e emissão do filme. Entretanto, os demais comprimentos de conjugação participam, com menor amplitude, dos processos de emissão e absorção, provocando o alargamento destes espectros. 


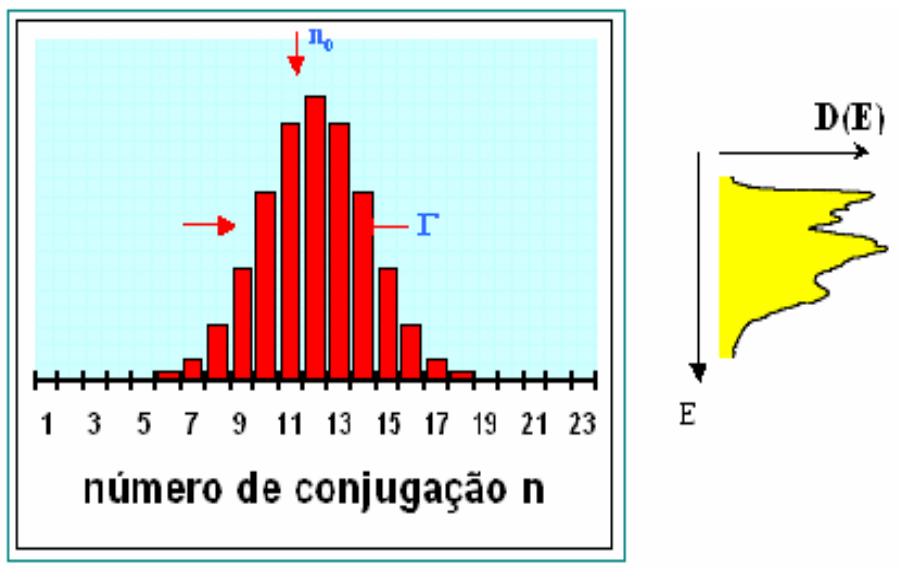

Figura 2.2.3 Distribuição de segmentos conjugados seguindo a forma de uma Gaussiana

\subsection{Moléculas ou Sistemas $\pi$ - Conjugados}

Conjugação é um termo usado para designar uma seqüência de ligações $\sigma$ (longas) e $\pi$ (curtas). Também conhecida como dimerização, a ligação $\pi$ é instável o que é explicado no teorema de Peierls[6].

O número de repetições de ligações simples e duplas alternadas e consecutivas é chamado de comprimento de conjugação, "n" (Figura 2.3.1), que interfere diretamente nas propriedades fotofísicas do polímero.

\section{$(-\mathrm{CH}=\mathrm{CH}-)_{\mathrm{n}}$}

Figura 2.3.1 Molécula de poli(acetileno) com $\mathbf{n}$ igual ao comprimento de conjugação

Os processos de polimerização de moléculas conjugadas fornecem uma distribuição estatística de comprimentos de conjugação. Um sistema 
polimérico, portanto, é identificado por seu comprimento efetivo de conjugação que é um valor médio dos diferentes segmentos conjugados. A interrupção da seqüência de ligações simples e duplas tem origem em defeitos químicos eventuais (impurezas, segmentos não saturados ou não conjugados) ou em torções conformacionais da molécula conjugada.

A configuração eletrônica de uma molécula conjugada, considerada um sistema $\pi$ conjugado, está centrada na hibridização $\mathbf{s p}^{2}$ do átomo de $C$, disponibilizando 3 ligações $\sigma$, axialmente simétricas ao plano da molécula, e no orbital restante $\mathbf{p}, \mathbf{p}_{\mathbf{z}}$ é perpendicular ao plano da molécula, responsável pela ligação $\pi$, Figura 2.3.2.

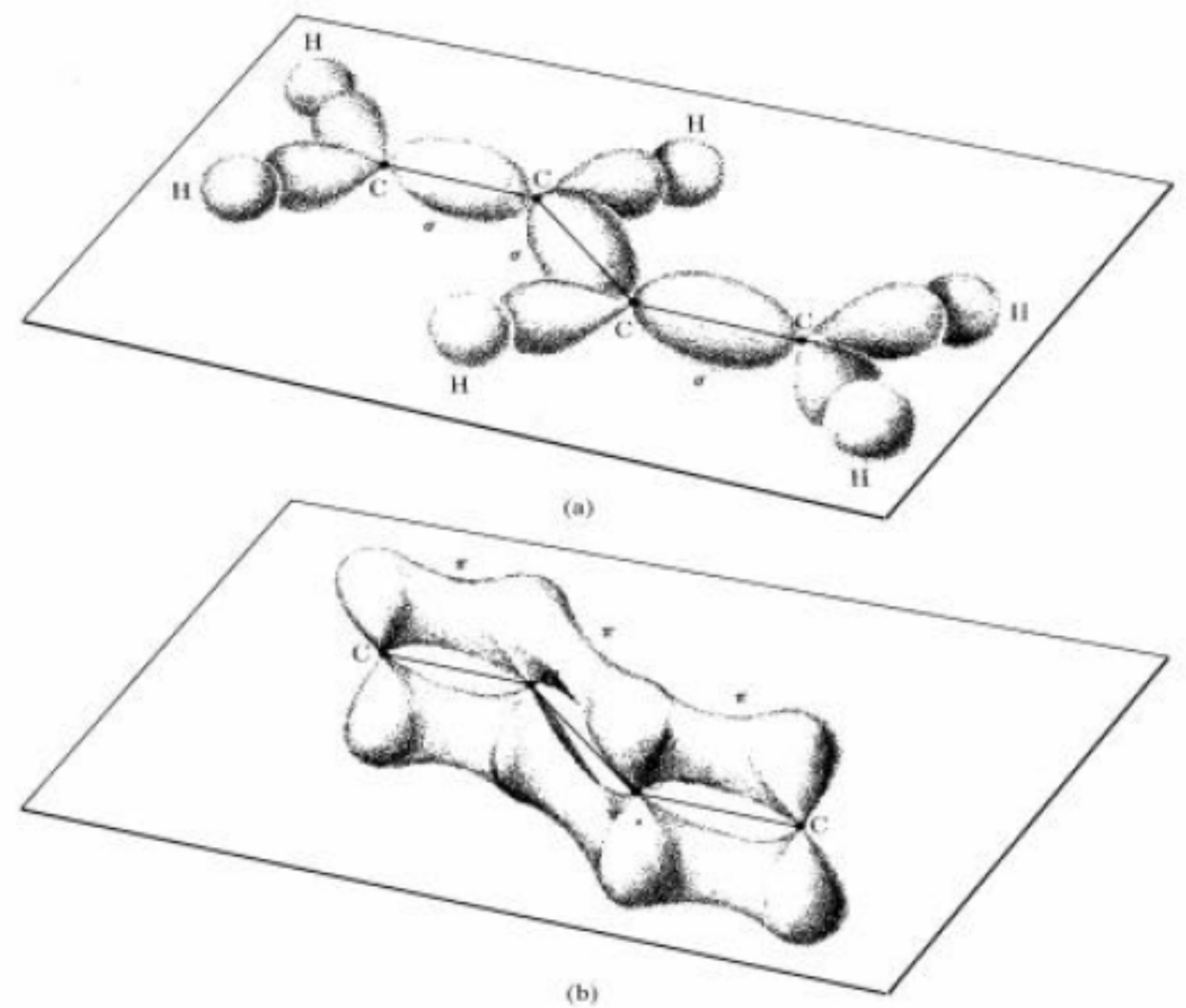

Figura 2.3.2 Molécula conjugada de butadieno, nuvens eletrônicas de probabilidade das ligações a) $\sigma$, no plano da molécula; e b) $\pi$, perpendicular ao plano da molécula. 
Os orbitais $\pi$, ligações fracas, não são localizados entre átomos de C vizinhos, estendem se por toda a molécula, Figura 2.3.2a), logo, permitindo a mobilidade de cargas. Contrariamente, as ligações $\sigma$ são bem localizadas, entre átomos vizinhos, na Figura 2.3.2 b), átomos de $\mathbf{C ~ e ~} \mathbf{H}$, e conferem a rigidez da molécula por serem ligações fortes. A natureza conjugada destas macromoléculas determina suas propriedades ópticas e físicas[7].

\subsection{Estrutura Eletrônica de Polímeros Conjugados}

Nos sólidos, aqui polímeros, os orbitais atômicos individuais, devido à proximidade e forte interação, superpõem-se, gerando orbitais que se estendem por toda a rede. Uma conseqüência disto é o desaparecimento da degenerescência e o aparecimento de níveis de energia permitidos. Os estados de energia agora são chamados de banda de valência (bv) e banda de condução (bc), cujos perfis dependem das distâncias interatômicas e das ligações químicas.

A banda de valência, estado não excitado, é populada e possui os níveis de energia dos estados ligados, já a banda de condução não é populada e contém os estados anti-ligados. Elas estão separadas por um intervalo de energia $\mathbf{E}_{0}$, cujo termo em inglês é "gap", correspondente à energia que um elétron, no nível mais elevado da bv, necessita, para 
alcançar o nível mais baixo na bc. Dependendo da ocupação eletrônica e do "gap" o sólido é classificado como condutor, semicondutor ou isolante.

A descrição da estrutura eletrônica das moléculas conjugadas data de várias décadas, entretanto mesmo a estrutura conjugada mais simples, o trans-poliacetileno (PA), foi compreendida apenas em 1950, com o surgimento do teorema de Peierls[6]. No PA (Figura 2.3.1) cada grupo $\mathbf{C}-\mathbf{H}$ disponibiliza um elétron $\pi$, formando uma banda $\pi$ semi-preenchida, induzindo um caráter metálico cuja instabilidade, segundo Peierls, e a quebra de simetria abrem um "gap", no nível de Fermi, e transformam o caráter metálico, termodinamicamente instável, em semicondutor comprovado experimentalmente.

O modelo de Huckel consiste em um método semi-empírico para a resolução do hamiltoniano de um sistema- $\pi$ conjugado, através das simplificações: i) as estruturas $\pi$ e $\sigma$ são totalmente separadas, ii) as ligações $\sigma$ são localizadas, formando uma estrutura rígida, e iii) os orbitais $\pi$ não são localizados e estendem se a todos os átomos da molécula.

Para a estrutura do trans-poliacetileno, Su, Schrieffer e Heeger [8, 9] propuseram um modelo (modelo SSH) com a aproximação "tight-binding" que não leva em conta a interação elétron-elétron. A cadeia polimérica é considerada como uma seqüência de átomos de $\mathbf{C}$ unidos por ligações $\sigma$, representadas por molas de constante de força $\mathbf{K}$. O termo de interação elétron-fônon é contabilizado pela adição de uma integral de "overlap" de primeiros vizinhos no Hamiltoniano, que é expandido linearmente em torno da posição de equilíbrio dos átomos de $\mathrm{C}, t_{0}+\alpha\left(u_{n}-u_{n+1}\right)$, onde $\mathbf{u}_{\mathbf{n}}$ é o 
deslocamento do sítio $\mathbf{n}$, e os elétrons $\sigma$ são parametrizados através da constante de força K. O Hamiltoniano do sistema é expresso por:

$$
H=-\sum\left[t_{0}+\alpha\left(u_{n}-u_{n+1}\right)\right]\left(c_{n}^{+} c_{n+1}+c_{n+1}^{+} c_{n}\right)+\frac{1}{2 M} \sum_{n} p_{n}^{2}+\frac{K}{2} \sum_{n}\left(u_{n}-u_{n+1}\right)^{2}
$$

Nesta equação o primeiro termo indica a energia cinética dos elétrons $\pi,{ }^{C_{n}}$ e ${ }^{C_{n}^{+}}$são os operadores aniquilamento e criação no sítio $\mathbf{n}$ de elétrons $\pi$; o segundo termo é a energia cinética do átomo ( ${ }^{p_{n}}$ é o momento do átomo no sítio n) e o terceiro termo determina a energia de ligação. A banda de elétrons $\pi$ é semi-preenchida, logo a configuração com igual espaçamento entre os grupos C-H é instável devido a dimerização, segundo o teorema de Peierls[6], provocando uma distorção na rede e abrindo um "gap" no nível de Fermi. A curva de dispersão de energia[10], Figura 2.4.1, mostra a estrutura da banda do PPV em esquema de zona reduzida.

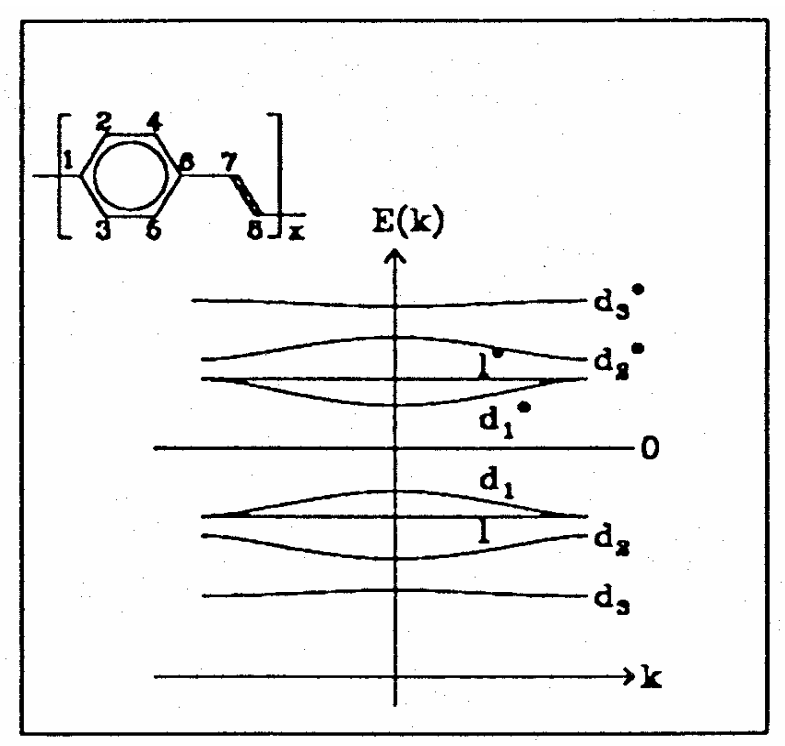

Figura 2.4.1 Curva de dispersão de energia para o PPV. As letras d indicam os estados localizados e não localizados, $\pi \mathrm{e} \pi^{*}$. 


\subsection{Espectros de Absorbância $\mathrm{e}$ Luminescência}

A análise de espectros de absorbância e luminescência do PPV propicia informações sobre a estrutura, a anisotropia e a distribuição dos segmentos conjugados no filme. Essas propriedades induzem relevantes conclusões a respeito da dinâmica de transferência de energia e da eficiência da luminescência dos filmes finos de PPV. Assim sendo, discorremos sucintamente, nesta seção, sobre as principais características e informações providas pelos espectros de absorção e emissão do PPV.

O espectro de absorbância (Figura 2.5.1) reflete a densidade de segmentos conjugados da rede, remete às transições entre os estados conjugados $\pi$ e $\pi^{*}$. A banda de maior intensidade da absorbância indica diretamente em que intervalo espectral a maior quantidade de segmentos absorve, destes dados podemos inferir, qualitativamente, o comprimento de conjugação efetivo do filme. Entretanto, a forma de linha da absorbância é pouco resolvida devido a distribuição dos segmentos conjugados comportarse como uma gaussiana, ver seção 2.2, e ao forte acoplamento elétronfônon[11]. 


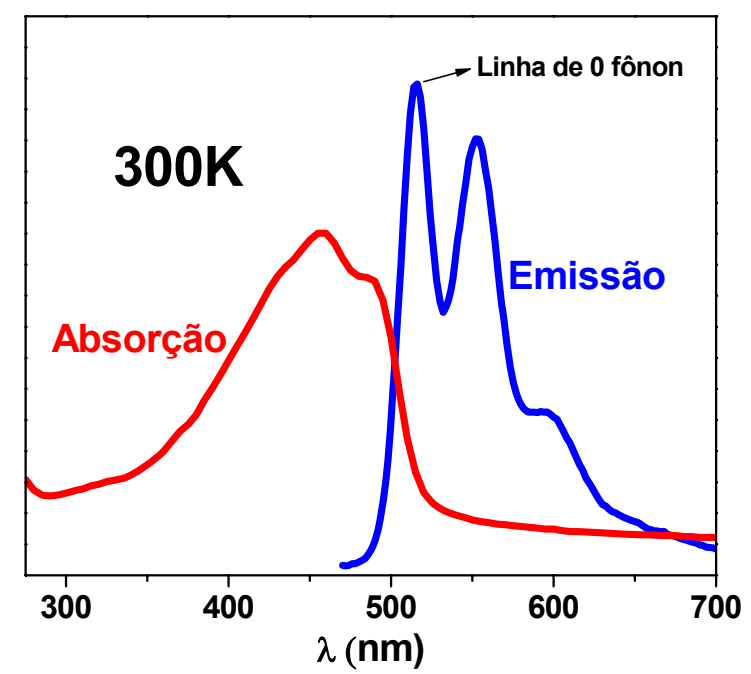

Figura 2.5.1 Espectros característicos de absorbância e de emissão de um filme SA de PPV sobre quartzo.

A excitação óptica, nos polímeros conjugados, consiste na transição de um elétron da banda $\pi$ à banda $\pi^{*}$ através da absorção de um fóton. $O$ sistema excitado, estado singleto, portanto, é formado por um elétron na banda $\pi^{*}$ e um buraco na banda $\pi$, unidos por atração coulumbiana, o par elétron/buraco é chamado de éxciton. A recombinação excitônica é responsável pela emissão de luz, embora devam ser levados em conta vários processos intermediários, não radiativos, que concorrem para a diminuição da eficiência da emissão.

Sobre um segmento conjugado excitado, sistema excitado ilustrado na Figura 2.5.2, atuam processos não radiativos extremamente rápidos $(\sim 0,1 p s)$, que provocam a relaxação energética do elétron $\pi^{*}$, por meio da ativação de fônons (relaxação vibracional), aos níveis mais baixos da banda $\pi^{*}$, este processo é chamado de Conversão Interna $(\mathrm{Cl})$, Figura 2.5.2. 
Neste estágio, há uma probabilidade de $25 \%$ de que ocorra a recombinação excitônica e tenhamos a emissão de luz ou fluorescência, não obstante haja a transferência dessa energia a centros supressores que reduzem a eficiência da emissão. Ainda ocupando o nível energético mais baixo da banda $\pi^{*}$, o elétron pode relaxar energeticamente a estados tripletos de menor energia, este processo é o Cruzamento Intersistema (CSI).

Há $75 \%$ de probabilidade de que o éxciton recombine, radiativamente (fosforescência), via estados tripletos, entretanto a eficiência deste processo é baixa, pois o tempo de vida, neste estado, é da ordem microsegundos a minutos. Neste intervalo de tempo, a recombinação por processos de multifônons ou transferência a centros supressores atuam reduzindo a eficiência da emissão.

A recombinação excitônica, via estados singletos, é majoritariamente responsável pela luz emitida dos polímeros conjugados. Haja vista que o longo tempo de vida do estado tripleto reduz consideravelmente os possíveis processos de recombinação radiativa.

Ambos processos $\mathrm{Cl}$ e CSI estão presentes na relaxação energética que ocorre no segmento conjugado. Entretanto a Transferência Foerster é outra importante forma de relaxação em que a excitação difunde-se dos pequenos segmentos conjugados aos maiores, ou seja, dos estados mais aos menos energéticos, através de interações dipolo-dipolo, essa modalidade de transferência de energia será tratada detalhadamente a seguir. 
O espectro de emissão é determinado pelos processos de transferências de energia descritos acima que intermedeiam a absorção óptica e a emissão final, pois sua localização espectral depende do tamanho do segmento conjugado em que ocorre a emissão final. Sua forma de linha é mais resolvida em relação aos espectros de absorbância (Figura 2.5.1), uma vez que a transferência de energia direciona grande parte da excitação aos estados finais, o que define as bandas. O acoplamento elétron-fônon determina o posicionamento espectral dos picos de acordo com a relação $E_{0}-m h v$, com $m=0,1,2,3 \ldots$ múltiplo inteiro da energia $h v$ de um fônon e $E_{0}$ a energia de transição puramente eletrônica (a primeira estrutura de banda corresponde a linha de 0 fônons).

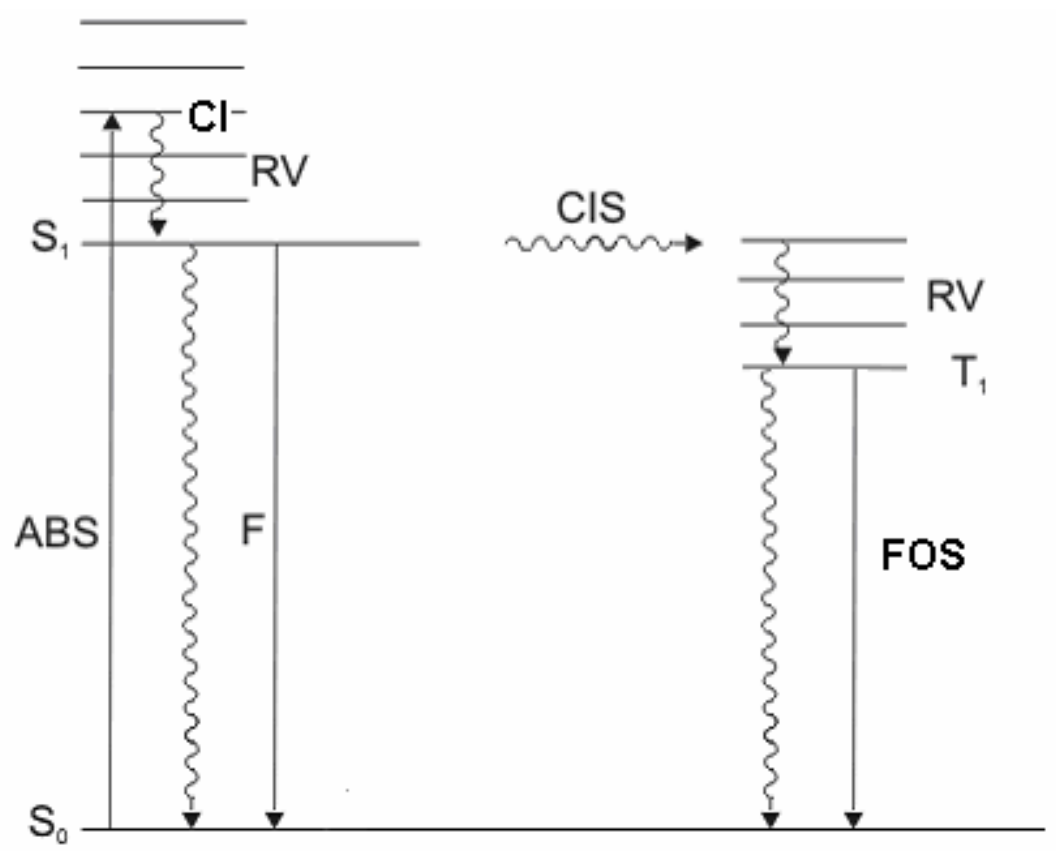

Figura 2.5.2 Diagrama de Jablonski[12] ilustrando possíveis processos de recombinação intramolecular após excitação. ABS - absorção , RV - relaxação vibracional, $\mathrm{CI}$ - conversão interna, F - fluorescência , FOS - fosforescência, CIS cruzamento intersistema, $S_{0}$ - estado singleto fundamental, $S_{1}$ e $T_{1}$ - primeiros estados de singleto e tripleto excitados. As setas onduladas são os processos que 
envolvem a geração de fônons ou multifônons enquanto que as setas lineares envolvem fótons.

\subsection{Dinâmica do estado excitado eletrônico em sistemas poliméricos: efeito da organização molecular e concentração}

A difusão da excitação eletrônica, em um conjunto de moléculas distribuídas, aleatoriamente, tem desafiado pesquisadores teóricos e experimentais há muito tempo. A dinâmica desse processo está intimamente associada aos fenômenos radiativos, como a luminescência, em sistemas orgânicos.

A explicação dos fenômenos associados à migração do estado excitado apresenta aspectos de mecânica quântica e mecânica estatística. Förster [13] trata o problema da transferência de energia com uma teoria baseada na interação dipolo-dipolo e, a partir dela, faz predições corretas relacionando observáveis espectroscópicos com as interações intermoleculares, além de deduzir a taxa de transferência relacionada à geometria molecular.

Nos filmes estruturados em multicamadas, todo o processo de transferência ocorre em três dimensões, obedecendo aos impositivos calculados por Foerster na taxa de transferência, tornando o entendimento do caminho seguido pela excitação ainda mais complexo. 
A habilidade de moldar e controlar polímeros semicondutores com propriedades moleculares exclusivas tem produzido uma grande variedade de aplicações que não encontram similares em outros materiais. O controle e a melhoria das propriedades ópticas e elétricas dos dispositivos poliméricos emissores de luz está, intimamente, relacionada ao arranjo estrutural (distâncias inter-moleculares e ordenamento molecular) de suas cadeias nos filmes sólidos e aos mecanismos de transportes de energia entre os segmentos conjugados que absorvem e aqueles que emitem luz. Apesar do grande desenvolvimento na área de materiais orgânicos nos últimos anos, ainda é pequeno o entendimento da relação entre arranjo e estrutura molecular e as propriedades de transporte e recombinação radiativa dos portadores de carga nesses materiais.

Neste trabalho, nos dedicamos ao estudo dos processos fotofísicos em polímeros luminescentes sujeitos (i) a uma ordem orientacional dos segmentos conjugados induzida por estiramento e (ii) a mudanças das interações inter- e intramoleculares utilizando-se a separação dos segmentos conjugados através de uma molécula espaçadora específica.

\subsection{Processos de relaxação da excitação eletrônica em sistemas poliméricos}

No caso de polímeros conjugados luminescentes, a unidade molecular está associada a segmentos conjugados, dispostos ao longo da cadeia, que 
devido à desordem imposta pela conformação molecular, podem ser considerados distintos e de tamanho de conjugação dado por uma distribuição de tamanho destes segmentos. Neste sistema molecular, a excitação pode relaxar sua energia através de vários caminhos ou processos fotofísicos que podem ser resumidos a seguir [14]. A excitação de um segmento conjugado (doador D) se faz pela absorção de um fóton com energia $h v$

$$
D+h v \rightarrow D^{*} \quad \text { absorção }
$$

Dentre os muitos caminhos a serem tomados pela excitação (D*), no processo de relaxação energética, até o decaimento radiativo, dois deles estão associados à transferência de energia e correspondem a duas situações experimentais distintas:

$$
D^{*}+D \rightarrow D+D^{*} \quad \text { migração de energia entre doadores }
$$

Em um sistema ideal de uma só componente ou de um só tipo, a excitação é transferida, entre segmentos conjugados, desde que condições envolvendo a posição e a orientação relativa entre os segmentos, bem como de ressonância entre estados energéticos, sejam satisfeitas. Esta situação é referida como transferência doador-doador. Neste processo, o estado final alcançado pela excitação poderá ser um estado emissivo. Se, por outro lado, centros supressores são introduzidos na matriz polimérica, a excitação pode migrar entre segmentos conjugados e finalmente ser abatida pelo centro supressor (aceitador $\mathbf{T})$. 


$$
D^{*}+T \rightarrow D+T^{*}
$$

migração de energia para centro supressor

Este caso é responsável pelo decréscimo da eficiência de emissão em sistemas moleculares. O caso limite ocorre quando a concentração de doadores é pequena tal que a transferência de energia se faz diretamente do segmento conjugado doador para o centro supressor e corresponde ao caso de supressão direta da excitação. Particularmente para polímeros conjugados, os processos (2.5.2) e (2.5.3) são extremamente rápidos e podem ser observados nos espectros de luminescência resolvidos no tempo na escala de picosegundos.

Após o processo de migração, a excitação pode decair radiativamente em uma escala de nanosegundos, o que é denominado de luminescência

$$
D^{*} \rightarrow D+h v \quad \text { Luminescência }
$$

$\mathrm{Na}$ maioria dos casos, os estados energéticos de segmentos conjugados podem ser alterados devido à interação molecular, entre sistemas moleculares densos ou altamente desordenados, o que resulta em estados de agregados $\left(\boldsymbol{D}_{\mathbf{n}}\right)$.

$$
\begin{aligned}
& D^{*} \rightarrow D_{n}^{*} \rightarrow D_{m}^{*} \quad \text { migração para agregados } \\
& \downarrow \quad \downarrow \\
& h v_{n} \quad h v_{m} \quad \text { decaimento radiativo }
\end{aligned}
$$

A formação de agregados moleculares pode gerar também estados transientes devido à interação entre um segmento conjugado no estado excitado $\left(\mathbf{D}^{*}\right)$ e outro no estado fundamental (D). O complexo gerado pela agregação intercadeia é chamado de excímero, dando origem a estados de 
excímeros (D...D) ${ }^{*}$, com perda de energia, deslocamento espectral para o vermelho (estados de baixa energia)

$$
D^{*}+D \rightarrow(D \ldots D) * D+D+h v
$$

Estados de agregados e estados de excímeros podem decair radiativamente com emissão de um fóton e não-radiativamente através de conversão molecular interna. A presença de estados agregados e de excímeros pode o diminuir do rendimento quântico da luminescência e adicionar um deslocamento do peso espectral.

\subsection{Transferência de energia}

O entendimento da natureza das excitações e dos processos de relaxação energética de portadores de carga em semicondutores é essencial para a aplicação dessa classe de materiais no futuro. Por exemplo, existe atualmente um grande esforço para entender e controlar processos intermediários em semicondutores orgânicos relacionados com a dinâmica de relaxação energética na matriz sólida (transferência de energia e/ou carga inter- ou intramolecular durante a difusão espectral, intermitência, luminescência, etc) e, conseqüentemente, aumentar a eficiência dos processos radiativos nestes materiais.

A Transferência de Energia (TE) entre moléculas conjugadas é um relevante processo que influencia diretamente a emissão final de luz. Proposto por Foerster[13], o mecanismo de interação dipolo-dipolo revela a transferência da excitação entre uma molécula "doadora", excitada, e uma 
"aceitadora", a ser excitada, através de uma taxa média[15] que é escrita como:

$$
k_{D A}(t)=a \frac{Q_{0}}{n^{4} \tau}\left\langle\frac{\kappa^{2}\left(\hat{r}_{D A}, \vec{\mu}_{D}, \vec{\mu}_{A}\right)}{r^{6}{ }_{D A}}\right\rangle_{t} \int_{0}^{\infty} \frac{f(\hat{v}) \varepsilon(\hat{v}) d \hat{v}}{\hat{v}^{4}}
$$

Em que $a$ é uma constante numérica, $\tau_{\mathrm{e}} Q_{0}$ são respectivamente o tempo de vida e a eficiência quântica do doador na

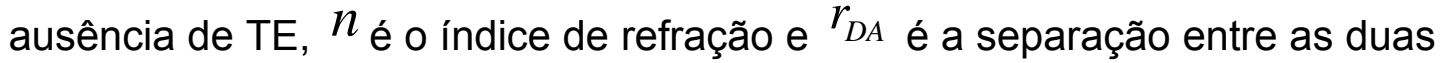
moléculas. A integral leva em conta a superposição entre a densidade de estados eletrônicos do doador $f(\hat{v})$ e a densidade de estados da molécula aceitadora $\varepsilon(\hat{v})$, no intervalo de comprimentos de onda entre $\hat{v}$ e $\hat{v}+d \hat{v}$, com a normalização $\int_{0}^{\infty} f(\hat{v}) d \hat{v}=1$. A quantidade anisotrópica $\kappa\left(\hat{r}_{D A}, \vec{\mu}_{D}, \vec{\mu}_{A}\right)$ é uma função dos momentos de transição $\vec{\mu}_{D}, \vec{\mu}_{A}$ considera a dependência com a orientação dos momentos de dipolo envolvidos na transferência e com a distância relativa entre eles $r_{D A}$. A dependência explicita com os momentos de transição é:

$$
\kappa\left(\hat{r}_{D A}, \vec{\mu}_{D}, \vec{\mu}_{A}\right)=\vec{\mu}_{D} \cdot \vec{\mu}_{A}-3\left(\vec{\mu}_{D} \cdot \hat{r}_{D A}\right)\left(\vec{\mu}_{A} \cdot \hat{r}_{D A}\right)
$$

Com as suposições de que os centros de massa estejam fixos dentro do tempo de resposta experimental, uma vez que seja a TE muito mais 
rápida do que a translação molecular, tratamos somente o efeito da reorientação molecular.

O raio de Foerster, $\mathbf{R}_{\mathbf{0}}$, representa a distância crítica em que a TE e o decaimento radiativo são igualmente prováveis. Ao tomarmos uma distribuição isotrópica, uma média sobre o fator orientacional resulta em 2/3 e o raio de Foerster fica da seguinte maneira:

$$
R_{0}^{6}=a \frac{2 Q_{0}}{3 n^{4}} \int_{0}^{\infty} \frac{f(\bar{v}) \varepsilon(\bar{v})}{\bar{v}^{4}} d \bar{v}
$$

Redefinimos então a taxa de TE:

$$
k_{D A}=\frac{3}{2 \tau} \kappa^{2}\left(r_{D A}, \mu_{D}, \mu_{A}\right)\left(\frac{R_{0}}{r_{D A}}\right)^{6}
$$

Analisando a eq. 2.8.4, para que ocorra TE: a distância entre a molécula doadora e a aceitadora não deve ser muito maior do que o raio de Foerster, a orientação relativa de seus momentos de dipolo não deve anular o fator orientacional, segundo a eq. 2.8.2, e o tempo de vida da excitação no doador não de ser muito longo.

A Figura 2.8.1 exibe a dependência da taxa de TE de Foerster em função do razão entre a distância de separação Doador-Aceitador e o raio de Foerster $\left(r_{D A} / R_{0}\right)$ e também a compara com as taxas de decaimento radiativos $\left(\mathrm{K}_{\mathrm{DF}}\right)$ e vibracional $\left(\mathrm{K}_{\mathrm{RV}}\right)$. Logo vemos que, para $\frac{\boldsymbol{r}_{D A}}{\boldsymbol{R}_{\boldsymbol{o}}}$ menores que 1, há maior possibilidade de haver TE, intervalo $\frac{\boldsymbol{r}_{D A}}{\boldsymbol{R}_{\boldsymbol{o}}}<0.3$, para $0.3<\frac{\boldsymbol{r}_{D A}}{\boldsymbol{R}_{\boldsymbol{o}}}<$ 
1.0 a probabilidade de relaxação vibracional predomina sobre as demais taxas e, para $\frac{r_{D A}}{\boldsymbol{R}_{o}}>1.0$ a TE possui menor possibilidade de ocorrência. Deste modo separações entre Doador-Aceitador permitem o relativo controle dos processos presentes durante a dinâmica do estado excitado, o que foi feito neste trabalho.

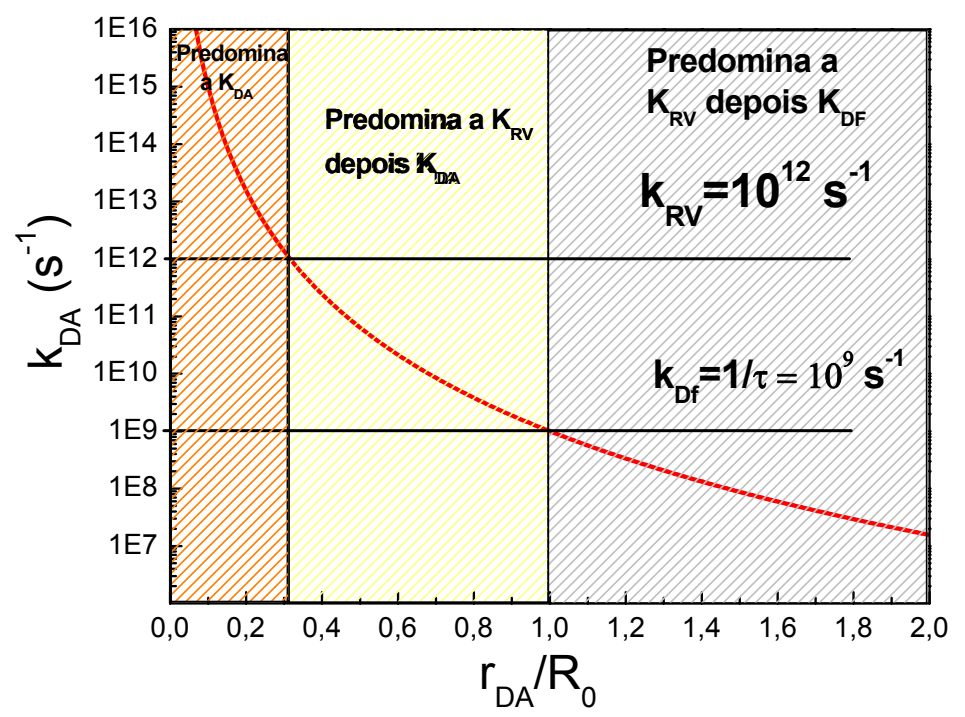

Figura 2.8.1 - Comparação entre as taxas de decaimento que concorrem durante a difusão espectral.

Logo, em um filme cujas moléculas estejam compactadas e distribuídas isotropicamente, a emissão de luz não se dá preferencialmente no eixo do vetor campo elétrico da excitação, devido a TE. Assim, a molécula doadora, uma vez excitada, transfere sua energia para a molécula aceitadora cujo momento dipolar, agora, forma certo ângulo com o eixo dipolar da molécula doadora. A molécula aceitadora torna-se seqüencialmente uma molécula doadora e passa sua energia de excitação para outra molécula com nova orientação em relação ao eixo do campo elétrico da luz de excitação, 
repetindo-se esse processo até a emissão final. $O$ vetor campo elétrico dessa luz emitida não tem a mesma orientação do vetor campo elétrico da luz de excitação, constituindo, portanto, em uma emissão despolarizada. Em resumo, os processos de transferência de energia são responsáveis pela redistribuição orientacional da excitação no plano do filme molecular, levando ao desacoplamento entre a polarização da luz na absorção com aquela emitida na luminescência.

Entretanto, ao induzirmos certo grau de anisotropia às moléculas, ainda ocorrendo a TE, a emissão se dá sobre um eixo preferencial. No nosso caso, vemos a despolarização da emissão quando não há estiramento, distribuição isotrópica, e a emissão polarizada à medida que aumenta o grau de elongação que gera uma anisotropia no filme.

Uma característica importante dos sistemas moleculares desordenados é a distribuição estatística das distâncias e das orientações relativas intermoleculares, que leva a uma distribuição de taxas de transferência entre uma molécula excitada e as moléculas não excitadas em sua vizinhança. Assim, não há um único caminho para que a excitação seja transferida, entre duas moléculas, mas um infinito conjunto de possíveis caminhos envolvendo todas as moléculas da amostra. Deste modo, na análise da TE, em sistemas moleculares, se faz necessário realizar uma média sobre todo o conjunto de possíveis caminhos. Um tratamento teórico da TE, em sistemas desordenados, é uma tarefa de considerável complexidade e exige o conhecimento da configuração microscópica das moléculas no sistema estudado. Portanto, consideraremos efeitos de transferência de energia de modo indireto, se conhecermos explicitamente outros efeitos, como a 
excitação durante a absorção de uma distribuição previamente conhecida na orientação de segmentos conjugados, por exemplo, em um filme polimérico estirado. Este assunto será tratado a seguir.

\subsection{Excitação de um sistema molecular contendo uma distribuição angular de segmentos conjugados: efeito da organização molecular}

No tratamento teórico da TE, descrito no item anterior, foi suprimido o efeito da excitação em um sistema molecular contendo uma distribuição angular de segmentos conjugados homogênea em todo o filme. Entretanto agora o trataremos, em separado, indicando as alterações que gera nos processos ópticos dos polímeros conjugados. Aqui, vamos considerar somente o efeito da excitação durante o processo de absorção, sem levar em consideração dos processos posteriores de TE. Assim, esperamos distinguir efeitos que ocorrem devido a excitação de um sistema molecular específico daqueles envolvendo TE.

O seguinte modelo teórico utiliza osciladores clássicos da eletrodinâmica e apresenta ferramentas que tratam da emissão de luz em filmes cuja orientação molecular pode ser aferida através da determinação do grau de anisotropia. Embora, nesta discussão teórica, a princípio, não sejam levados em conta os importantes processos de transferência de 
energia por meio dos segmentos conjugados, o desenvolvimento feito é bastante elucidativo para explicarmos os dados obtidos.

A excitação de um segmento conjugado, por radiação, requer que seu dipolo elétrico tenha, ao menos, uma componente sobre o eixo do vetor campo elétrico da radiação incidente[16] o que resulta em uma probabilidade de excitação dependente do $\cos ^{2}(\alpha)$, em que $\boldsymbol{\alpha}$ é o ângulo entre o eixo molecular e o vetor campo elétrico da luz incidente.

Supomos o momento de dipolo do segmento conjugado sobre o eixo molecular. Uma vez excitado, o segmento conjugado emite luz planopolarizada no eixo molecular OA, indicando a anisotropia da amostra.

Nos nossos filmes sob estiramento, a deformação uniaxial [17] provoca apenas o alinhamento médio da cadeia polimérica, orientando os dipolos elétricos, sem originar qualquer tipo de tração, que altere as propriedades das ligações químicas. Portanto, sabemos que há anisotropia nas amostras e que esta varia com o grau de elongação aplicado.

A Figura 2.9.1 mostra as orientações dos vetores campo elétrico da luz incidente $\mathrm{OP}_{1}$ e emitida, assim como o eixo molecular $\mathrm{OA}$. 


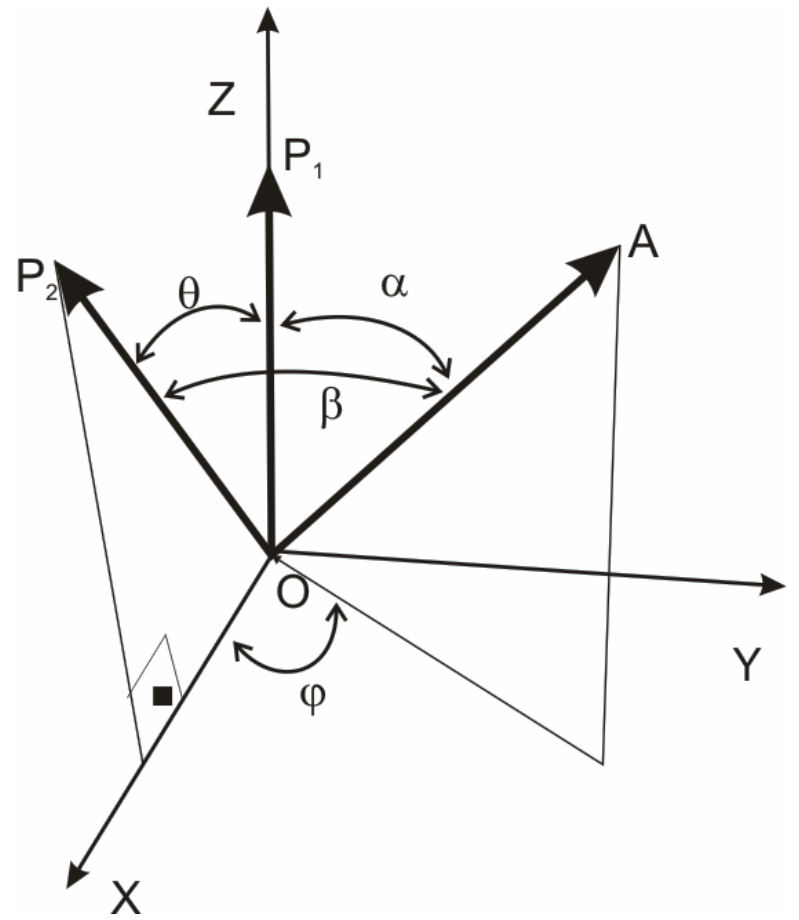

Figura 2.9.1- Ângulos especificando a orientação do eixo molecular (OA), do vetor campo elétrico da luz incidente (OP1) e a componente polarizada da luz emitida (OP2).

A partir da construção da Figura 2.9.1 podemos inferir a intensidade da luz emitida, $i_{\theta}[16]$

$$
i_{\theta}=K \Phi \cos ^{2} \alpha \cos ^{2} \beta
$$

em que $\mathrm{K}$ e $\Phi$ são, respectivamente, a probabilidade máxima de excitação quando o eixo molecular coincide com a direção do vetor campo elétrico incidente (direção OZ) e a eficiência da emissão. O fator $\cos ^{2}(\beta)$, na relação acima, leva em conta a projeção do dipolo molecular (direção do campo elétrico da luz emitida) sobre o eixo do analisador na direção $\left(\mathrm{OP}_{2}\right.$ sobre o plano XZ), considerando que a direção de observação é paralela ao eixo OY. 
Quando o filme já apresenta anisotropia devemos introduzir uma função de distribuição angular, $\Omega(\boldsymbol{\alpha}, \boldsymbol{\varphi})$, para o cálculo da intensidade total da luz emitida que se encontra plano-polarizada na direção $\left(\overline{\mathrm{OP}_{2}}\right)$ :

$$
I_{\theta}=(1 / 2 \pi) K \Phi \int_{0}^{2 \pi \pi / 2} \int_{0}^{2} \Omega(\alpha, \varphi) \cos ^{2} \alpha \cos ^{2} \beta \operatorname{sen} \alpha d \alpha d \varphi
$$

Expressando $\cos ^{2} \beta$ em termos de $\alpha, \varphi$ e $\theta$, as intensidades da luz emitida perpendicular e paralela ao eixo molecular têm a seguinte forma:

$$
I_{\perp}=(1 / 2 \pi) K \Phi \int_{0}^{2 \pi} \int_{0}^{\pi / 2} \Omega(\alpha, \varphi) \cos ^{2} \alpha \operatorname{sen}^{3} \alpha \cos ^{2} \varphi d \alpha d \varphi
$$

e

$$
I_{/ /}=(1 / 2 \pi) K \Phi \int_{0}^{2 \pi} \int_{0}^{\pi / 2} \Omega(\alpha, \varphi) \cos ^{4} \alpha \operatorname{sen} \alpha d \alpha d \varphi
$$

O grau de anisotropia, $S=\left(I_{/ /}-I_{\perp}\right) /\left(I_{/ /}+I_{\perp}\right)$ e o grau de polarização $P=I_{/ /} / I_{\perp}$, podem ser aferidos ao se encontrar a função que simula a distribuição orientacional dos segmentos conjugados no filme. São mostradas abaixo duas funções estatísticas da distribuição de orientação dos segmentos conjugados e seus respectivos gráficos polares em função do grau de elongação $\lambda=$ L/Lo para um estiramento axial ao longo do eixo $Z$, que podem ser usadas para o cálculo das intensidades descritas acima[17, 18]: 


$$
\Omega(\alpha)=\lambda^{3 / 4} \operatorname{sen} \alpha /\left(\lambda^{-3 / 4} \cos ^{2} \alpha+\lambda^{3 / 2} \operatorname{sen}^{2} \alpha\right)^{3 / 2}
$$

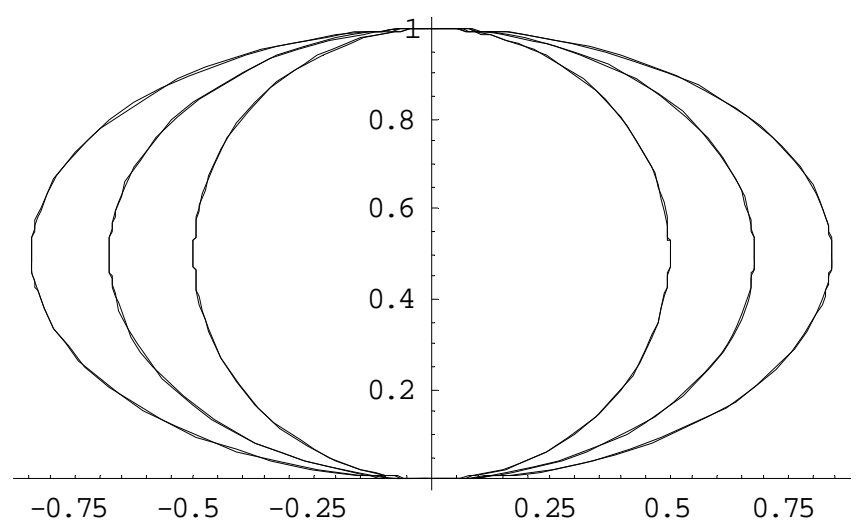

Figura 2.9.2 Gráfico Polar da eq (2.9.5)

e

$$
\Omega(\alpha)=\lambda^{3}\left(\cos ^{2} \alpha+\lambda^{3} \operatorname{sen}^{2} \alpha\right)^{-3 / 2}
$$

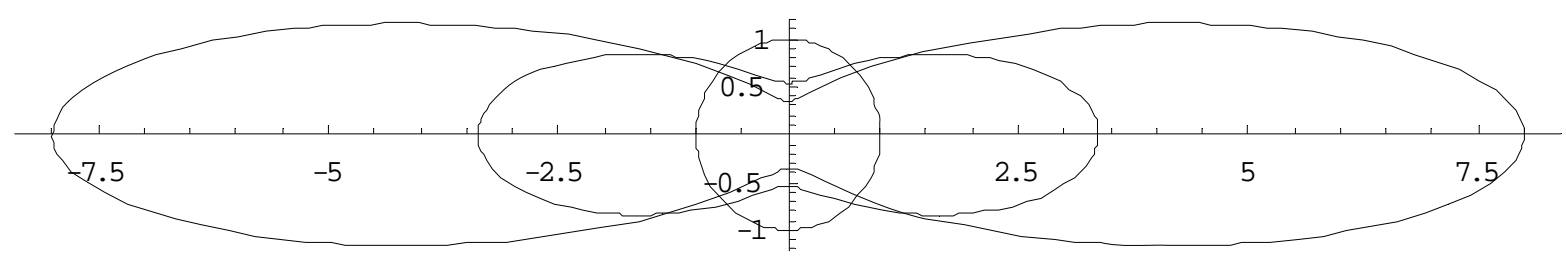

Figura 2.9.3 Gráfico Polar da eq. 2.9.6

A distribuição dada pela equação (2.9.6) é mais realista e descreve bem a orientação do nosso sistema.

Para o caso de uma distribuição isotrópica de segmentos conjugados, $\Omega(\alpha)=1$, temos que $I_{/ /}=(1 / 5) K \Phi{ }_{\mathrm{e}} I_{\perp}=(1 / 15) K \Phi$. Neste caso, o grau de polarização é $P=I_{/ /} / I_{\perp}=3$, independentemente da direção do vetor campo elétrico da luz polarizada incidente. 
É interessante considerar o caso do estiramento axial tratado neste trabalho. A Figura 2.9.4 mostra a dependência da razão da intensidade da luz emitida paralelamente ao eixo de estiramento, $\mathbf{I}_{/ /}$, (eq.2.9.4) pela intensidade da luz emitida perpendicularmente ao eixo de estiramento $\mathbf{I}_{\perp}$ (eq.2.9.3), à medida em que se aumenta a elongação, dada pela razão do comprimento da amostra estirada pelo seu comprimento original, $\lambda=L_{/} L_{0}$, ( tendo variação de 1 à 2). A direção do vetor campo elétrico da radiação de excitação foi considerada paralela ao estiramento. As curvas Figura 2.9.4 foram calculadas a partir das distribuições consideradas acima nas equações (2.9.5) e (2.9.6).

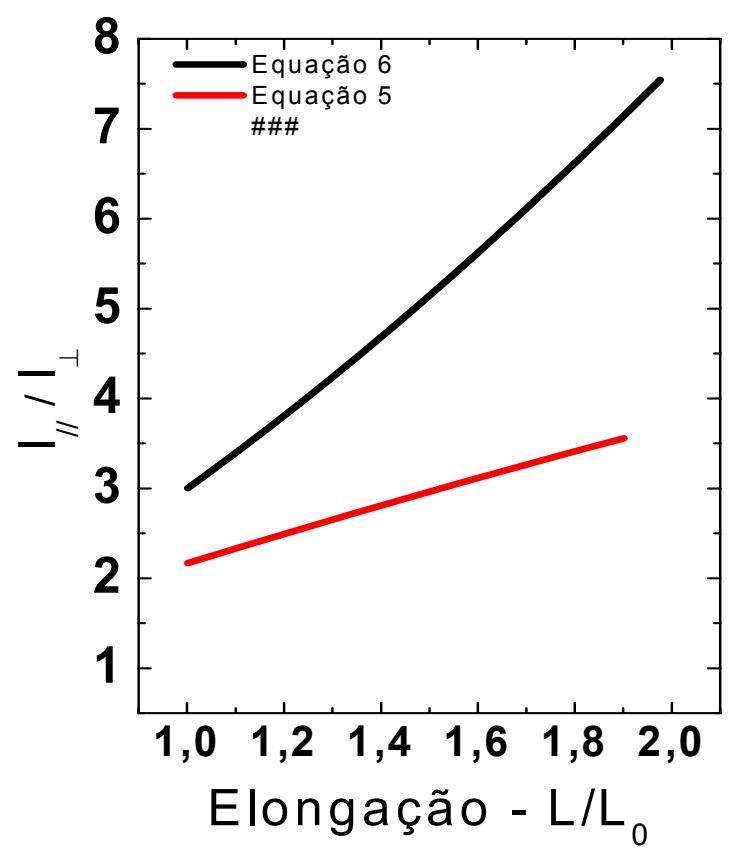

Figura 2.9.4 Razão de $I_{/ /}$(eq. 6.4) por $I_{\perp}$ (eq. 6.3) em função da elongação $L / L_{0}$. 


\subsection{Absorção em um sistema molecular contendo uma distribuição angular de segmentos conjugados: efeito da organização molecular}

A absorção da luz por um segmento conjugado depende da orientação de seu momento dipolar de transição[19] que, em relação ao vetor campo elétrico da luz incidente, é definido abaixo:

$$
\mu^{0 m}=\int \Psi_{m}\left(e \sum \vec{r}_{i}\right) \Psi_{0} d \tau
$$

em que $\Psi_{0}$ e $\Psi_{m}$ são funções de onda, respectivamente, do estado fundamental e excitado da molécula e $e \sum \vec{r}_{i}$ é o operador dipolo elétrico, sendo $e$ a carga eletrônica e $\vec{r}_{i}$ a posição do i-ésimo elétron da molécula. Com todas as moléculas tendo orientação equivalente, a energia média W absorvida por molécula, por segundo, devido um processo de absorção dipolar, é:

$$
W=\pi v\left|\vec{E}_{0} \mu^{0 m}\right|^{2} \rho^{0 m}(v) / 2 \hbar
$$

em que $\vec{E}_{0}$ é a amplitude do vetor campo elétrico da luz incidente e $\rho^{0 m}$ é a função densidade de energia da banda de absorção que obedece à condição de normalização, $\int \rho^{0 m}(v) d v=1$. Destas equações definimos o coeficiente de extinção: 


$$
\varepsilon=\left(N / \ln 10 \times 10^{3}\right) W / I_{c}
$$

em que $N$ é o número de Avogadro e $I_{c}=c n E_{0}{ }^{2} / 8 \pi$ é a intensidade da radiação incidente.

A equação (2.10.3) remete ao coeficiente de extinção de uma molécula com respeito ao seu sistema de coordenadas. Para as medidas efetuadas, o referencial é o do laboratório, logo, por meio de uma transformação de coordenadas, obtemos os coeficientes de extinção macroscópicos. E, conseqüentemente, chegamos à absorbância, por meio da introdução da expressão (2.10.4) que indica a média da orientação de uma distribuição estatística de segmentos conjugados, relativamente, ao eixo e grau de estiramento:

$$
\left\langle\cos ^{2}(\omega)\right\rangle=\frac{\lambda^{3}}{\left(\lambda^{3}-1\right)}-\frac{\lambda^{3}}{\left(\lambda^{3}-1\right)^{\frac{3}{2}}} \arctan \left(\left(\lambda^{3}-1\right)^{\frac{1}{2}}\right)
$$

onde $\omega$ é o ângulo entre os segmentos estatísticos e o eixo de estiramento, $\lambda=L / L_{0}$ é a elongação.

Como estamos interessados em sistemas com estiramento axial, os coeficientes de extinção macroscópicos, paralelo e perpendicular, à direção de estiramento, podem ser escritos na forma:

$$
\begin{aligned}
& E_{/ /}=\left\langle\operatorname{sen}^{2} \omega\right\rangle \varepsilon_{\perp}+\left\langle\cos ^{2} \omega\right\rangle \varepsilon_{\amalg} \\
& \mathrm{e} \\
& E_{\perp}=0.5\left(\left\langle\cos ^{2} \omega\right\rangle+1\right) \varepsilon_{\perp}+0.5\left\langle\operatorname{sen}^{2} \omega\right\rangle \varepsilon_{\amalg}
\end{aligned}
$$


A absorbância é calculada das equações (2.10.7) e (2.10.8) usando a lei de Lambert-Beer:

$$
A_{/ /}=E_{\amalg} c d
$$

e

$$
A_{\perp}=E_{\perp} c d
$$

nas equações (2.10.7) e (2.10.8) c e d são, respectivamente, a concentração molar do PPV e a espessura do filme estudado.

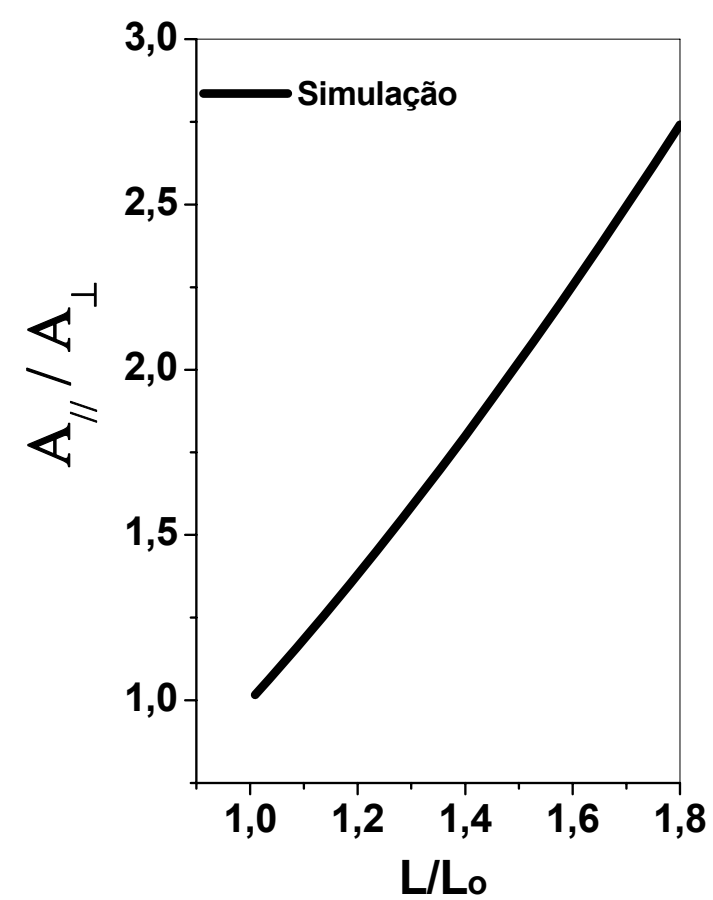

Figura 2.10.1 A reta é a simulação de $A_{/ /} / A_{\perp}$ utilizando as equações 2.10 .7 e 2.10.8. $A_{/ /}$e $A \perp$ são respectivamente as absorbâncias na posição do analisador paralela $e$ perpendicular ao eixo de estiramento.

Para demonstrar a algumas propriedades do modelo apresentado acima, assumimos os valores de $\varepsilon_{/ /}=100 \times 10^{3}\left[\mathrm{Lmol}^{-1} \mathrm{~cm}^{-1}\right]$ e 
$\varepsilon_{\perp}=2,5 \times 10^{3}\left[\mathrm{Lmol}^{-1} \mathrm{Cm}^{-1}\right]$ e calculamos o grau de anisotropia $A_{/ /} / A_{\perp}$ da absorção causada pelo estiramento, que independe da espessura do filme. A Figura 2.10.1 mostra $A_{/ /} / A_{\perp}$ calculado para um filme "casting". Observamos que a dependência calculada coincide com os valores experimentais para baixos estiramentos. Vemos que a os baixos valores de anisotropia na absorção não são suficientes para explicar os altos valores de polarização da luminescência. Deste resultado concluímos que os altos valores de polarização da luminescência devem ser explicados por processos de TE entre segmentos não orientados para segmentos com orientação na direção do estiramento. 
Capítulo 3

3. Materiais e Métodos 


\subsection{Metodologia}

No conteúdo deste capítulo, focamos a metodologia, com adoção de técnicas específicas de engenharia molecular, direcionada para a realização do trabalho. Encontra-se todo o processo de manuseio do polímero precursor, PTHT (poli(cloreto de xilideno tetrahidrotiofeno), até sua conversão, em PPV (poli(p-fenileno vinilideno), que é um polímero conjugado emissor de luz (de que estudamos as características ópticas).

Neste trabalho, voltamos a atenção para a compreensão, mais clara, das restrições a que os éxcitons obedecem, para migrarem de cromóforo a cromóforo, antes de seu decaimento radiativo ou extinção por centros supressores, não-radiativos, variados (defeitos da rede e impurezas, por exemplo). 
Devido à requisição de se isolarem as moléculas, para observações mais sensíveis de seu comportamento, durante a transmissão da energia, trabalhamos sobre filmes extremamente finos, fabricados a partir da técnica 'self-assembly' (SA) ou automontagem (LbL) e por 'Spin-Cast' que permitem grande controle nas taxas de deposição molecular, ou seja, da espessura e homogeneidade dos filmes sobre grandes áreas. Depositamos o PPV, com sucesso, em substratos de Teflon (Dielectrix, 250micrometros de espessura), quartzo e vidro, todos apresentam janela de comprimento de onda transparente, na região espectral, em que se dá a caracterização dos filmes, absorção e emissão do PPV, Figura 2.5.1.Isto aliado a técnicas de engenharia molecular, possibilitou-nos a separação do polímero estudado, por meio de um polímero inerte (PDAC), bem como, separar os segmentos conjugados ao longo da cadeia. Deste modo, as moléculas opticamente ativas se apresentavam com menor interação entre si, dificultando as transferências inter ou intracadeia.

Atrelado ao interesse de se insularem as moléculas emissivas, a fim de coibir, parcialmente, a migração do éxciton, nas transferências intracadeias, desenvolvemos nova metodologia capaz de separar os segmentos conjugados, ao longo da cadeia. Através da incorporação de um sal orgânico (DBS). A Incorporação deste sal será apresentada, abaixo, aliada à redução do tempo de tratamento térmico para a conversão do polímero precursor (PTHT), em PPV, permitiu-nos um controle, no nível molecular do tamanho de conjugação médio do PPV, além de reduzir a formação de defeitos advindos da exposição às altas temperaturas. 
Este capítulo tem a intenção de mostrar toda a metodologia utilizada em função do estudo direcionado para filmes finos. Detalhamos os passos para a obtenção de filmes de PPV, sobre Teflon, que foram submetidos à ordenação molecular sob estiramento. Apresentamos a engenharia molecular utilizada a fim de separarmos os segmentos conjugados de PPV de duas formas: (i) dentro da cadeia do copolímero PTHT-PPV e (ii) separando as cadeias do copolímero por moléculas opticamente inertes de PDAC.

\subsection{Materiais Utilizados}

Os materiais usados para o estudo das propriedades ópticas do PPV estão relacionados na Tabela 1 .

Os materiais que serviram de substrato para a confecção dos filmes são: (i) Vidro KB7 “Optical Glass”, (ii) quartzo da "Heraeus Quarzglas” e (iii) Teflon (Dielectrix, 250micrometros de espessura). 
Tabela 1 - Materiais formadores dos filmes estudados

\begin{tabular}{|c|c|c|}
\hline Símbolo & Nome por extenso/função/origem & Concentração \\
\hline PTHT & $\begin{array}{c}\text { Poli(cloreto de xilideno tetrahidrotiofeno) } \\
\text { /poliânion do precursor do PPV/ * }\end{array}$ & $0,3 \mathrm{mg} / \mathrm{ml}$ \\
\hline$D B S$ & $\begin{array}{l}\text { Dodecilbenzeno Sulfonado/ policátion do } \\
\text { PTHT/Aldrich }\end{array}$ & $10^{-2} \mathrm{M}$ \\
\hline$P P V$ & $\begin{array}{c}\text { Poli(p-fenileno vinileno)/camada ativa } \\
\text { emissora de luz }\end{array}$ & $0,5 \mathrm{mg} / \mathrm{ml}$ \\
\hline$P D A C$ & $\begin{array}{l}\text { Poli(cloreto de dialildimetil amônia) em água } \\
\text { material espaçador 1/Aldrich }\end{array}$ & $0,5 \mathrm{mg} / \mathrm{ml}$ \\
\hline$P S S$ & $\begin{array}{l}\text { Poli(estireno sulfonado) em água 20\% em } \\
\text { peso/ policátion do material espaçador } 1 / \text { Aldrich }\end{array}$ & \\
\hline
\end{tabular}

\subsection{Síntese do PTHT (precursor do PPV)}

O PPV (Figura 3.3.1 a)) é um polímero conjugado insolúvel na maioria dos solventes orgânicos, por este motivo, para a obtenção do polímero precursor do PPV, sintetizamos primeiramente o seu precursor, poli(cloreto de xilideno tetrahidrotiofeno) ou PTHT (Figura 3.3.2 a)->b) ).

O PTHT é um polieletrólito, podendo assim formar filmes. Após o tratamento térmico (Figura 3.3.2 c)->d)), ocorre a conversão de PTHT em PPV.. 


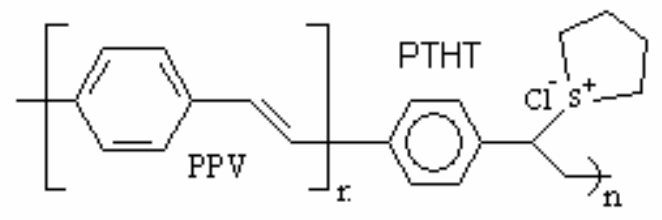

a)

b)

Figura 3.3.1 Estrutura química do copolímero PTHT-PPV. Na figura, podemos separar o polímero conjugado PPV, a), cujo segmento possui $r$ repetições da estrutura entre colchetes, e o polietrólito PTHT, b), cujo comprimento da cadeia é de n repetições da estrutura fora dos colchetes.

O PTHT em solução aquosa é obtido a partir da reação da polimerização do monômero p-xilileno-bis(cloreto de tetrahidrotiofeno), estrutura a) na Figura 3.3.2, utilizamos os materiais: Balão volumétrico de três entradas, Pulga, Nitrogênio, Gelo, Vaso (bacia), Agitador magnético, Balança de precisão, Pipeta, Pipeta de Pasteur e Termômetro no processo de polimerização. 
(a)<smiles>Cl[SiH]1CC[SiH](Cl)C1</smiles><smiles>[CH2]c1ccc(C[Sb]2CCCC2)cc1</smiles>

Monômero $\mathbf{c l}^{\ominus}$<smiles>Cc1ccc(C=CC(C)(C)C)cc1</smiles>

Filme de PPV

\section{Polimerização}

i) $\mathrm{NaOH}$

ii) $\mathrm{HCl}$

iii) Diálise

(b)

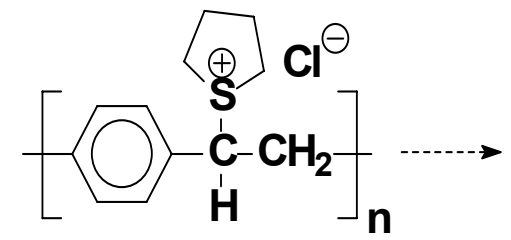

Polieletrólito sulfônido do Polímero precursos em solução (c)

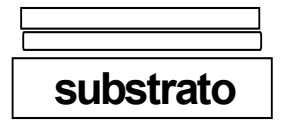

Filmes automontados
Tratamento Térmico: $\mathrm{T}=110^{\circ} \mathrm{C}$ $\mathrm{t}=30 \mathrm{~min}$ $p=65$ Torr

Figura 3.3.2 Esquema mostrando desde e reação química de polimerização do PTHT, passando pela formação dos filmes, até o tratamento térmico e obtenção do PPV

Dissolvemos 1,021 g do monômero, Figura 3.3.2 a), (0,0029 moles) em $10 \mathrm{~mL}$ de metanol, a solução é resfriada a $0{ }^{\circ} \mathrm{C}$ e desoxigenada por um fluxo constante de $\mathrm{N}_{2(\mathrm{~g})}$. Em seguida, adicionamos $6,9 \mathrm{~mL}$ de solução de $\mathrm{NaOH}$ ( 0,4 mol. $\left.\mathrm{L}^{-1}\right)$, gota à gota, com pipeta Pasteur, à solução com o monômero sob fraca e constante agitação. Após a total adição, mantido o fluxo de $\mathrm{N}_{2(\mathrm{~g})}$, a solução permaneceu sob agitação por 20 min, então colocamos, por meio de uma pipeta graduada, $8,7 \mathrm{~mL}$ da solução de $\mathrm{HCl}\left(0,357 \mathrm{~mol} . \mathrm{L}^{-1}\right)$, pelo mesmo procedimento da solução de $\mathrm{NaOH}$.

A solução resultante foi colocada em uma membrana de diálise (cut off 10.000-12500 com) e esta em uma proveta preenchida com água Mili-Q e protegida contra luz. A água foi trocada a cada duas horas, durante 6 dias. 
Deste modo, obtivemos uma solução aquosa, transparente, livre de monômeros de PTHT, Cloreto de Sódio, tetrahidrotiofeno, oligômeros residuais, homogênea e incolor, o PTHT, solúvel em diferentes solventes orgânicos e também em água.

O PTHT mantido a $0^{\circ} \mathrm{C}$ e protegido da luz não apresenta degradação no período de 2 a 3 meses. Sua conversão em PPV, após formação de um filme, Figura 3.3 .2 c), ocorre com a eliminação do chamado grupo de saída (tiofeno) da macromolécula de PTHT através de tratamento térmico.

Entretanto, neste trabalho, utilizamos uma inovação, para a o processo de conversão térmica, desenvolvida no Grupo de Polímeros do Instituto de Física de São Carlos por Marletta e colaboradores[1] , utilizando o contraíon DBS. Esse processo não convencional será discutido a seguir.

\subsection{Processo alternativo para formação de filmes de PPV}

O procedimento convencional, Figura 3.4.1 A), se dá pela saída do polietrólito PTHT, via tratamento térmico, do radical sulfônico (tiofeno), convertendo o em PPV. Essa reação acontece em estufa, sob vácuo (10${ }^{6}$ torr), a temperaturas de $230^{\circ} \mathrm{C}$ a $300^{\circ} \mathrm{C}$ e durante tempos não inferiores a 180min. Contudo esse tratamento térmico provoca defeitos na rede 
polimérica, como exemplo: a incorporação de carbonila. Estes defeitos atuam como centros supressores da energia de excitação e diminuem a eficiência da emissão.

O procedimento alternativo, Figura 3.4.1 B), se baseia na incorporação do contra íon de cadeia longa, DBS, na molécula de PTHT, onde o dodecilbenzeno sulfônico, DBS, substitui o contra íon de cloro (Cl-) complexado pelo grupo sulfônico de saída (tiofeno) no tratamento térmico. Formam-se dois compostos: (i) PTHT complexado com DBS e (ii) e PTHT.

O PTHT complexado com DBS converte-se em PPV a temperaturas mais baixas que as necessárias ao procedimento convencional. A conversão térmica resulta em um copolímero de bloco PPV-PTHT, o segmento de PPV advém da eliminação do grupo sulfônico de saída (tiofeno) da molécula de PTHT, que foi complexada com DBS, enquanto que o segmento de PTHT presente no copolímero é a parte da molécula que não foi complexada com DBS e, desta maneira, precisaria de maiores temperaturas para se converter. 


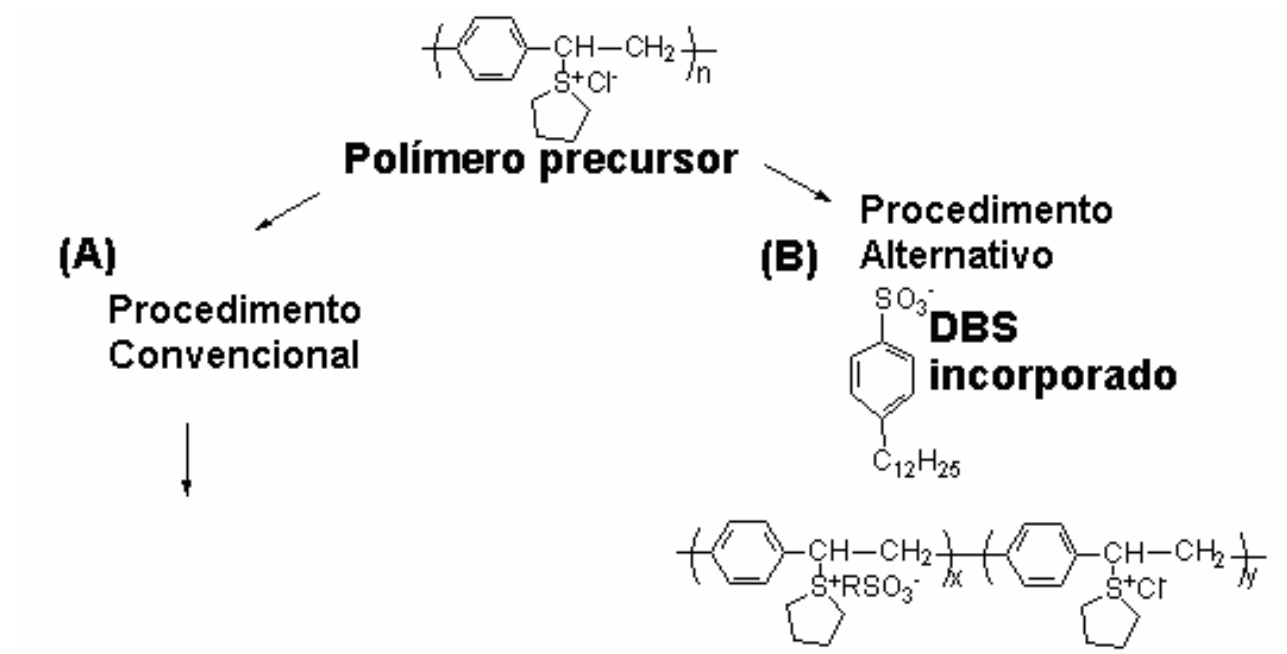

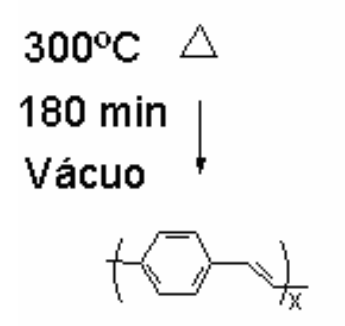

Polímero PPV

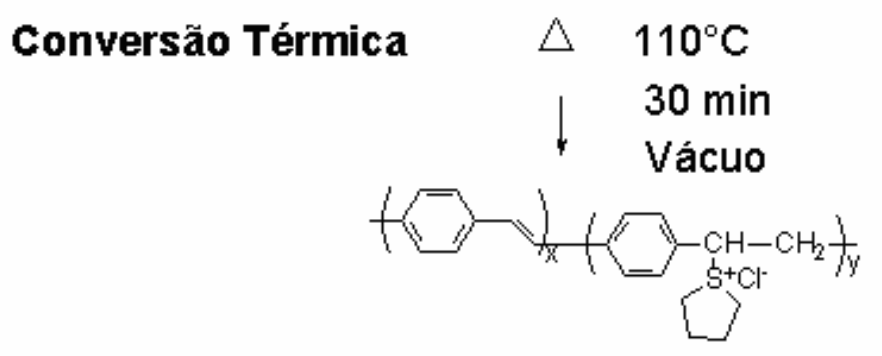

Copolímero de PPV com PTHT

Figura 3.4.1 - a) procedimento convencional, em que a conversão PTHT em PPV ocorre pela eliminação térmica do grupo de saída sulfônico (tiofeno)[11]. b) procedimento alternativo de formação do copolímero PPV-PTHT, através da substituição do contra íon $\mathrm{Cl}$ - pelo íon de cadeia longa DBS. Esse procedimento tem a vantagem de requer menor tempo e temperatura mais baixa do que o convencional. 


\subsection{PDAC e PSS}

Os polietrólitos PDAC, poli(cloreto de dialildimetil amônia), e PSS, Poli(estireno sulfonado), não apresentam atividade óptica nas regiões espectrais de absorção e emissão do PPV, logo, utilizamos esses materiais para a formação de filmes, uma vez que não haveria prejuízo das informações ópticas do PPV.

Adaptamos o PDAC como separador das moléculas de PPV, fazendo soluções catiônicas a partir de frações da solução de PTHT e da solução de PDAC, usamos a solução aniônica de DBS a fim de completar o processo de automontagem. Deste modo, na estrutura do filme havia moléculas do copolímero PPV-PTHT separadas por moléculas de PDAC. Já o PSS constituiu o poliânion da solução aniônica para construirmos filmes em que o DBS foi incorporado diretamente na solução de PTHT<smiles></smiles>

a) PDAC<smiles>CCC(C)c1ccc(S(=O)(=O)[O-])cc1</smiles>

b) PSS

Figura 3.5.1 Moléculas de PDAC e PSS, policátion e poliânion, usados na formação de filmes orgânicos automontados.

A solução diluída de PDAC (concentração $1,0 \mathrm{mg} / \mathrm{ml}$ ) foi obtida a partir da solução original (densidade 1,04g/ml, 20\% wt) diluindo $0,480 \mathrm{ml}$ $(100 \mathrm{mg}) \mathrm{em} 200 \mathrm{ml}$ de água ultrapura. O mesmo procedimento foi utilizado para a obtenção da solução de PSS (concentração 2,0 mg/m/). 


\subsection{Limpeza e tratamento dos substratos}

Para a limpeza de lâminas de quartzo, vidro e das fitas de Teflon utilizadas como substrato, empregamos o método RCA [20] de hidrofilização. Este método consiste da lavagem dos substratos em soluções químicas com caráter básico e ácido de composições descritas na Tabela 2, a fim de eliminarmos suas impurezas e Ihe conferirmos um caráter hidrofílico, uma vez que as solução que usamos para a formação de filmes são aquosas.

A limpeza RCA obedece a duas etapas:

1. A limpeza prévia dos substratos deve ser realizada com água e detergente esfregando-os suavemente com uma esponja macia, e após a lavagem, devem ser imersos em acetona P.A. aquecida $\left(\sim 80^{\circ} \mathrm{C}\right)$ durante 10 a 15 minutos. As lâminas são imersas na solução básica ainda fria e aquecidas até $80^{\circ} \mathrm{C}$ sem, no entanto, exceder $85^{\circ} \mathrm{C}$, permanecendo durante 15 minutos. Em seguida, as lâminas são exaustivamente lavadas com água ultrapura por 5 minutos. Com essa etapa garantimos que os substratos estão livres de gordura e metais alcalinos do tipo IB e IIIB (Cu, Ag, Zn, Cd).

2. Na segunda etapa, os substratos são imersos na solução ácida, previamente, aquecida a $80^{\circ} \mathrm{C}$. aquecida $\left(75-80^{\circ} \mathrm{C}\right)$. Após um período de 15 minutos as lâminas são, novamente, lavadas em água ultrapura e deixadas em descanso por mais 20 minutos em água. Ao final dessa etapa dissolvem-se os íons alcalinos e 
hidróxidos de $\mathrm{Fe}^{3+}, \mathrm{Al}^{3+}$ e $\mathrm{Mg}^{3+}$ da superfície dos substratos. Os substratos devem ser mantidos em água Mili-Q por no máximo 24 horas. Após este período todo o processo de limpeza RCA deve ser refeito

Tabela 2 - Componentes e proporções das soluções usadas para limpeza de substrato

\begin{tabular}{|l|c|l|l|l|}
\hline & \multicolumn{5}{|c|}{ Componentes } & \\
\hline Solução & I & II & III & Proporção \\
\hline Básica & $\mathrm{H}_{2} \mathrm{O}$ & $\mathrm{H}_{2} \mathrm{O}_{2}$ & $\mathrm{NH}_{4} \mathrm{OH}$ & $5: 1: 1$ \\
& (ultrapura) & $(30 \%)$ & $(30 \%)$ & \\
\hline Ácida & $\mathrm{H}_{2} \mathrm{O}$ & $\mathrm{H}_{2} \mathrm{O}_{2}$ & $\mathrm{HCl}$ & $6: 1: 1$ \\
& (ultrapura) & $(30 \%)$ & $(37 \%)$ & \\
\hline
\end{tabular}

A água ultrapura usada, em todos os experimentos, foi obtida através do 'Nanopure Infinity- Ultrapure Water System' da 'Barnstead' com resistividade de $18,3 \mathrm{M} \Omega \cdot \mathrm{cm}$.

\subsection{Instrumentação}

As propriedades e características dos materiais usados no desenvolvimento deste trabalho foram avaliadas nas suas propriedades ópticas e estruturas com ênfase na uniformidade, espessura de filmes, linearidades da adsorção camada-por-camada, morfologia de superfície dos filmes orgânicos e metálicos, usando as seguintes ferramentas da análise de materiais. 


\subsection{Absorbância UV-VIS e infravermelho}

A caracterização óptica através da espectroscopia de absorção utilizou o espectrofotômetro Hitachi U-2001, do grupo de Polímeros do IFSC, que trabalha em uma fonte de radiação com uma larga banda de emissão, na faixa que vai do ultravioleta próximo ao infravermelho próximo (190 a 1100 $\mathrm{nm})$. As medidas experimentais são apresentadas como um gráfico da absorbância versus comprimento de onda, com que fazemos o acompanhamento do crescimento dos filmes e a aquisição de espectros de absorbância.

Dos espectros de absorbância podemos inferir informações como: (i) medidas qualitativas da quantidade de material depositado, tomando o valor da absorbância, a cada bicamada, mantendo o comprimento de onda do feixe fixo, e (ii) avaliar, a partir da localização espectral da densidade de portadores, o comprimento médio do segmento conjugado de PPV. 


\subsection{Sistema óptico de um espectrofotômetro}

Figura 3.9.1 Sistema óptico do espectrofotômetro Hitachi 2001 para medida de absorbância.

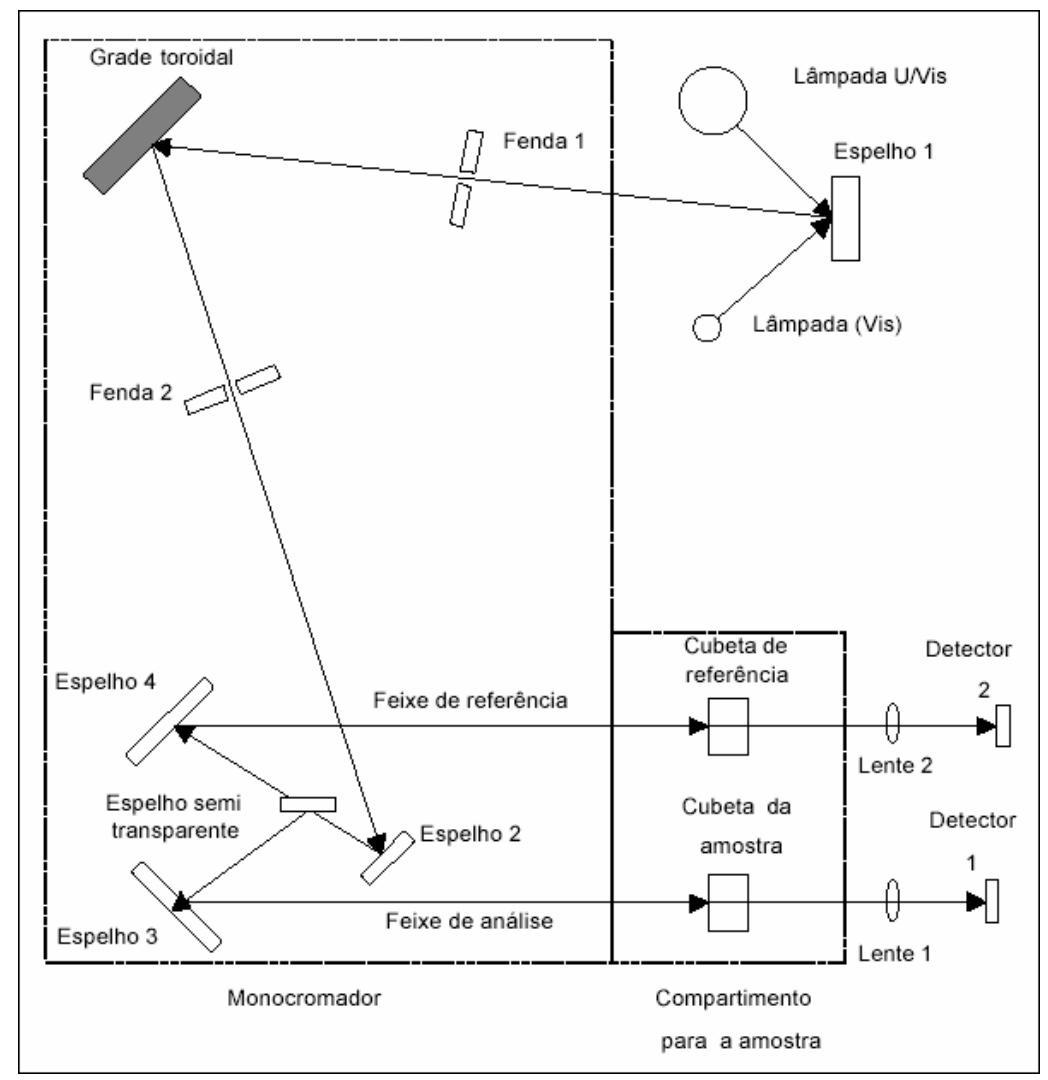

A luz emitida pelas lâmpadas é direcionada para o monocromador (grade toroidal) difratando a luz e dispersando-a em componentes espectrais. Cada componente é direcionada para um espelho semitransparente que divide o feixe em dois, um feixe de referência, outro para amostra. A seguir são direcionados para as correspondentes cubetas (porta-amostras) e depois focalizadas sobre os detectores (fotodiodos de silício) 1 e 2, pelas lentes 1 e 2, respectivamente, onde são convertidos em sinais elétricos. 
A luz ao passar através da amostra sofre uma redução na sua intensidade. Esta redução, $d l$, é proporcional à intensidade incidente $/$ e à espessura $d x$ do material .

$$
d l=-\alpha \cdot I d x
$$

onde a é o coeficiente de proporcionalidade. Para obter a intensidade que emerge da amostra de espessura l, somamos sobre todas as intensidades do lado esquerdo da equação e sobre toda a espessura do lado direito da equação. Integrando a eq. (31), vemos que a intensidade decai exponencialmente com a espessura:

$$
I_{f}=I_{i} 10 e^{-\beta l} \text { ou então } \log \left(I_{f} / I_{i}\right)=-\beta \cdot l
$$

onde $\beta$ é chamado coeficiente de absorção molar que depende da molécula e da freqüência da luz, a constante $T=I_{i} / I_{f}$ é chamada de transmitância e $A=\beta . l$ a absorbância da amostra, mas em geral escrita como:

$$
A=\log (1 / T)
$$

sendo que sua unidade é dada em 1/(concentração x comprimento), e temos a dependência de $\beta$ com a freqüência $v$ de radiação[21]. Assim podemos fazer $\mathbf{A}=\mathbf{A}(\lambda)$. 


\subsection{Fotoluminescência Independente do Tempo (PL)}

As medidas de fotoluminescência, em polímeros conjugados, baseiamse na recombinação dos portadores de carga, elétron e buraco, gerados por uma fonte, no caso fotoexcitação, cuja energia da radiação incidente é maior que o 'gap' energético. Logo, por meio dos espectros de PL e de absorbância, sondamos, praticamente todo o caminho percorrido pela energia de excitação, desde a formação dos portadores de carga à sua recombinação, emitindo luz, ou supressão, da energia, por centros não radiativos (defeitos na rede, impurezas e processos de multifônons).

Os dados obtidos são curvas da intensidade da luminescência em função do comprimento de onda. O aparato usado para estas medidas é formado por uma fonte de excitação, monocromador, detector de luz (TFM tubo fotomultiplicador) e 'lock-in', os detalhes experimentais estão discutidos abaixo.

\subsection{Aparato experimental para obtenção das medidas de fotoluminescência}

A descrição funcional para obtenção do espectro de fotoluminescência é mostrada na Figura 3.11 .1 descrita a seguir. A medida de fotoluminescência independente do tempo utiliza fonte de luz contínua (CW) 
para a fotoexcitação do material. Seleciona-se o comprimento de onda da excitação, comumente, sobre a banda em que a absorção apresenta maior intensidade. Para excitar o PPV, utilizamos a luz de um laser de Ar+ em 442 nm (KIMMON). A intensidade do laser foi ajustada para a potência em torno de $100 \mathrm{~mW}$.

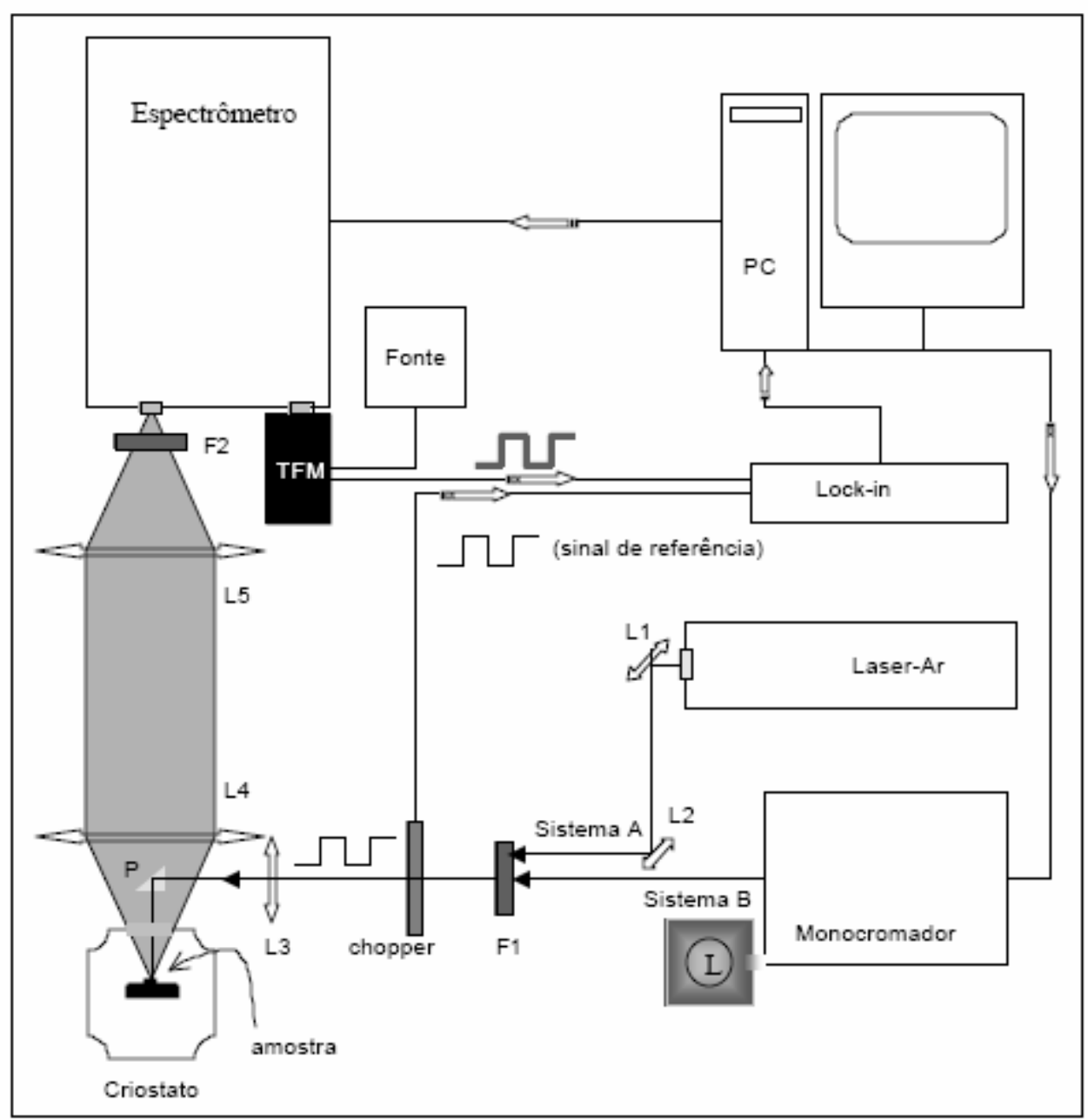

Figura 3.11.1 - Diagrama esquemático do arranjo experimental para medida do espectro de luminescência (Sistema A) e excitação seletiva (Sistema B) pela técnica de detecção pelo "Lock-in".

A luz emitida pela amostra é direcionada por meio de um sistema de lentes ( $L 1$ e $L 2$ ) para a abertura do espectrômetro de meio metro (SPEX 0,5M) com um filtro (F2) de luz (Oriel 570) para cortar luz espalhada da 
excitação. No espectrômetro a luz é resolvida em suas componentes por meio de uma grade de difração e, na saída, detectada usando uma fotomultiplicadora Hamamatsu (TFM) de elétron apropriada e alimentada por uma fonte de tensão. Na região do visível a faixa de comprimento de onda de detecção da fotomultiplicadora de Arseneto de Gálio é particularmente útil. Ele opera com uma boa eficiência quântica na faixa de $280-900 \mathrm{~nm}$ e apresenta uma perda de corrente no escuro suficientemente baixa. A intensidade da luminescência é detectada como uma fotocorrente que é amplificada por um "lock-in" e convertida para um sinal de voltagem. A maioria dos autores cita a emissão em 'unidade arbitrária', isto é devido à dificuldade de calibrar o sistema de detecção de modo apurado.

Nas medidas de luminescência a intensidade da excitação foi modulada por um "chopper" (Scientific Instruments - Mod SC3) em uma freqüência de $80 \mathrm{~Hz}$. O sistema de detecção "lock-in" é fixado para registrar somente o sinal na freqüência de referência. Isto elimina eficientemente todos os 'ruídos' exceto aqueles aproximadamente centrados na freqüência de modulação. A magnitude e a fase do sinal luminescente que chega ao “lock-in" é então comparado com o sinal de referência. A variação da temperatura da amostra é feita em um criostato de circuito de Hélio fechado na região de $4 \mathrm{~K}$ a $300 \mathrm{~K}$. 


\subsection{Sistema de medidas da anisotropia molecular}

Estudamos as propriedades ópticas dos filmes de PPV por espectroscopia de absorção e fotoluminescência $(P L)$ polarizadas através de um aparato experimental montado exclusivamente para o estudo do ordenamento molecular em filmes sobre Teflon sob estiramento e em filmes sobre vidro e quartzo, depositados pelo método SA.

A luz emitida pela amostra, após ser excitada, com comprimento de onda de $\lambda=441 \mathrm{~nm}$ do laser de He-Cd, com polarização linear prédeterminada pelo polarizador Babinet P1, é colimada e direcionada para o analisador (polarizador com eixo de transmissão rotatório variando de num intervalo de ângulo de $0^{\circ}$ a $360^{\circ}$ ) e em seguida para um detector (fototransistor de área grande ou foto-multiplicadora) acoplado a um Lock-in (Figura 3.12.1).

Figura 3.12.1 - Esquema do aparato experimental montado para determinar as propriedades da polarização da luminescência.

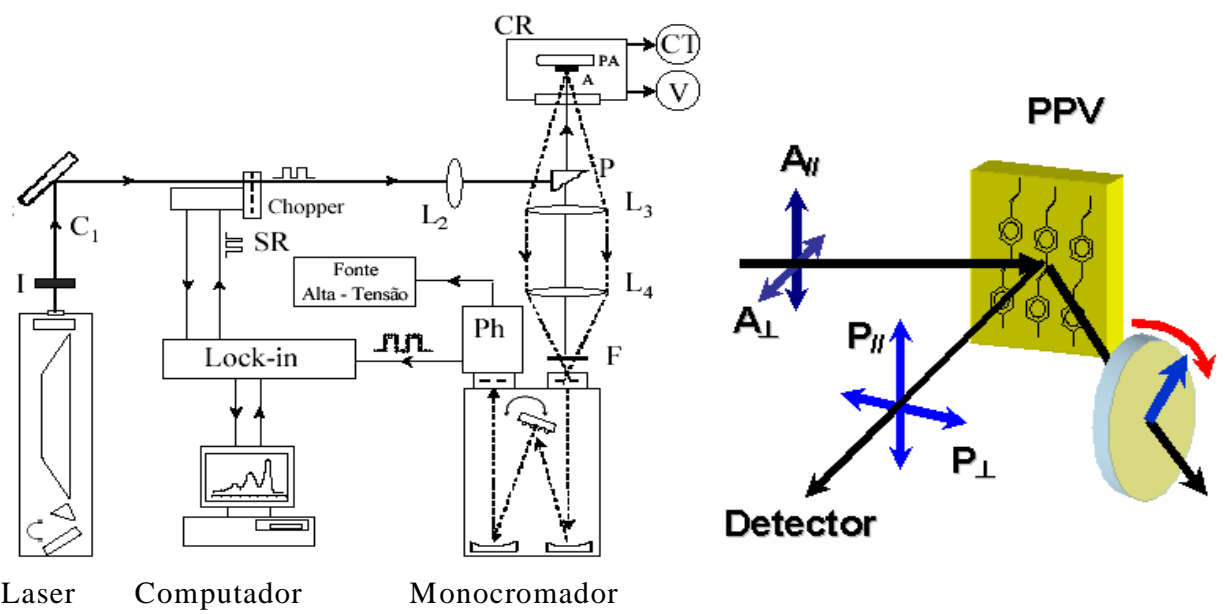


Através da medida da intensidade da luz em função do ângulo do analisador, determinamos a direção da polarização da luz emitida pelo filme para as diferentes direções de polarização da luz incidente e o grau de anisotropia óptica dos filmes.

\subsection{Método de adsorção de filmes automontados}

Filmes orgânicos ultrafinos $(<100 \mathrm{~nm})$ são usados como camada ativa em dispositivos emissores de luz por apresentarem maior eficiência quântica. Como nosso estudo está direcionado para os eventos que precedem a emissão de luz nos polímeros conjugados, escolhemos o método de fabricação de filmes finos "self-assembly" (SA) ou automontagem desenvolvido por Decher e outros [22].

Esta metodologia de construção permite trabalharmos:

- Com grande variedade de materiais estudados;

- Com elevado controle da espessura do filme, variando o número das monocamadas ultrafinas $(\sim 1 \mathrm{~nm})$, e

- Com diferentes substratos, específicos para cada experimento requerido.

A formação de filmes automontados consiste na deposição alternada, sobre um substrato, de dois materiais de carácter eletrostático opostos. 


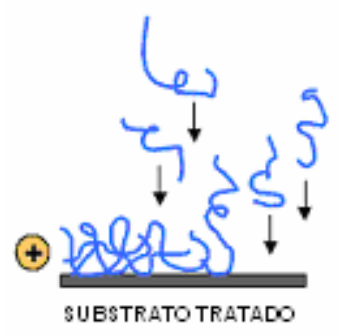

A) Superficie carregada e automontagem da primeira monocamada de polieletrólito

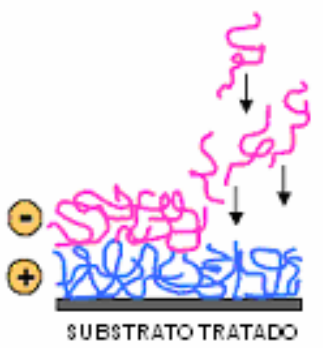

B) Superficie carregada, primeira monocamada e automontagem da segunda monocamada de polieletrólito

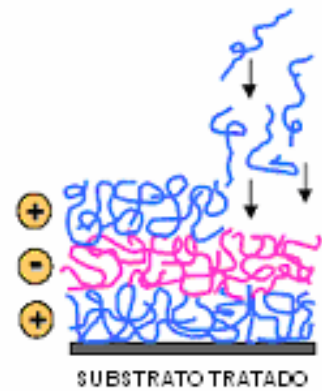

Superficies carregada, primeira bicamada e automontagem da terceira monocamada de polieletrólito

Figura 3.13.1 - Esquema que ilustra a adsorção das bicamadas catiônica/aniônica de polieletrólitos sobre o substrato tratado.

Os passos que seguimos estão indicados na Figura 3.13.1. Na etapa A, temos a imersão do substrato hidrofilzado, na solução que contém o policátion, PTHT. Por atração eletrostática, as moléculas de PTHT são adsorvidas à superfície do substrato. Ao atingir a saturação do número de moléculas que poderiam aderir à superfície, com a formação da primeira monocamada de filme, o substrato, cuja nova superfície apresenta caráter positivo, é imerso na solução aniônica, DBS, (etapa B) em que as moléculas de DBS, também por atração eletrostática, adsorvem à superficie. A seqüência de passos A e B encerra uma bicamada do filme cujo número regula sua espessura. O tempo de imersão, em cada solução, foi de 30 segundos.

No método LbL convencional, entremeando cada imersão, o filme é mergulhado em água ultra-pura, a fim de que sejam retirados os excessos de material, e submetido a um jato de $N_{2(g)}$ para secagem. $O$ jato de $N_{2(g)}$ gera uma não uniformidade no filme e provoca certa anisotropia. 
Em nosso trabalho utilizamos novo procedimento de secagem: prendemos o filme a um rotor caseiro que, ao girar, retira o excesso de material através da força centrífuga. Com esta técnica, conseguimos filmes mais homogêneos o que nos propiciou maior poder de sondagem dos processos ópticos, além de uma relevante otimização do tempo, pois a imersão em água ultra-pura e a secagem com o jato de $\mathrm{N}_{2}(\mathrm{~g})$, substituídas pela rotação do filme, como exemplificado na Figura 3.13.2, influenciam na distribuição molecular, provocando filmes não homogêneos.

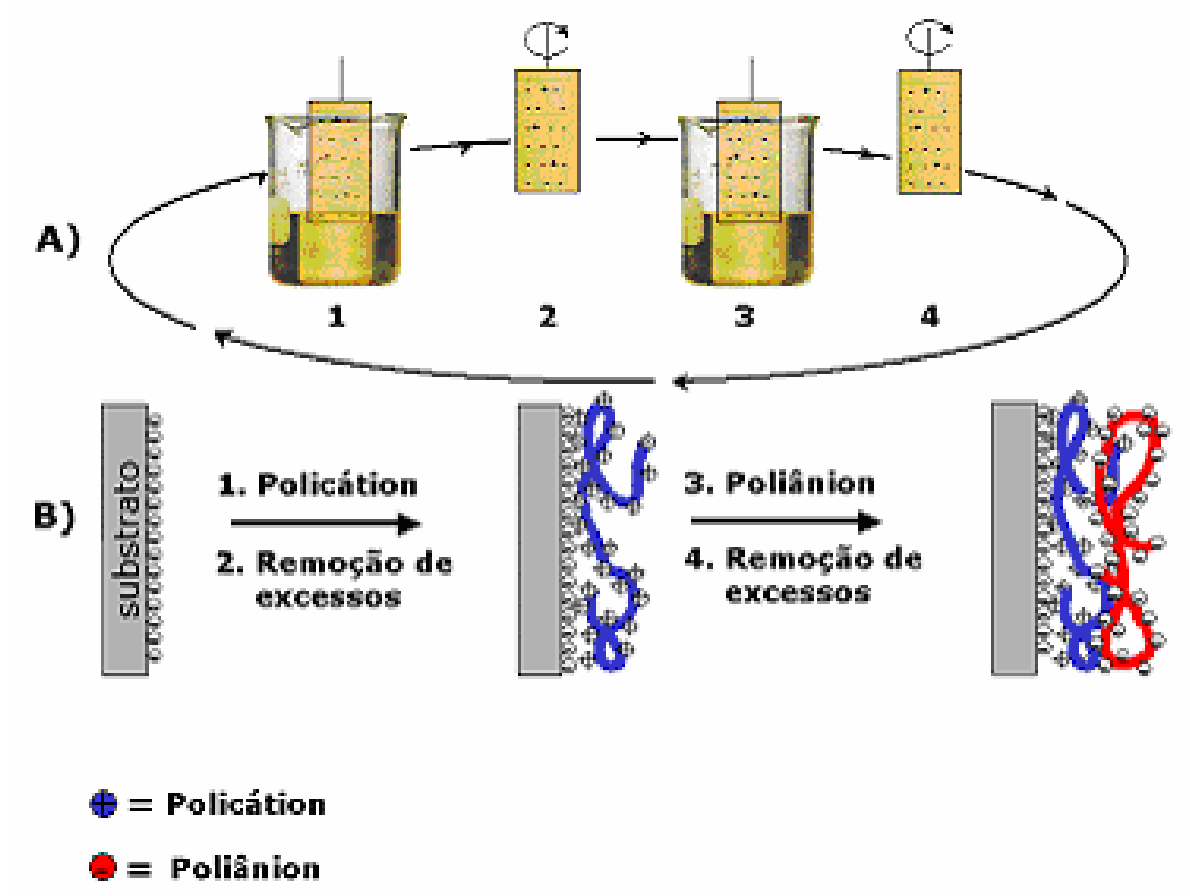

Figura 3.13.2- Esta figura simula a seqüência das imersões do filme (B), nas soluções aniônica e catiônica, entremeadas pela secagem e retirada do excesso de material (A) através da rotação do filme em formação. 


\subsection{Estrutura Molecular dos Filmes LbL estudados}

Fundamentamos nossa sistemática de estudo dos filmes LbL em três tipos de diluições que consistiam na separação dos segmentos conjugados:

- Separação intracadeia:

Composição das soluções:

Solução catiônica:(PTHT poli(cloreto de xilideno tetrahidrotiofeno) + PDAC poli(hidrocloreto de alilamina) + Solução aniônica (DBS ion de cadeia longa que é obtido do sal de sódio do dodecilbenzeno sulfônico)

Os filmes obtidos com esta sistemática de preparação apresentam, após a conversão térmica (vácuo em estufa, $110^{\circ} \mathrm{C}$ por 30 minutos), as cadeias do copolímero PTHT-PPV separadas pelas moléculas do polímero inerte PDAC.

- Separação intercadeia:

Composição das soluções:

Solução catiônica:(PTHT + DBS) + Solução aniônica(PSS)

Incorporamos diretamente, à solução de PTHT, o sal orgânico DBS cuja concentração, em solução, regula o tamanho do segmento de PPV do copolímero durante o processo de conversão térmica (vácuo em estufa, $110^{\circ}$ C por 30 minutos).

A estruturação desses filmes baseia-se na concentração de DBS incorporado, quanto mais DBS, em solução, maior o comprimento do segmento conjugado de PPV atingido pós-conversão.

- Separação inter e intracadeia: 
Composição das soluções:

Solução catiônica:(PTHT + PDAC + DBS ) + Solução aniônica(PSS)

Somamos ambas diluições, 1 e 2, e conseguimos uma estrutura molecular, para esses filmes, que combina a separação intracadeia e a intercadeia.

Para a fabricação da primeira série de filmes consideramos a diluição em termos da fração volumétrica $\mathbf{x}$ de PDAC na solução catiônica, dado um volume $\mathbf{V}$ de solução, em que $\mathbf{V}=\mathbf{V}_{\text {volume da solução de PDAC }}+\mathbf{V}_{\text {volume da solução de }}$

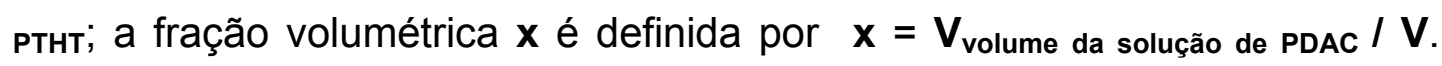
Para a segunda série de filmes, incorporamos, com uma micropipeta, à solução de PTHT, volumes de uma soluça de DBS. Já para a terceira série de filmes, fundimos os dois procedimentos da primeira e da segunda séries.

No processo de conversão térmica, todos os filmes de série eram convertidos simultaneamente.

\subsection{Preparação dos filmes sobre Teflon}

Com intuito de avaliarmos o peso do ordenamento molecular na Transferência de Energia, depositamos filmes de PPV sobre fitas de Teflon cuja elasticidade permite seu estiramento ao longo de um eixo preferencial. 
O substrato de Teflon (Dielectrix, 250 micrometros de espessura) suporta as exigências da conversão térmica, PTHT em PPV, em que o substrato é exposto a temperaturas de $100^{\circ} \mathrm{C}$ à $220^{\circ} \mathrm{C}$.

A natureza hidrofóbica da superfície do Teflon apresentou-nos considerável dificuldade de deposição de filme pelo método LbL, uma vez que as soluções usadas são aquosas. Entretanto, conseguimos filmes LbL, com razoável homogeneidade, através da diminuição das concentrações das soluções de PTHT e DBS.

Para a fabricação de filmes spin-coat, sobre Teflon, realizamos a desidratação da solução de PTHT, através do vácuo de estufa, até que seu volume ficasse bastante diminuído. Diluímos, então, esta solução, com álcool isopropílico o que reduziu a tensão superficial, e a depositamos, sobre as fitas de Teflon, obtendo filmes de PPV bastante homogêneos, Figura 3.15.1. O procedimento para a montagem do filme spin consistia em prendermos a fita de Teflon ao suporte do rotor (Photo-resist spinner, modelo 1-EC101DT-R484 da Hedway Research Inc.), depositarmos a solução de PTHT diluído em álcool isopropílico sobre a fita de Teflon, e aplicar rotação de 1.000 rpm, por 3 min, ao rotor . 


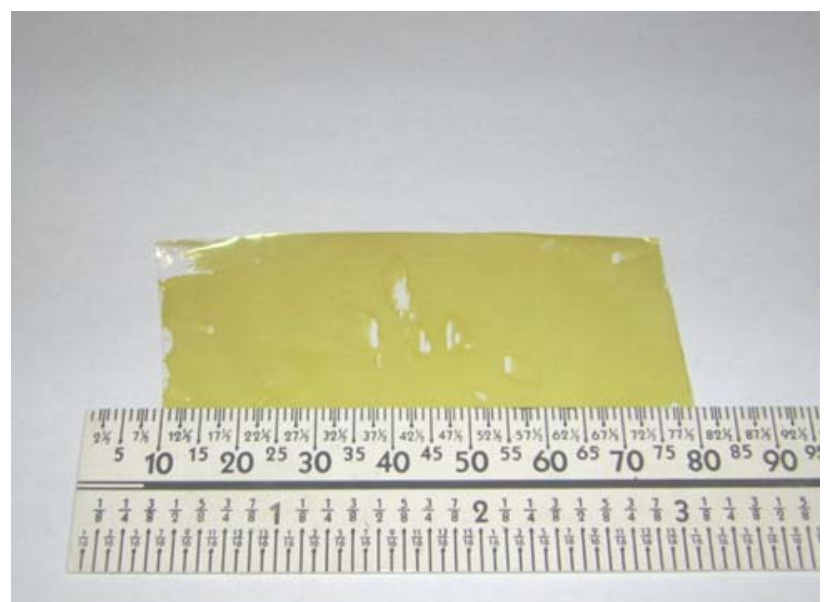

Figura 3.15.1 Filme de PPV sobre Teflon montado pela técnica de Spin-Coat. 


\section{Capítulo 4}

\section{Fotofísica de filmes poliméricos conjugados sem estiramento}


Filmes finos emissores de luz à base de polímeros e moléculas conjugadas são novos materiais que combinam as propriedades optoeletrônicas e mecânicas dos semicondutores juntamente às vantagens do processamento dos plásticos. Na prática, materiais orgânicos conjugados têm sido estudados por terem grande potencial para aplicação em dispositivos emissores de luz. A emissão radiativa nessa classe de materiais é apenas o processo final de uma cadeia de eventos interligados. $\mathrm{O}$ entendimento da natureza destes processos intermediários à excitação e à luminescência, bem como do alcance dos fatores que os controlam constituem ferramentas de alta importância para o aumento da eficiência luminosa dos chamados OLED's.

Ainda não é possível entender, a fundo, as complexidades de cada interação e processos inter- ou intramoleculares que operam em arranjos supramoleculares, em estruturas de multicamadas e em moléculas estruturalmente complexas. Por exemplo, existe, atualmente, um grande esforço para entender e controlar processos intermediários, em semicondutores orgânicos, relacionados com a dinâmica de relaxação 
energética na matriz sólida (transferência de energia e/ou carga inter- ou intramolecular durante a difusão espectral, intermitência, luminescência, etc) e, conseqüentemente, aumentar a eficiência dos processos radiativos nestes materiais.

Dentro deste contexto, o objetivo do presente trabalho é estudar mais detalhadamente (i) a influência do ordenamento molecular no estado de polarização da luz emitida pelos filmes poliméricos emissores de luz, obtidos através de ordenamentos moleculares específicos impostos por diferentes graus de estiramento, (ii) os tipos de mecanismos de transporte de energia que ocorrem entre as moléculas nestes filmes anisotrópicos, (iii) o efeito da separação das cadeias conjugadas utilizando-se moleculas opticamente, inertes, na região de interesse e (iv) o efeito da separação dos segmentos conjugados ao longo da cadeia através de segmentos não conjugados. Para tal, são estudadas as propriedades ópticas de absorção e emissão (luminescência) polarizadas de filmes de poli ( $p$-fenileno vinileno) (PPV) estirados, assim como as evidências da influência da diluição inter e intracadeia no processo de transferência de energia e no estado final de polarização da luz emitida. 


\subsection{Propriedades ópticas do PPV sobre filme de Teflon}

A Figura 4.1.1 compara espectros de absorbância e luminescência do PPV, convertido a $110^{\circ} \mathrm{C}$, com os espectros de absorbância dos substratos de Teflon e quartzo, utilizados neste estudo. Podemos observar que o teflon é praticamente transparente à emissão do PPV, o que é importante quando visamos algum tipo de aplicação tecnológica. Além disso, esta figura mostra que é possível utilizar a janela óptica na absorbância do teflon para realizar medidas de absorção do PPV, sem que o Teflon influencie espectro do PPV de forma acentuada.

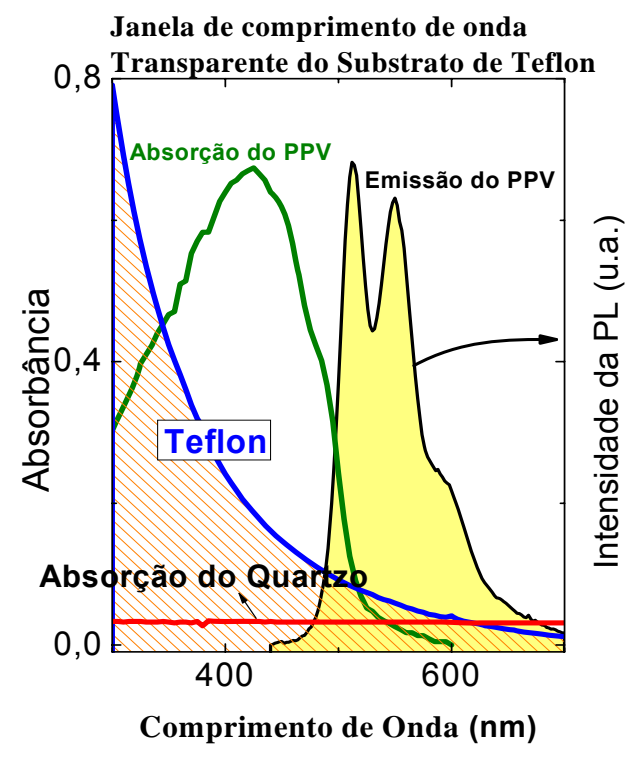

Figura 4.1.1 Mostra que a absorção do Teflon e do Quartzo não interferem nas medidas de Absorbância e Emissão do PPV 


\subsection{Processos fotofísicos em filmes não estirados}

Apresentamos, a seguir, medidas de absorbância e luminescência obtidas a partir de filmes de PPV sem estiramento mecânico $\left(L^{\prime} \mathbf{L}_{0}=1\right)$. Destacamos a influência do ordenamento molecular no estado de polarização da luz emitida para filmes de PPV preparados por automontagem por 'spincast' e (LbL) sobre uma fita (substrato) de Teflon.

\subsubsection{Filmes spincast}

De acordo, com a Figura 3.12.1, a convenção utilizada para as direções das polarizações da luz de excitação e emissão para as amostras spincast é:

- $\mathbf{A}_{/ /}$e $\mathbf{A}_{\perp}$, direção da polarização da luz de excitação perpendiculares que, nos filmes com estrutura molecular isotrópica é arbitrária;

- $\mathbf{P}_{/ /}$e $\mathbf{P}_{\perp}$, direção do eixo de polarização do analisador paralela e perpendicular à polarização da excitação. 

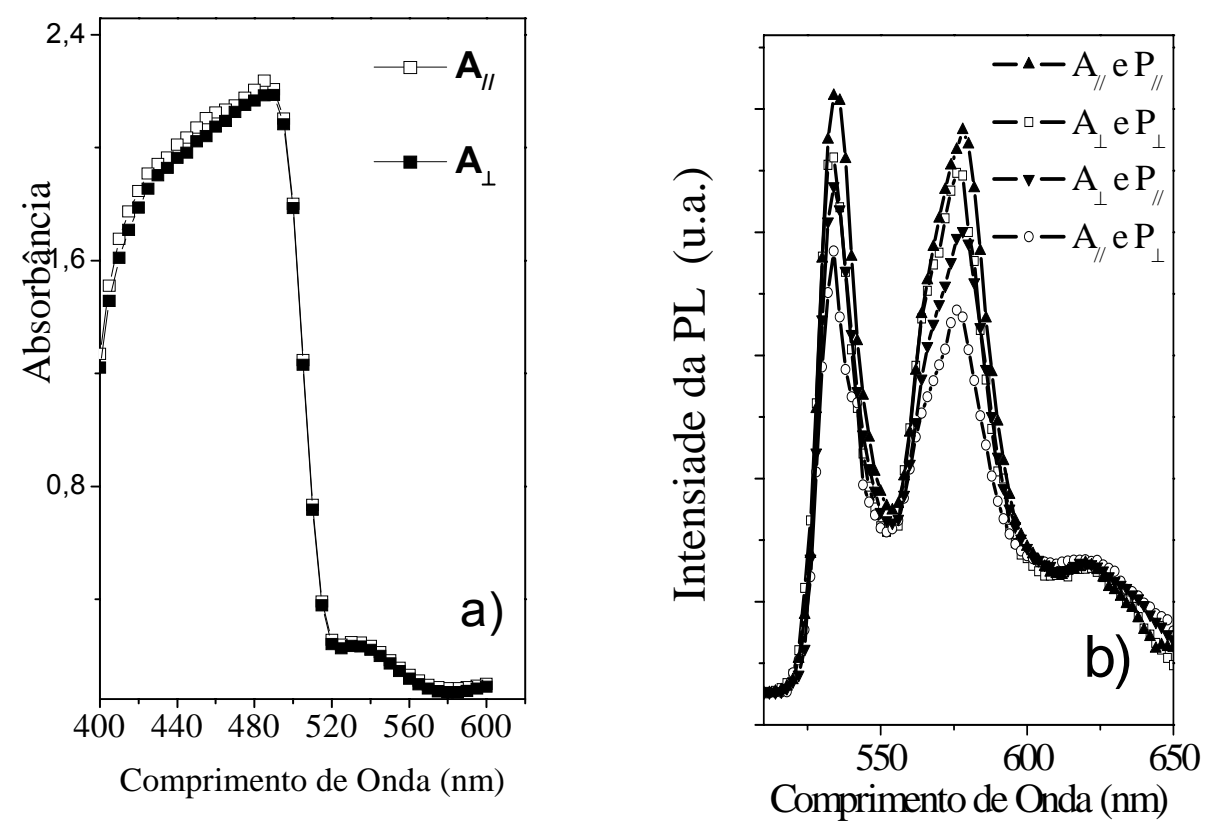

Figura 4.2.1 Medidas de polarização da absorbância (a) e fotoluminescência (b) à temperatura ambiente para o filme spincast-PPV sobre teflon.

A Figura 4.2.1a) apresenta os espectros de absorbância para duas direções perpendiculares arbitrárias $\mathbf{A}_{\perp}$ e $\mathbf{A}_{/ /}$da luz incidente para um filme spincast-PPV sobre teflon. Podemos ver que os espectros de absorbância nas duas polarizações perpendiculares são praticamente coincidentes, uma conseqüência da distribuição isotrópica de segmentos conjugados no plano do filme e uma característica típica de amostras spincast. Assim, a razão de polarização entre os máximos e mínimos de absorção, $\mathbf{A}_{/ /} / \mathbf{A}_{\perp}=1,0$, coincide com 0 valor esperado obtido para $L / L_{0}=1$ nos calculados apresentados na seção 2.9 (ver Figura 2.10.1). Desta maneira, inferimos que estes filmes não apresentam anisotropia na absorção e, conseqüentemente, o valor do parâmetro de ordem molecular no plano do filme dado por fator de anisotropia $r=\left(\mathbf{A}_{/ /}-\mathbf{A}_{\perp}\right) /\left(\mathbf{A}_{/ /}+\mathbf{A}_{\perp}\right)$ é aproximadamente nulo. 
Medidas de luminescência polarizada (Figura 4.2.1b) da mesma amostra não apresentam a mesma isotropia. Podemos ver que a intensidade dos espectros de luminescência pouco depende da polarização da luz incidente, bem como das direções paralela e perpendicular do analisador em relação à polarização da excitação. Além disso, que a intensidade da luminescência é máxima na direção de polarização da luz de excitação, ou seja, $\left(\mathbf{A}_{/ /}, \mathbf{P}_{\|}\right)$e $\left(\mathbf{A}_{\perp}, \mathbf{P}_{\perp}\right)$.

O estado de polarização da luz emitida dos filmes spincast-PPV pode ser melhor visualizado através da medida da intensidade integrada da luminescência em função do ângulo do analisador. O ângulo inicial do analisador (ângulo zero) foi tomado para a direção de polarização do analisador paralela à direção $A_{/ /}$, que é considerada arbitrária para o caso de amostras isotrópicas. A intensidade integrada foi medida por um fotodetector de grande área de Si. A Figura 4.2.2 apresenta a variação da intensidade da emissão normalizada de uma amostra spincast-PPV para duas direções de polarização ortogonais da luz de excitação. 


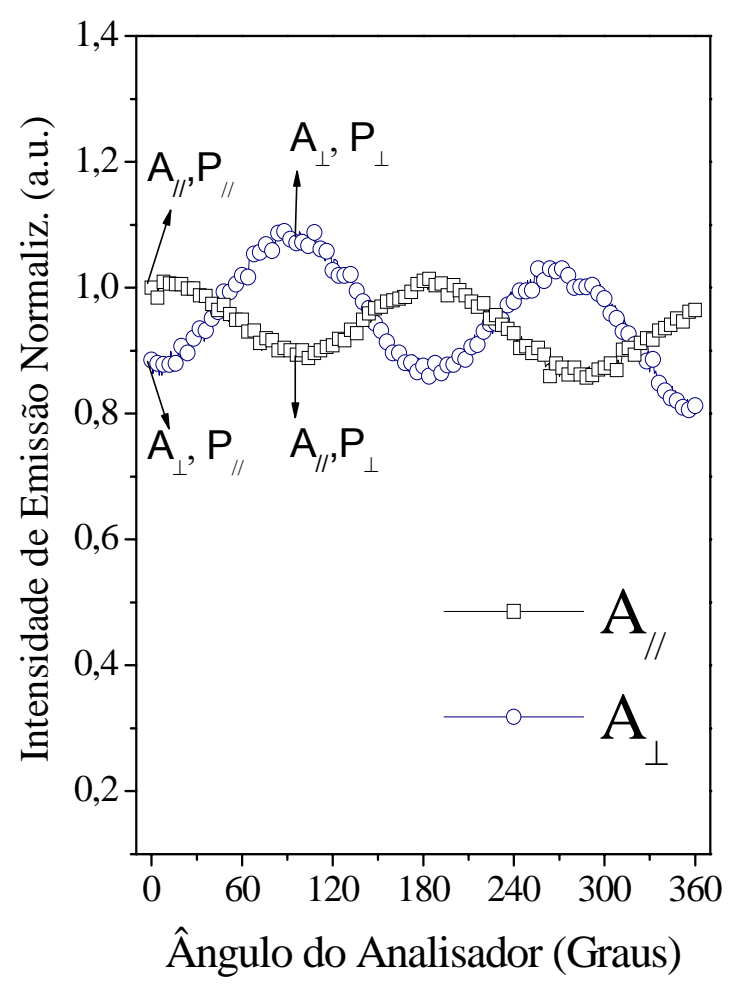

Figura 4.2.2 Dependência da intensidade da luminescência normalizada de um filme de PPV 'spin' para as polarizações paralela e perpendicular da excitação.

É interessante notarmos que, apesar da distribuição de segmentos conjugados ser isotrópica, a luz emitida apresenta um certo grau de polarização, intensidade é máxima na direção de polarização da excitação. A razão de polarização $\mathbf{P}_{/ /} / \mathbf{P}_{\perp}$ extraída dessas medidas é aproximadamente igual a 1,2 para os dois casos de polarização $\mathbf{A}_{/ /}$e $\mathbf{A}_{\perp}$ da luz incidente. Estes resultados não podem ser explicados apenas com base na absorção de uma luz de excitação linearmente polarizada por uma distribuição isotrópica de segmentos conjugados.

Compostos orgânicos fluorescentes possuem, em geral, um certo grau de anisotropia óptica na absorção e na emissão da luminescência. Um polímero emissor de luz pode ser visto como um sistema composto de 
segmentos conjugados, opticamente ativos, com diferentes tamanhos de conjugação ao longo de sua cadeia [23, 24]]. Devido ao enovelamento, típico destes materiais, e a sua distribuição aleatória, em toda a extensão do filme, os segmentos conjugados apresentam-se dispersos no meio através de uma estrutura desordenada de modo a resultar em uma distribuição molecular isotrópica.

Se não considerarmos processos de TE e/ou carga em um meio isotrópico $(\Omega(\alpha)=1$ ), a intensidade da componente polarizada da luminescência medida pelo analisador, na direção $\theta$ emitida pelo sistema polimérico, é obtida a partir da equação 2.7.2, ou seja, $I_{\theta}=(1 / 15) K \Phi\left(\operatorname{sen}^{2} \theta+3 \cos ^{2} \theta\right)$. Desta relação, inferimos que a intensidade da componente paralela à excitação, $P / /=I \theta(\theta=0)=1 / 5$, é três vezes maior que a da componente perpendicular, $P \perp=1 \theta(\theta=\pi / 2)=1 / 15$. , o fator de anisotropia da emissão dado pela expressão $r=(P / /-P \perp) /(P / /+P \perp)$ é sempre $1 / 4$ e o grau de polarização $p=P / / / P \perp=3$, não importando a direção do vetor campo elétrico da luz polarizada incidente. Este mesmo valor para $r$ foi obtido utilizando a função distribuição de segmentos conjugados da equação (2.7.5) e calculado na Figura Figura 2.9.4, para $\lambda=L / L o=1$.

Este resultado não corresponde aos dados extraídos dos filmes PPVspincast. Conforme a discussão acima, os valores do grau de polarização $p$ e do parâmetro de anisotropia r são, respectivamente 1.2 e 0,1 . Isto significa que processos de despolarização da luminescência estão atuando de modo eficiente em amostras desordenadas do tipo spincast. Processos de TE e/ou carga podem estar atuando na despolarização da luminescência nestes 
materiais. Uma vez que o processo de TE entre segmentos conjugados de mesma espécie depende da orientação relativa entre os momentos de dipolos do segmento doador e do aceitador, a excitação pode migrar de forma a ser redistribuída para todas as direções possíveis do sistema polimérico. O resultado deste processo é a despolarização da luminescência que pode ser total ou parcial, dependendo da eficiência do processo de transferência.

\subsubsection{Filmes LbL}

Apresentamos, a seguir, medidas de absorbância e luminescência polarizados obtidas a partir de filmes de PPV sem estiramento mecânico $\left(L / L_{o}=1\right)$ preparados por automontagem $(L b L)$. Devido ao processo de preparação através do empilhamento de camadas de polieletrólitos de carga oposta em meio aquoso, estes filmes apresentam uma estrutura molecular mais ordenada. Como as monocamadas de PPV estão separadas por um polieletrólito inerte, o que muda a dinâmica de transferência de energia nestes filmes. Além disso, o escoamento das soluções de imersão, ao se retirar o filme para a secagem e para depositar a próxima camada, pode produzir um certo ordenamento das cadeias na superfície do filme na direção do fluxo de água. Esta direção preferencial de ordenamento molecular, nos filmes LbL, será utilizada para determinarmos a direção de polarização destas amostras. Assim, a convenção utilizada para as direções das polarizações da luz de excitação e emissão (Figura 3.12.1) para as amostras LbL é: 
$A_{/ /}$e $A_{\perp}$, direção da polarização da luz de excitação paralela e perpendicular à direção de escoamento da solução.

$\mathrm{P}_{/ /}$e $\mathrm{P}_{\perp}$, direção da polarização da emissão paralela e perpendicular à direção de escoamento da solução.

A Figura Figura 4.2.3a) apresenta os espectros de absorbância para duas direções $A_{\perp}$ e $A_{/ /}$da luz incidente para um filme LbL-PPV depositado sobre Teflon. Diferentemente dos espectros spincast, os espectros de absorbância, nas duas polarizações paralela e perpendicular ao escoamento, são ligeiramente distintos, o que é uma conseqüência da pequena anisotropia produzida pela técnica LbL. Assim, a razão de polarização, no comprimento de onda de excitação do laser He-Cd (440 nm), $A_{/ /} / A_{\perp}=1,1$ (Figura 4.2.3a)), corresponde a uma maior orientação bem como concentração dos segmentos conjugados de PPV ao longo do da direção de escoamento do que na direção perpendicular. 

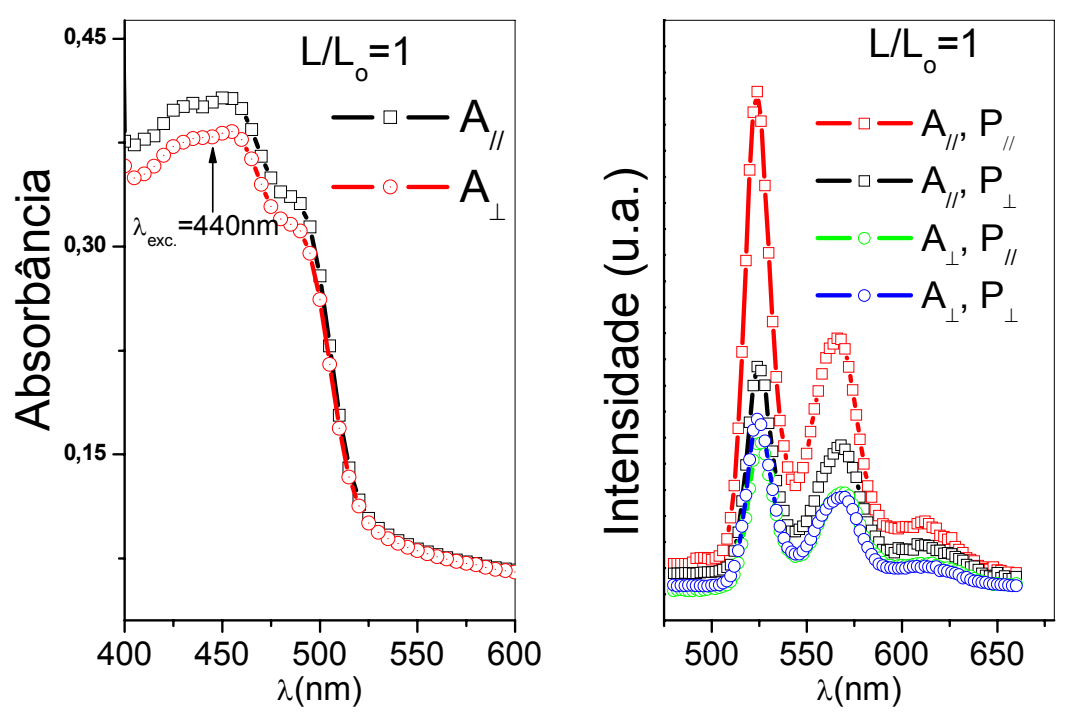

Figura 4.2.3 Medidas de polarização: (a) absorbância e (b) fotoluminescência à temperatura ambiente para o filme LbL-PPV sobre teflon.

Medidas de luminescência polarizada da mesma amostra, excitada em 440 nm (laser He-Cd), são mostradas na Figura 4.2.3b). Percebemos que, diferentemente das amostras spincast, a intensidade dos espectros de luminescência possui uma forte dependência com polarização da luz incidente, bem como das direções paralela e perpendicular do analisador em relação à polarização da excitação. Ademais, que a intensidade da luminescência é máxima na direção de polarização da luz de excitação, ou seja, $\left(A_{/ /}, P_{/ I}\right)$ e $\left(A_{\perp}, P_{\perp}\right)$. Este resultado pode ser melhor visualizado, através da medida da intensidade integrada da luminescência, em função do ângulo do analisador (Figura 4.2.4). Para as amostras LbL, referenciamos como ângulo inicial do analisador (ângulo zero para a direção de polarização) a direção A// paralela à direção de escoamento da água. Pode-se ver que a luminescência deste filme é expressivamente polarizada $\left(P_{/ /} / P_{\perp}=2,1\right)$ para a 
polarização da excitação paralela a esta direção $\left(A_{/ /}\right)$. Já no caso da excitação perpendicular $\left(A_{\perp}\right)$, a polarização da emissão é praticamente isotrópica. A curva contínua, na figura, calculamos a partir da expressão $I_{\theta}=(1 / 15) K \Phi\left(\operatorname{sen}^{2} \theta+3 \cos ^{2} \theta\right)$. A análise do comportamento da polarização dos filmes LbL será tratada mais adiante neste trabalho.

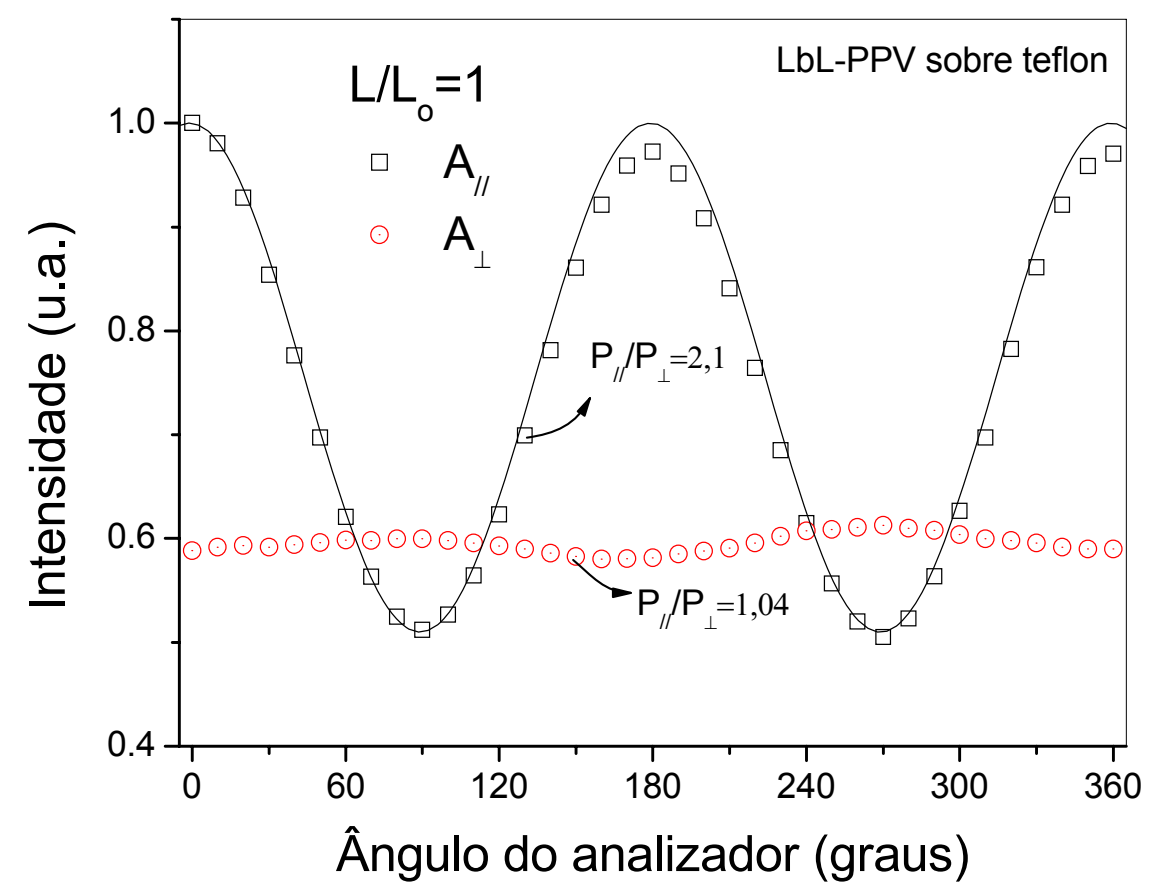

Figura 4.2.4 Dependência da intensidade da luminescência normalizada de um filme de LbL-PPV para as polarizações paralela e perpendicular da excitação. A curva contínua corresponde à calculada de acordo com capítulo 2 .

É importante ressaltarmos, o estado de polarização das amostras LbL é extremamente dependente das condições de preparação dos filmes. As polarizações $P_{/ /} / P_{\perp}$ podem variar de 2 a 5 sobre uma mesma amostra, o que dificultou, em muito, a análise dos resultados obtidos para essas amostras. Porém, isto demonstra que o estado de polarização em filmes LbL-PPV 
sobre Teflon é bastante dependente de pequenas alterações da estrutura molecular, 


\subsection{Propriedades ópticas de filmes com pequeno grau de estiramento: orientação axial das cadeias}

É particularmente interessante estudar as propriedades ópticas de filmes poliméricos sob a influência de um estiramento mecânico. Filmes poliméricos com alto grau de estiramento $\left(\mathbf{L} / \mathbf{L}_{\mathbf{0}}>10\right)$ são utilizados tradicionalmente para produzir um material contendo alta anisotropia molecular e melhora na eficiência de emissão. Recentemente, PPV altamente orientado era preparado através do estiramento de filmes espessos, livres do substrato, durante o processo de conversão térmica do material precursor em PPV. Medidas ópticas, em filmes com baixo grau de estiramento (L/Lo<2), são raramente encontrados na literatura especializada. Recentemente, filmes de PPV com baixo grau de estiramento foram alongados a frio antes do processo de conversão térmica. No presente trabalho, utilizamos novo procedimento que permite estirar, a frio, filmes ultrafinos de PPV. Este método consiste em depositar o material precursor sobre uma fita de Teflon e, após a conversão térmica, o PPV sobre Teflon é continuamente estirado na região de baixo grau de deformação $(1 \leq \lambda \leq 2)$. 0 uso da fita de teflon, como substrato, permite a aplicação de uma deformação axial, em filmes extremamente finos, com contração lateral quase isotrópica, o que elimina problemas de ruptura. Este procedimento 
Propriedades ópticas de filmes com pequeno grau de estiramento: orientação axial

possibilita ainda a realização de medidas ópticas de luminescência e absorção durante o processo de estiramento.

Os resultados da seção anterior demonstram que a estrutura e o arranjo molecular têm grande influência, nas propriedades de emissão em filmes de polímeros conjugados. Isto pode ser visto principalmente pela grande diferença, na polarização da luz emitida, para os filmes 'spincast' e LbL. Filmes LBL de PPV não estirados, possuem naturalmente uma pequena anisotropia molecular, deste modo apresentam alta polarização $\left(P_{/ /} / P_{\perp}=2.1\right)$, quando comparados aos filmes isotrópicos do tipo 'spincast' $\left(P_{/ /} / P_{\perp}=1.2\right)$.

Logo, interessamo-nos pelo estudo do efeito que a estrutura e arranjo molecular causam nas propriedades de polarização dos filmes spincast e LbL. Como um pequeno ordenamento molecular pode produzir grandes efeitos, no estado de polarização da luz emitida, estudamos suas origens, dos efeitos, através da aplicação controlada de pequenos estiramentos nesses filmes. Para isso, foi desenvolvida uma metodologia específica, ao longo deste trabalho (ver seção 3.12), que possibilitou a aplicação contínua de uma deformação axial, em filmes poliméricos depositados sobre Teflon. Focamos o efeito de pequenos estiramentos (menores que $100 \%$ ou $\left.1 \leq \mathrm{L} / \mathrm{L}_{0}<2\right)$ ), nas propriedades ópticas, pois, na literatura somente grandes estiramentos (maiores que $500 \%$ ) foram tratados com detalhe.

Nesta seção, investigamos a influência do ordenamento molecular nas propriedades ópticas de filmes de PPV sobre Teflon. Impusemos o ordenamento através de pequenos estiramentos, feitos por meio do estirador (Figura 3.15.1). Após serem convertidas termicamente, as amostras 
PPV/Teflon foram estiradas continuamente,.à temperatura ambiente, dentro de um criostato, em vácuo de 10-5 torr. Aqui, apresentaremos os resultados das propriedades ópticas de filmes de PPV preparados sobre fita de Teflon pelas técnicas 'LbL' e 'spincast'. Ao contrário do que é feito na literatura especializada $[16,23]$ mostraremos que se podem obter altos graus de polarização da luz emitida através de pequenos graus de estiramento aplicados aos filmes.

\subsubsection{Filmes spincast}

Realizamos medidas de absorbância em função do estiramento para filmes 'spincast' de PPV. As direções da polarização da luz de excitação utilizadas correspondem às direções paralela $(A / /)$ e perpendicular $\left(A_{\perp}\right)$ à direção de estiramento. A Figura 4.3.1 compara os espectros de absorbância para os valores de estiramento iguais a $L / L o=1$ e $L / L o=1.67$. Como era de se esperar, o filme é praticamente isotrópico antes do estiramento, pois os espectros de absorbância são praticamente coincidentes. Neste caso, o peso espectral está deslocado para a região de alta energia, indicando que os espectros possuem o domínio de transições ópticas oriundas em segmentos conjugados com tamanho de conjugação efetivo pequeno. Isto se deve à grande desordem molecular introduzida pelo enovelamento das cadeias que, conseqüentemente, produz a diminuição do tamanho de conjugação médio do material. Este quadro muda drasticamente com o estiramento. 


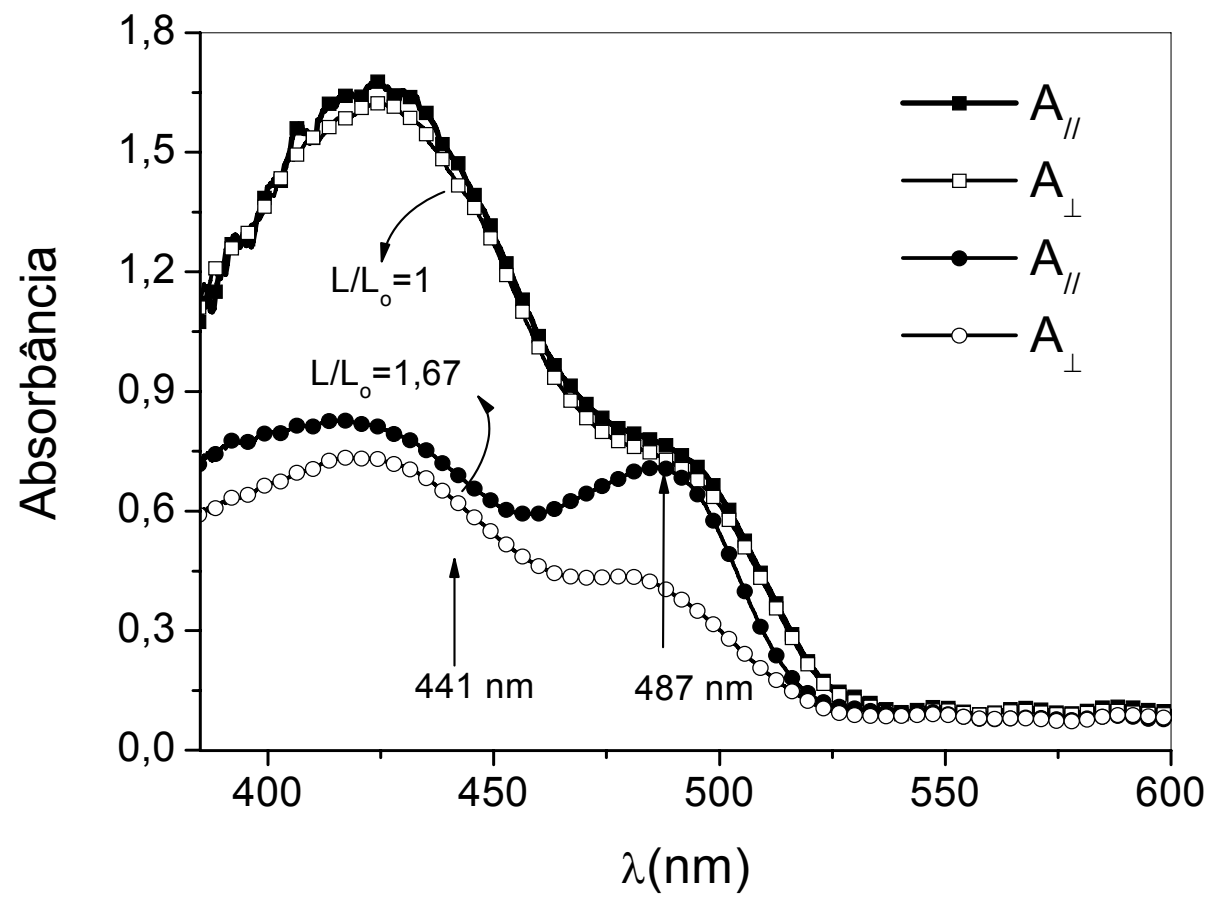

Figura 4.3.1 Medidas de absorbância (300 K) para filmes 'spincast' de PPV sobre teflon para valores de estiramento iguais $a \mathrm{~L} / \mathrm{Lo}=1 \mathrm{e} L / \mathrm{Lo}=1.67$ considerando os casos da incidência paralela $\left(A_{/ l}\right)$ e perpendicular $\left(A_{\perp}\right)$.

Primeiramente, a intensidade espectral da absorbância decresce com o aumento do estiramento, o que é explicado pela diminuição da espessura do filme de PPV com o aumento do estiramento. Ao mesmo tempo, existe uma forte redistribuição do peso espectral para o caso da absorbância medida com a luz incidente paralela ao estiramento $\left(A_{/ /}\right)$. Para o grau de estiramento $L / L_{0}=1.67$, o peso espectral se desloca para a região de baixa energia, colocando em evidência a uma banda na região de baixas energias (por volta de $487 \mathrm{~nm}$ ). Para o caso da polarização da excitação perpendicular ao estiramento $\left(A_{\perp}\right)$, o peso espectral continua deslocado para as altas energias, como para as amostras sem estiramento, o que significa que nesta direção existe ainda a predominância de segmentos conjugados 
pequenos. Esta redistribuição da densidade de estados, para $A_{/ /}$, deve se ao aumento da densidade média de segmentos de maior grau de conjugação, em torno da direção de estiramento, devido ao crescimento do ordenamento molecular nessa direção. Os segmentos conjugados possuem um grau de conjugação maior e, portanto, energias de transição menores, ao se alinharem em torno do eixo de estiramento.

Podemos ver ainda, na Figura 4.3.1, que a razão de polarização da absorbância, $A_{/ /} / A_{\perp}$, depende do comprimento de onda. Considere por exemplo dois comprimentos de onda específicos: um em $441 \mathrm{~nm}$ e outro em $487 \mathrm{~nm}$, que correspondem, respectivamente, ao comprimento de onda do laser de excitação de He-Cd e da borda de absorção (ver setas na Figura 4.3.1). Nestes dois casos, $A_{/ /} / A_{\perp}=1,2$ para $\lambda=441 \mathrm{~nm}$ e $A_{/ /} / A_{\perp}=2,0$ para $\lambda=487$ nm. Este resultado será importante para a discussão a seguir.

A razão de polarização da absorbância aumenta com o estiramento para o comprimento de onda de $487 \mathrm{~nm}$. Esta dependência pode ser vista na Figura 4.3.2 para a região de estiramentos $1<L / L_{\circ}<1.67$. Observamos que este aumento se deve à orientação dos segmentos conjugados com o estiramento, como é previsto pela simulação teórica (seção 2.10) 


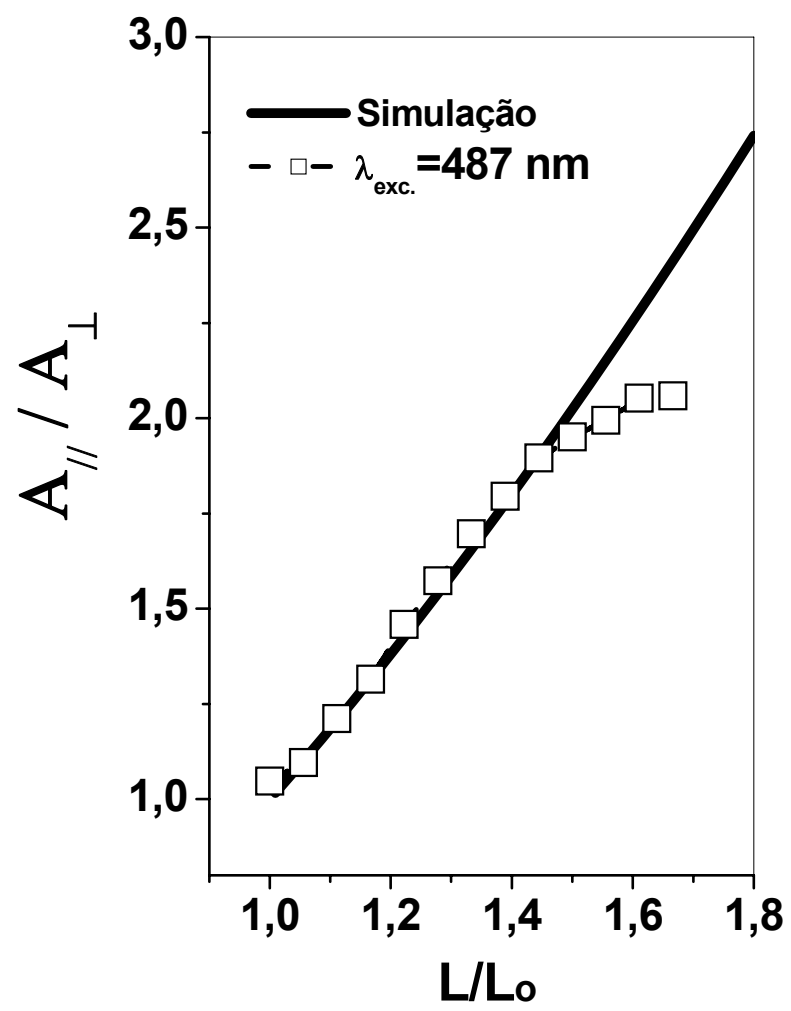

Figura 4.3.2 Grau de polarização da absorbância, $A_{/ /} / A_{\perp}$, medida para o comprimento de onda de $487 \mathrm{~nm}$ em função do grau de estiramento

Comparamos espectros de fotoluminescência polarizada do mesmo filme 'spincast' de PPV, sobre teflon, nas Figura 4.3.3 a) e b),para dois valores de estiramentos $L / L_{0}=1$ e $L / L_{0}=1.67$, respectivamente. Novamente, utilizamos, no experimento, as direções de polarização da luz do laser de excitação de $\mathrm{HeCd}(441 \mathrm{~nm})$ e da emissão paralela e perpendicular ao estiramento . Além disso, o máximo da luminescência ocorre na direção paralela à polarização da luz de excitação, ou seja, nas condições $\left(A_{/ /}, P_{/ /}\right)$e $\left(A_{\perp}, P_{\perp}\right)$. Observamos ainda que a polarização da luminescência aumenta, com o aumento do estiramento, de $L / L_{0}=1$ para $L / L_{0}=1.67$. Este resultado é surpreendente, pois, mesmo para pequenas anisotropias de absorção 
$\left(A_{/ /} / A_{\perp}=1,2\right.$ para $\left.\lambda=441 \mathrm{~nm}\right)$, a luminescência é extremamente polarizada para $L / L_{0}=1.67$, ou seja, $P_{/ /} / P_{\perp}=5$ para polarização da luz de excitação paralela ao estiramento $\left(A_{/ /}\right)$e $P_{/ /} P_{\perp}=3.6$ para a direção perpendicular $\left(A_{\perp}\right)$. Isto significa que uma pequena anisotropia molecular é suficiente para gerar uma grande anisotropia na polarização da emissão em polímeros conjugados com baixo grau de estiramento. Esta eficiente conversão de uma absorção isotrópica para emissão altamente polarizada em sistemas com baixo grau de estiramento pode, a princípio, ser controlada e utilizada em dispositivos optoeletrônicos com base em materiais orgânicos. Apesar da enorme versatilidade destes dispositivos, ainda restam muitas dificuldades no que diz respeito ao entendimento dos processos fotofísicos nestes materiais, que ainda é muito pobre, e que dificulta a otimização de suas propriedades emissivas.
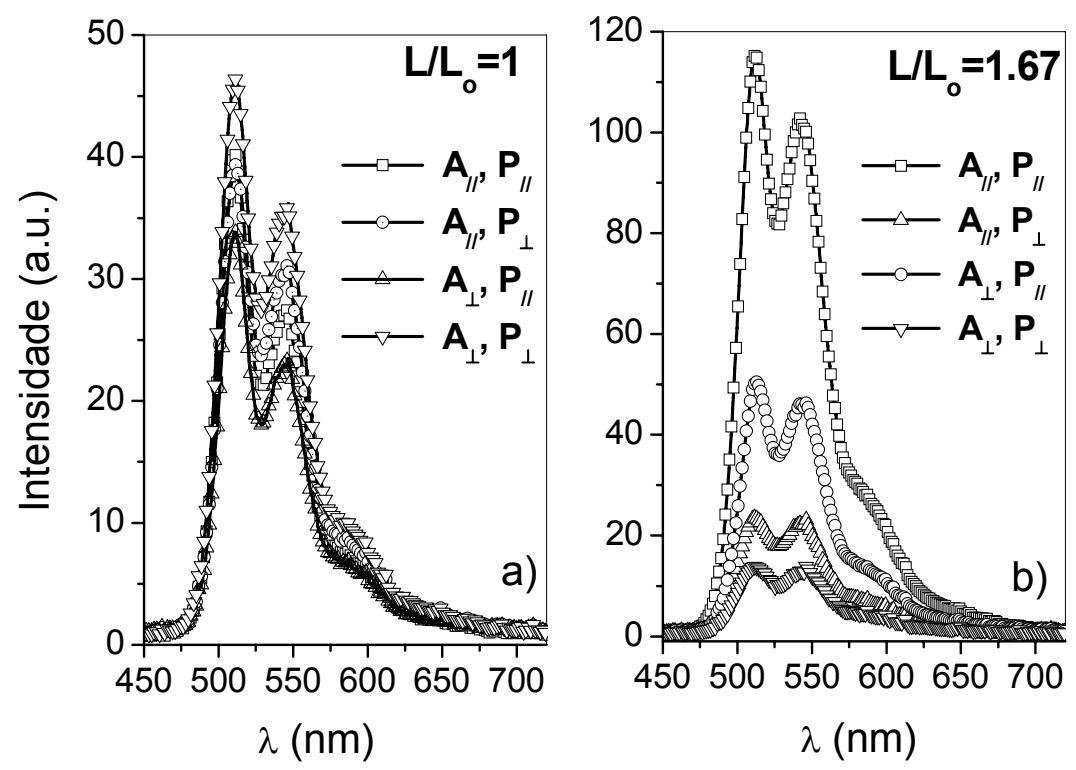

Figura 4.3.3 Espectros de fotoluminescência polarizada $(300 \mathrm{~K})$ para diferentes configurações da polarização da luz de excitação (lazer de excitação de $\mathrm{HeCd}$ em 441 
nm) e emissão paralela e perpendicular ao estiramento de filmes 'spincast' de PPV sobre teflon para valores de estiramento a) $L / L o=1$ e b) $L / L o=1.67$..

Verificamos, na Figura 4.3.3 a) e Figura 4.3.3b), que os espectros apresentaram pouca variação na posição e na largura das linhas espectrais, indicando que os valores de estiramentos utilizados pouco afetam o PPV no nível da subestrutura molecular. Porém, estes efeitos são suficientes para promover um ordenamento tal que grandes anisotropias na emissão são produzidas. Podemos, então, concluir que o estiramento somente produz um desenovelamento e não uma tensão nas cadeias poliméricas. Assim, as mudanças da conformação polimérica produzidas pelo pequeno estiramento agem como força impulsionadora para uma forte migração da excitação dentro destes materiais. Os experimentos mostrados a seguir foram realizados com o objetivo de explicar estes fenômenos de forma mais qualitativa 


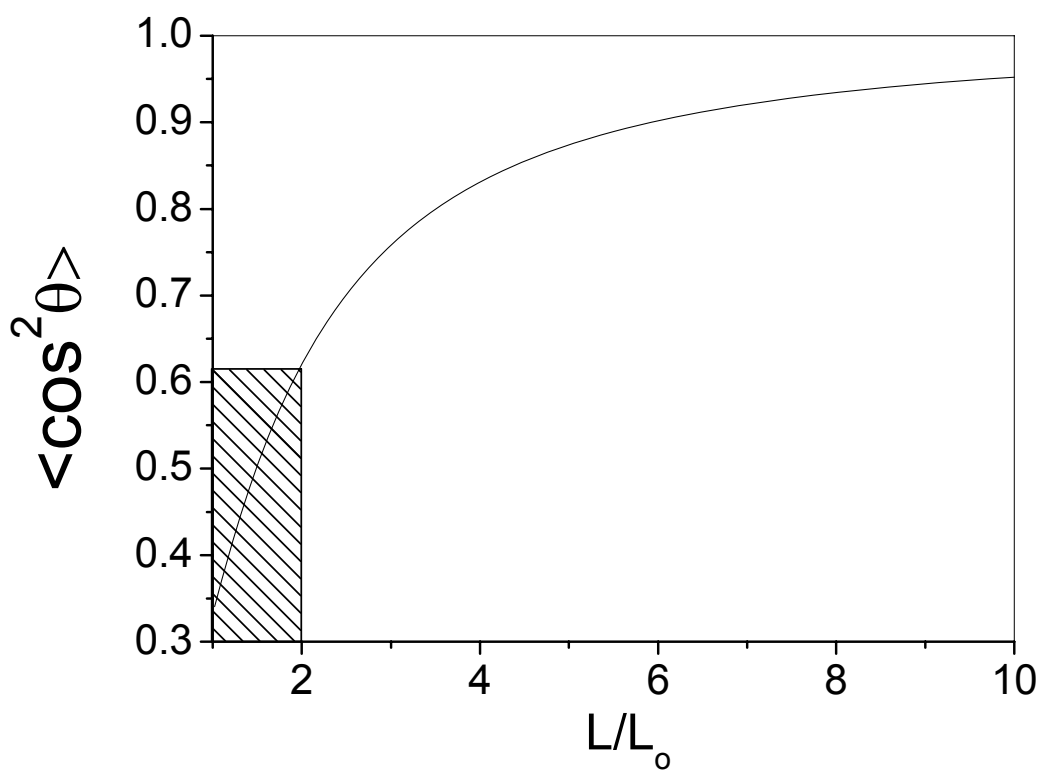

Figura 4.3.4 Orientação média (eq. 2.9.4) da rede estatística de segmentos conjugados em relação ao eixo de estiramento, em função do grau de estiramento $\lambda=L / L_{0}$.

Para $L / L_{0}=1.67$ e excitação perpendicular $\left(A_{\perp}\right)$, a intensidade máxima da luminescência não se apresenta mais polarizada na direção de polarização da excitação (Figura 4.3.3 b)), como mostramos anteriormente para a amostra 'spincast' de PPV sem estiramento, mas sim na direção do ordenamento molecular, ou seja, $\left(\mathrm{A}_{\perp}, \mathrm{P}_{\mathrm{I}} / \mathrm{)}\right.$. Isto indica que processos eficientes de transferência de energia ou de carga estão ocorrendo em amostras orientadas PPV-LbL. Mesmo com pequenos estiramentos (pequena anisotropia molecular), os portadores de carga fotoexcitados são transferidos eficientemente das moléculas desordenadas para as moléculas com direção média próxima ao eixo de estiramento. A Figura 4.3.4 mostra a dependência da orientação média (dada por $\left\langle\cos ^{2} \alpha\right\rangle$ na eq. 2.9.4.) rede estatística de segmentos conjugados em relação ao eixo de estiramento com o grau de estiramento $\lambda=L / L_{0}$. Vemos que, para a região de baixo 
estiramento (área achurada entre $1 \leq \mathrm{L} / \mathrm{L}_{\mathrm{o}} \leq 2$ ), a anisotropia de orientação média é pequena.

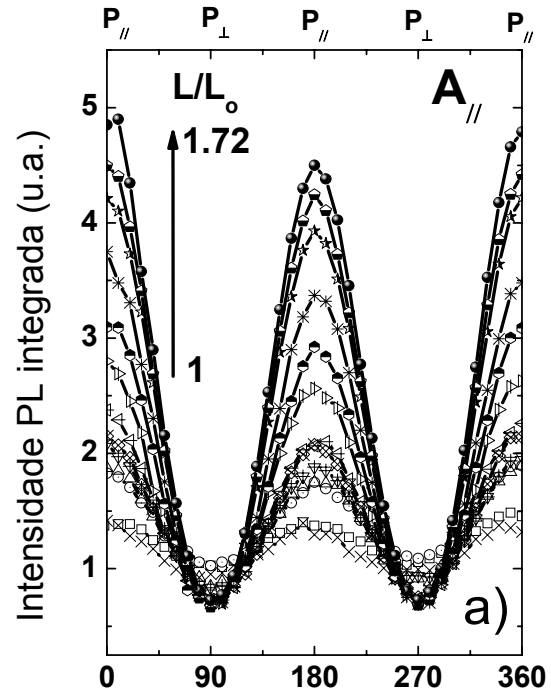

Ângulo do analizador (graus)

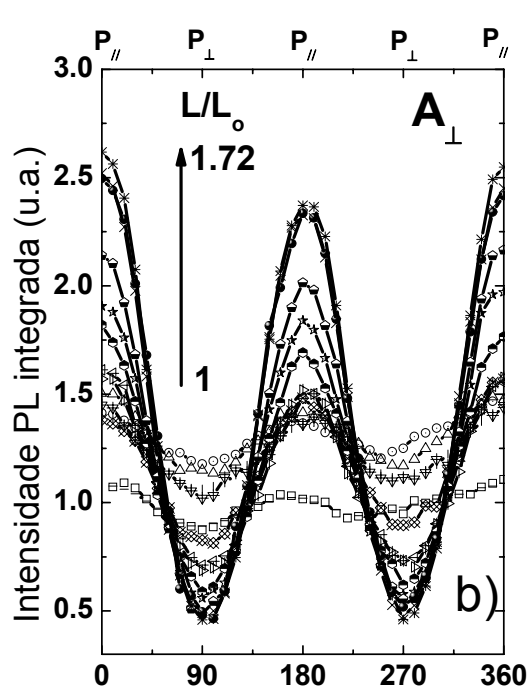

Ângulo do analisador (graus)

Figura 4.3.5 Intensidade integrada da luminescência de um filme 'spincast' de PPV sobre teflon em função do ângulo do analisador para graus de estiramentos (L/Lo) variando de $2 \%$ no intervalo de 0 a $72 \%$. A direção da excitação utilizadas foram a) paralela $A / /$ e b) perpendicular $A \perp$. $O$ ângulo zero corresponde à direção de polarização paralela ao eixo de estiramento.

A dependência da intensidade integrada da luminescência de um filme de PPV 'spincast', sobre Teflon, em função do ângulo do analisador é mostrada na Figura 4.3.5a) e b), para duas polarizações da luz de excitação: (i) paralela $\left(A_{/ /}\right)$e (ii) perpendicular $\left(A_{\perp}\right)$, ao eixo de estiramento. O ângulo zero corresponde à direção de polarização paralela ao eixo de estiramento. Neste experimento, variamos o grau de estiramento $(\lambda)$, em intervalos de $2 \%$, entre os valores de 0 a $72 \%$ do tamanho inicial da amostra (variação da razão de estiramento $\lambda=1$ a 1,72). Com o aumento do estiramento, observamos que a intensidade da emissão aumenta expressivamente na 
direção do analisador paralela ao estiramento $\left(P_{/ l}\right)$ e diminui na direção perpendicular $\left(\mathrm{P}_{\perp}\right)$ para os dois casos de excitação tratados no experimento, ou seja, $A_{/ /}$e $A_{\perp}$. Com isso, o grau de polarização $\left(p=P_{/ /} / P_{\perp}\right)$ também aumenta para os dois casos.

No entanto, o resultado mais importante é que a polarização sofre uma inversão, no intervalo de estiramentos muito pequenos, para o caso de excitação perpendicular à direção de estiramento $\left(A_{\perp}\right)$. Esta inversão pode ser vista, com mais detalhes, na Figura 4.3.6, para graus de estiramentos variando, em intervalos de 0.02 , entre $1 \leq \lambda \leq 1.12$. Para uma melhor visualização deste fenômeno, normalizamos a intensidade da PL no ângulo do analisador igual a $0^{\circ}$. Assim, a intensidade da luminescência, que é máxima na direção do campo elétrico da luz de excitação, no caso perpendicular ao estiramento $A_{\perp}$, para $L / L_{0}=1$, sofre uma inversão e passa a ser máxima na direção do estiramento $\left(P_{/ l}\right)$ à medida que o estiramento aumenta. Percebemos que um pequeno grau de estiramento é suficiente para produzir um reordenamento molecular de modo a inverter a polarização. Isto quer dizer que os portadores de carga, quando excitados perpendicularmente à direção de alinhamento molecular, são transferidos para segmentos conjugados que já possuem uma orientação média na direção paralela ao estiramento.

Todavia, um resultado relevante, que torna evidente a dependência da polarização da luminescência com a orientação molecular média da rede polimérica, é que a polarização da luz emitida, quando a excitação incidente $\left(A_{\perp}\right)$ é perpendicular ao estiramento Figura $\left.4.3 .5 \mathrm{~b}\right)$, mostra-se sobre o eixo 
de estiramento, à medida que $\lambda$ aumenta de 1 à 1,7 . A razão de termos maior intensidade da luz emitida polarizada, sobre o eixo de estiramento, provém do fato de que a TE ocorre, eficientemente, a energia de excitação aos portadores orientados sobre o eixo de elongação. Isto ocorre, mesmo considerando o decréscimo da absorção no comprimento de onda de excitação e a redistribuição de estados observados na Figura 4.3.1.

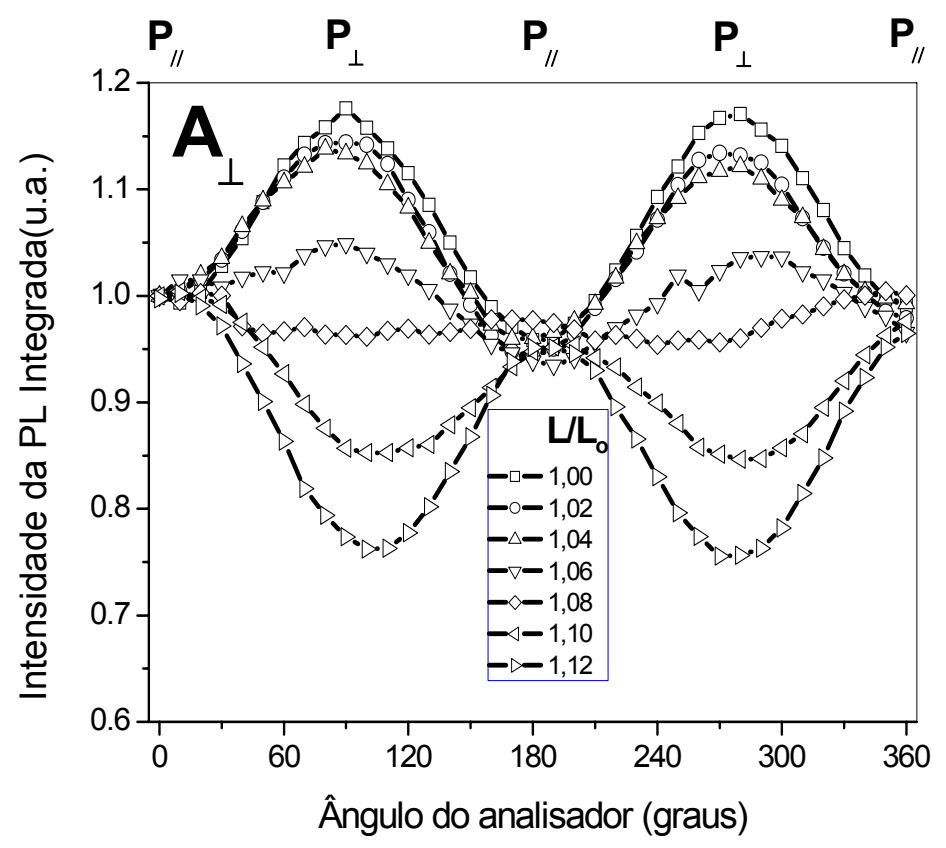

Figura 4.3.6 Intensidade normalizada da luminescência em função do ângulo do analisador para graus de estiramento extremamente pequenos variando na região de $1 \leq L / L o \leq 1.14$ para o caso de excitação perpendicular ao estiramento.

Encontramos a dependência da intensidade da luminescência, com o grau de estiramento, na Figura 4.3.7a). Observamos que a intensidade da luminescência aumenta linearmente para o caso da emissão paralela ao eixo de deformação (A// , P//), no o intervalo de estiramento entre 0 e $72 \%$. 
Contudo, a luminescência diminui quando detectada na direção perpendicular $\left(A / /, \quad P_{\perp}\right) . \quad O$ aumento da luminescência ocorre independentemente da diminuição da espessura do filme de PPV com o estiramento, o que causaria um decréscimo na absorbância da luz incidente. Para os casos não mostrados de polarização $\left(A_{\perp}, P_{l l}\right)$ e $\left(A_{\perp}, P_{\perp}\right)$, a intensidade integrada tem o mesmo comportamento, porém com menor variação. Isto indica que nos portadores de carga, em não equilíbrio, ocorre com maior probabilidade a recombinação radiativa na direção do ordenamento das cadeias poliméricas.
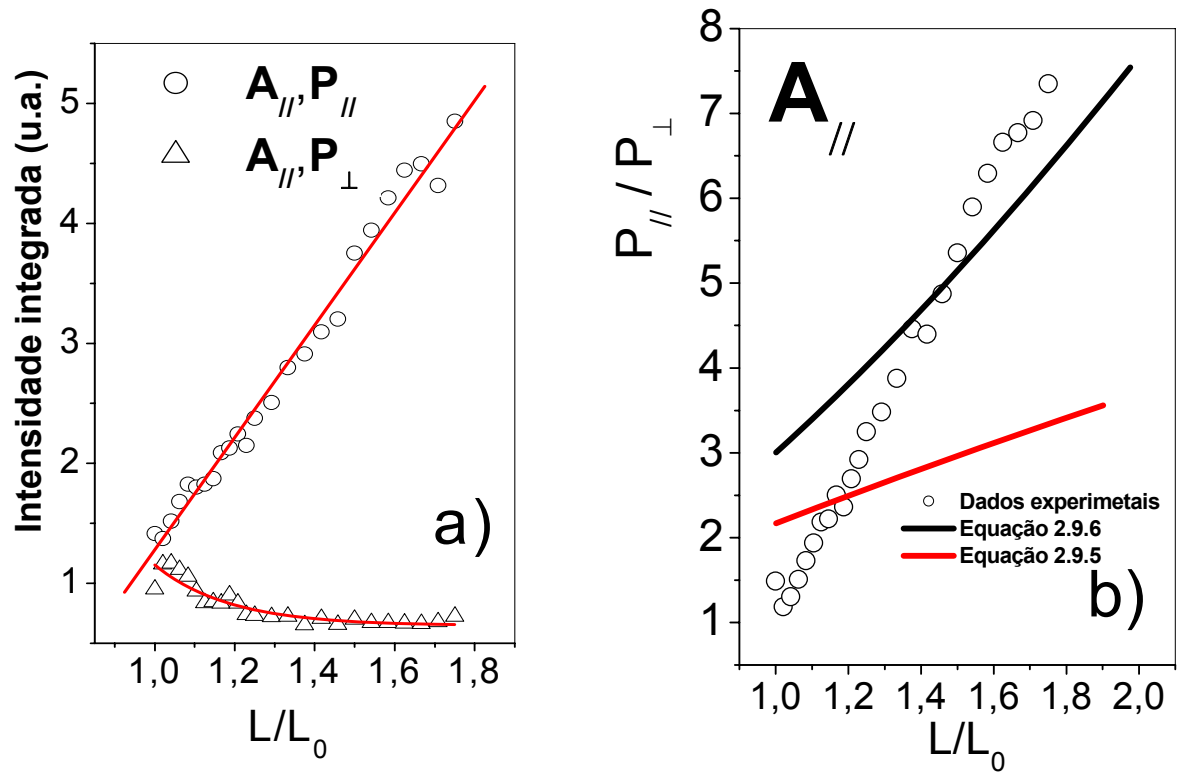

Figura 4.3.7(a) Intensidade da luminescência em função do estiramento para os casos de excitação paralela e emissão paralela e perpendicular à direção de estiramento. (b) curva de pontos, dados experimentais do grau de polarização da luminescência, $\mathbf{P}_{/ /} / \mathbf{P}_{\perp}$, em função do estiramento para polarização da excitação paralela ao estiramento; as curvas contínuas são simulações a partir das equações de distribuição molecular mostrada na seção 2.8-2. 
O grau de polarização $p=P_{/ /} / P_{\perp}$ para o caso $A_{/ /}$pode ser avalidado diretamente das intesidades da luminescência da Figura 4.3.7b). Este parâmetro é mais relevante do que a intensidade da luminescência, pois não depende da espessura do filme, ou seja, das variações da absorbância sofridas, em função da diminuição da espessura do filmes, durante o estiramento. Haja vista, o aumento linear do grau de polarização, com o estiramento, é uma evidência da independência deste parâmetro com a espessura do filme. Graus de polarização $p=P_{/ /} / P_{\perp}$ da ordem de 8 , para $L / L_{o}=1,72$, sugerem um grande alinhamento molecular que minimiza efeitos de despolarização por transferência de energia que, por sua vez, maximiza a eficiência da emissão sobre o eixo de orientação.

O aumento da eficiência da luminescência para excitação paralela, ao eixo de estiramento $\left(A_{/ /}\right)$, e o alto valor do grau de polarização $(p=8)$, obtidos na Figura 4.3.7 a) e b), são incompatíveis com os valores de polarização $\left(A_{/ /} / A_{\perp}=1.2\right)$ da absorbância, bem como com o seu decréscimo devido à variação da espessura Figura 4.3.1. Isto indica que outros processos que aumentam a eficiência da luminescência estão ocorrendo em paralelo. $\mathrm{O}$ processo mais provável é o de transferência de energia dos segmentos conjugados não orientados para aqueles que possuem um certo alinhamento ao longo do eixo de estiramento.

A Figura 4.3.7b) compara os valores experimentais do grau de polarização $p=P_{/ /} / P_{\perp}$, para excitação paralela $\left(A_{/ /}\right)$, aos valores teóricos obtidos a partir de duas equações de distribuição angular da rede polimérica (equações 2.9.5 e 2.9.6). É importante salientar que, nestes cálculos, consideramos apenas o efeito da distribuição angular de segmentos 
conjugados, promovida pelo estiramento, sobre as propriedades ópticas do PPV dentro da matriz polimérica. Não contabilizamos os efeitos extras de transferência de energia. Verificamos que a distribuição de segmentos conjugados, que melhor simula a distribuição real, é dada pela equação (2.9.5). Conforme a literatura, esta distribuição é a mais indicada para descrever o rearranjo molecular devido ao estiramento uniaxial.

Para estiramentos pequenos $(\lambda<1,2)$, o grau de polarização do PPV, sobre teflon, é dominado por processos de TE que despolarizam a luminescência, pois $P_{/ /} P_{\perp}$ é menor que o valor 3 esperado para uma distribuição isotrópica de segmentos (linha tracejada horizontal na Figura 4.3.7 b)). Vimos que a transferência de energia induz a uma redistribuição orientacional da excitação entre segmentos conjugados no plano do filme.

Para estiramentos $1,2<\lambda<1,4$, a polarização da luminescência é determinada tanto pela variação da distribuição angular de segmentos conjugados (curva teórica) como por processos de TE, que agora transferem a excitação para segmentos conjugados ao longo da direção de estiramento. Para $\lambda<1,4$, o grau de polarização experimental é maior que o valor calculado sem TE, significa que processos de TE atuam, através do fator orientacional da taxa TE, o efeito puramente orientacional na polarização da luminescência. Como a orientação molecular média não é tão expressiva para a região de estiramento considerada no presente trabalho, concluímos: os processos que promovem a migração de energia são bastante eficientes para transferir a excitação de segmentos conjugados, não alinhados, de grau de conjugação pequeno (alta energia) aos segmentos alinhados de alto grau de conjugação (baixa energia). Estes segmentos correspondem aos estados 
finais emissivos. Portanto, nessa região de estiramento, a configuração dos segmentos conjugados que participam da emissão reflete a orientação imposta pelo estiramento, ou seja, a distribuição de segmentos dada pela equação (2.7.5).

As medidas de polarização acima demonstram que, contrariamente à tendência da literatura especializada de trabalhar com grandes estiramentos, a maioria dos processos ópticos e transformações do arranjo molecular já ocorrem na região de estiramentos pequenos $(\lambda<2)$. Estes resultados têm importantes implicações tecnológicas, pois grandes anisotropias podem ser obtidas por meio de pequenas deformações do filme polimérico, gerando altas polarizações da luz emitida. Além disso, processos fotofísicos relevantes, responsáveis por tais propriedades, precisam ser entendidos, de modo mais abrangente, visando à aplicação tecnológica desses materiais na área de opto-eletrônica de filmes finos.

\subsubsection{Filmes LbL}

Efetuamos medidas de absorbância, em função de $\lambda$, para os casos de polarização da luz de excitação paralela $\left(A_{/ /}\right)$e perpendicular $\left(A_{\perp}\right)$, à direção de estiramento, para filmes PPV-LbL, sobre Teflon. A Figura 4.3.8 a) compara os espectros de absorbância para os valores extremos de estiramento, ou seja, L/Lo=1 e L/Lo=1,68 de um filme PPV-LbL. 

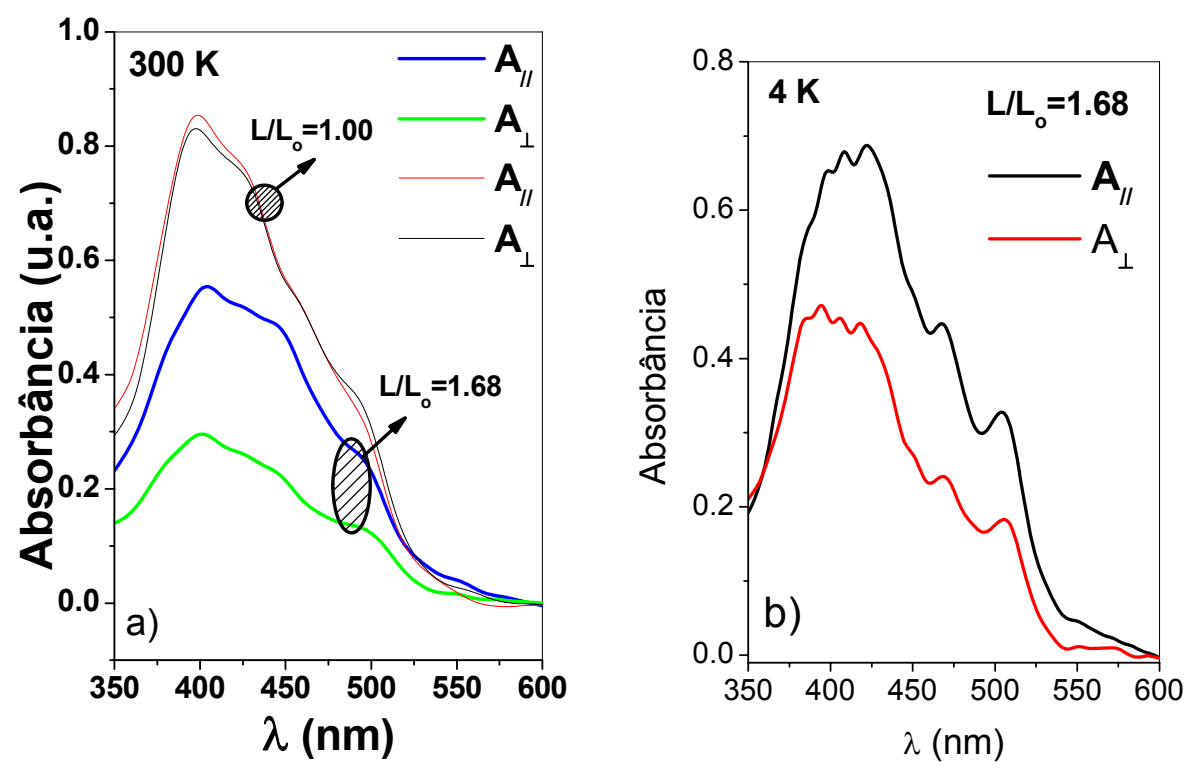

Figura 4.3.8 Espectros de absorbância medidos para diferentes configurações da polarização da luz de excitação paralela $A_{/ /}$e perpendicular $A_{\downarrow}$ ao estiramento de um filme LbL para temperaturas de a) $300 \mathrm{~K}$ e de b) $4 \mathrm{~K}$ para estiramentos $L / L_{0}=1$ e $\left.L / L_{o}=1,68\right)$.

Na seção 4.2.1, confirmamos que o filme LbL apresenta anisotropia residual $(\lambda=1)$ antes do estiramento, pois os espectros de absorbância não são perfeitamente coincidentes. O peso espectral, na Figura 4.3.8 a), deslocado para o azul, indica a predominância de transições ópticas oriundas de segmentos conjugados pequenos, nos filmes de PPV preparados por LbL sobre teflon.

Este quadro muda drasticamente com o estiramento de $\lambda=1,68$. $\mathrm{A}$ absorbância diminui na região de alta energia, indicando ao mesmo tempo uma redistribuição dos pesos espectrais e também a diminuição da espessura do filme. O estiramento produz o aumento do grau de anisotropia de $A_{/ /} / A_{\perp}=1,1(\lambda=1)$ para $A_{/ /} / A_{\perp}=2,0(\lambda=1.68)$, para os dois comprimentos de onda $\lambda=441 \mathrm{~nm}$ (laser de He-Cd) e $\lambda=487 \mathrm{~nm}$. Nestes filmes LbL, a 
estrutura, em $487 \mathrm{~nm}$, não é resolvida, a temperatura ambiente, para $\lambda=1.68$, como observamos anteriormente nas amostras spincast. Porém, o espectro de absorbância, a baixas temperaturas (4 K), (Figura 4.3 .8 b)) exibe estruturas mais resolvidas.

Extraímos espectros de absorbância a $4 \mathrm{~K}$, para diferentes configurações da polarização da luz de excitação paralela: $A_{/ /}$e perpendicular $A_{\perp}$, ao estiramento $\left(L / L_{\circ}=1,67\right)$ dos filmes $L b L$ da Figura 4.3.8b). Notamos o aparecimento de estruturas vibracionais resolvidas para a elongação de $\lambda=1.68$.
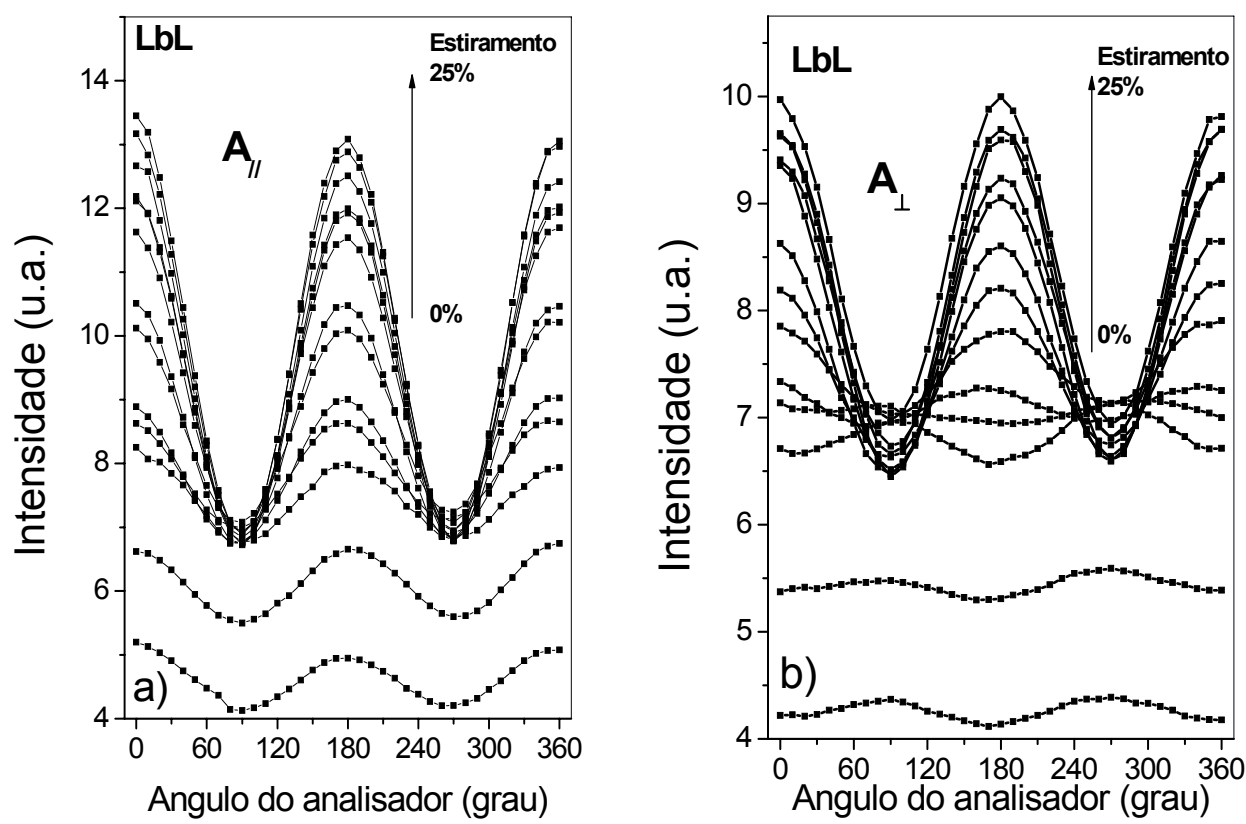

Figura 4.3.9 Intensidade integrada da luminescência de um filme LbL de PPV sobre teflon em função do ângulo do analisador (tomando-se o ângulo zero a direção de estiramento como referência) para graus de estiramentos $L / L_{\circ}$ variando de $2 \%$ no intervalo de 0 a $25 \%$. A direção da excitação utilizadas foram a) paralela $A_{/ /}$e b) perpendicular $A_{\perp}$ ao estiramento 
Mostramos a dependência da intensidade integrada da luminescência de um filme LbL de PPV, sobre Teflon, com o ângulo do analisador (tomando-se o ângulo zero a direção de estiramento como referência) nas Figura 4.3.9a) e b), para o comprimento da amostra variando de 0 a $25 \%$ do tamanho original (razão de estiramento de 1 a 1,25 ) com incremento de $2 \%$. Estas figuras correspondem, respectivamente, às direções da polarização da luz de excitação paralela $\left(A_{/ /}\right)$e perpendicular $\left(A_{\perp}\right)$ ao estiramento. Para $\lambda=$ 0 (curva de mais baixa intensidade nas duas figuras), o grau de polarização é pequeno e a intensidade é máxima na direção da excitação para os dois casos de excitação utilizados $\left(A_{/ /}\right.$e $\left.A_{\perp}\right)$. Este resultado é análogo àquele medido para filmes 'spincast' isotrópicos de PPV. Com o aumento do estiramento, observamos que tanto a intensidade da emissão quanto o grau de polarização $\left(p=P_{/ /} / P_{\perp}\right)$ aumentam. Além disso, inferimos que um pequeno valor no estiramento (por volta de $5 \%$ ) é suficiente para inverter a polarização da luminescência para o caso $A_{\perp}$ (Figura 4.3.9b)), fazendo com que os portadores de carga, quando excitados perpendicularmente ao alinhamento molecular, sejam transferidos para segmentos conjugados alinhados na direção paralela ao estiramento.

A Figura 4.3.10 mostra a dependência do grau de polarização $p=P_{/ /} / P_{\perp}$ com $\lambda$, para os casos de excitação paralela e perpendicular à direção de estiramento. Constatamos, nesta figura, uma inversão de polarização, em torno de $P_{/ /} / P_{\perp}=1$, para a região de estiramentos $1 \leq L / L o \leq 1,1$ considerando 0 caso de excitação perpendicular $\left(A_{\perp}\right)$. O grau de polarização aumenta, para L/Lo>1,1, e começa a saturar para estiramentos da ordem de $20 \%$. 
Diferentemente das amostras 'spincast', que tiveram um crescimento linear, esta saturação não era esperada para estiramentos tão pequenos. Atribuímos este comportamento à diferença de espessura dos dois filmes tratados aqui. Haja vista que o caráter hidrofóbico do Teflon prejudica a adsorção molecular, pois utilizamos polieletrólitos diluídos em água. Além disso, filmes LbL são extremamente finos e possuem espessura de 20 bicamadas de PTHT/BDS ( 2 nm por camada). Já os filmes spincast possuem espessuras típicas da ordem de centenas de nm.

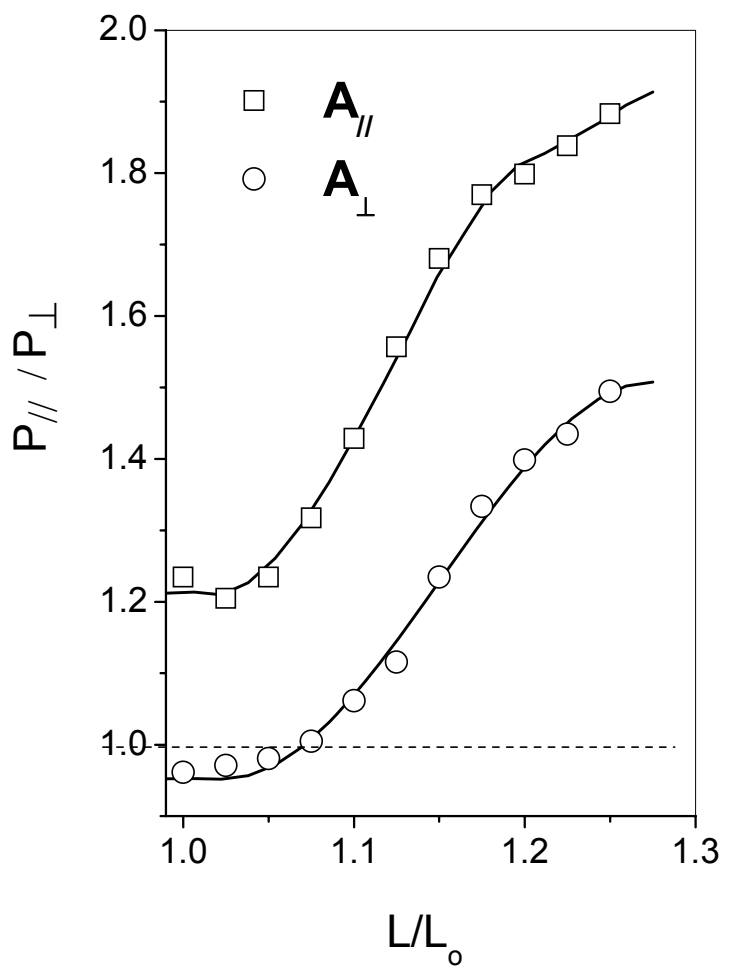

Figura 4.3.10 Grau de polarização calculado a partir das Figura 4.3.9a e b para amostra LbL de PPV sobre Teflon. As linhas contínuas servem com guia para os olhos.

Os filmes LbL possuem um ordenamento axial da rede polimérica mesmo antes do estiramento. Consideramos que esta anisotropia é advinda das imersões do substrato na solução, que organiza as cadeias dos 
Propriedades ópticas de filmes com pequeno grau de estiramento: orientação axial das cadeias

100

polieletrólitos na direção do fluxo da água, ou seja, em uma direção ortogonal a superfície da solução. Por isto, dedicamo-nos com mais atenção aos filmes spincast, haja vista que se apresentam isotrópicos, sem estiramento externo, nos propiciando o acompanhamento da influência do ordenamento gradual sobre as taxas de TE que determinam as propriedades ópticas do PPV. 
Migração das excitações eletrônicas em polímeros conjugados luminescentes diluídos

Capítulo 5

5. Migração das excitações
$\begin{aligned} & \text { eletrônicas em polímeros } \\ & \text { conjugados }\end{aligned}$
diluídos em uma matriz inerte


Migração das excitações eletrônicas em polímeros conjugados luminescentes diluídos em uma matriz inerte

No capítulo anterior, realizamos um estudo detalhado da influência do ordenamento molecular, no estado de polarização da luz, em filmes poliméricos de poli ( $p$-fenileno vinileno) (PPV), com baixo grau de estiramento. Nos filmes não estirados, os processos de transferência de energia, responsáveis pela migração da excitação, produzem a despolarização da luminescência, conferindo, a estes filmes, o caráter isotrópico. Verificamos que os processos de TE podem ser modificados mesmo para estiramentos extremamente pequenos (pequena ordem molecular), produzindo uma eficiente migração da excitação dos segmentos conjugados de PPV, não orientados, àqueles com ligeira orientação e, conseqüentemente, gerando uma alta polarização da luminescência na direção do estiramento.

Tendo em vista os resultados obtidos pelo estudo dos filmes estirados e não estirados, sobre Teflon, em que notamos a forte intervenção da TE não radiativa, tipo Foerster, no processo de emissão final, guiamo-nos ao 
Migração das excitações eletrônicas em polímeros conjugados luminescentes diluídos em uma matriz inerte

estudo direto da TE entre segmentos conjugados, sondando os, através de modificações na engenharia molecular que os influencia sobremaneira.

A TE não radiativa obedece, junta e principalmente, aos fatores orientacionais e à distância relativa entre DOADOR*->ACEITADOR ou DOADOR*->DOADOR $^{*}$, sendo assim, é que nos motivamos a estudar a influência, que separações entre os segmentos conjugados, exerceria nas taxas de TE e por conseqüência na eficiência da emissão. Além do que, o entendimento desses processos intermediários consiste em grande contribuição para otimizar a fabricação dos OLED's.

Utilizamos engenharia molecular específica para modificar controlada e sistematicamente os processos de transferência. $\mathrm{O}$ controle deste processo migratório, entre cadeias, foi feito por meio da diluição gradativa das cadeias luminescentes, em uma mistura sólida, com polímero separador inerte e da separação dos segmentos conjugados, dentro da cadeia, através de segmentos não conjugados. Bem como da separação dos sítios emissivos através da técnica de excitação seletiva da luminescência (PLE)

Deste modo, sistematizamos os experimentos a fim de interferirmos nas duas modalidades de TE: (i)Intercadeia e (ii)Intracadeia, que são extremamente atuantes na eficiência da emissão, pois sua combinação, aos fatores orientacionais de TE, é responsável por levar o éxciton a recombinar se nos estados finais, que podem ser radiativos ou de supressão energética.

Logo, demos início ao estudo deste processo migratório por meio (Figura 5.1):

- da separação dos segmentos conjugados intercadeia;

- da separação dos segmentos conjugados intracadeia e 
Migração das excitações eletrônicas em polímeros conjugados luminescentes diluídos em uma matriz inerte

- da separação dos segmentos conjugados inter e intracadeia:

Através da Figura 5.1 temos uma visão da disposição e do arranjo molecular na superfície do filme.
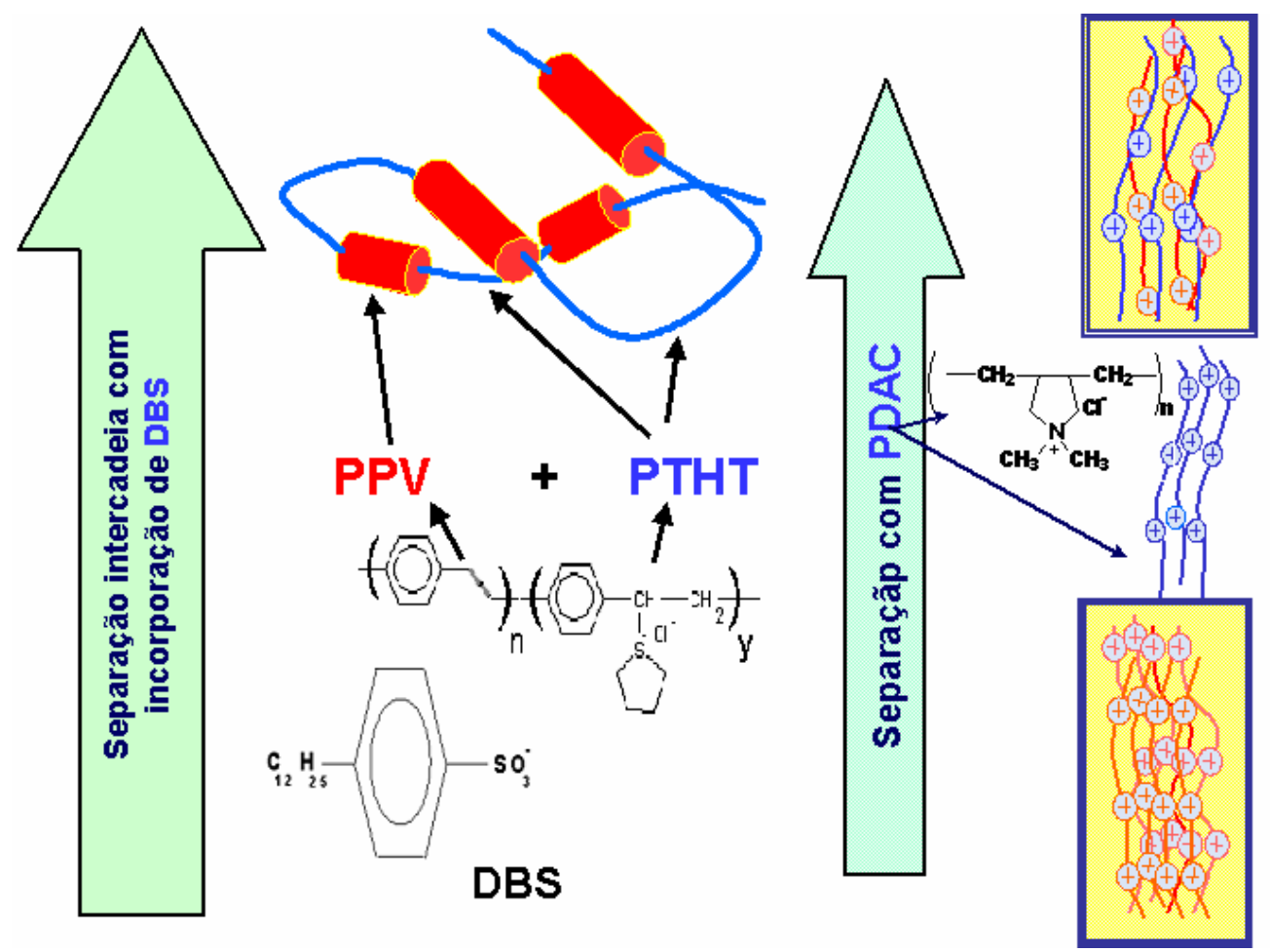

Figura 5.1 Esquema ilustrando a conformação molecular devido as diluições intra e intercadeias.

Nossa abordagem é diferente em dois aspectos que são essenciais para o entendimento dos resultados experimentais obtidos até o momento. Primeiramente, vamos variar a taxa de transferência e favorecer o decaimento radiativo em moléculas de menor tamanho de conjugação que antes participavam dos processos intermediários de transferência, mas não do processo final de emissão. Em segundo lugar e o mais importante, estudamos a natureza e a origem dos processos da TE, em polímeros conjugados, e que certamente determinam a difusão espectral neste sistema. 
Migração das excitações eletrônicas em polímeros conjugados luminescentes diluídos em uma matriz inerte

Considerações originadas nestes experimentos conduzem a algumas questões que ainda não foram suficientemente estudadas. Será que a desativação da luminescência por meio de centros supressores ocorre durante a relaxação espectral, (Projeto 1) via processos ressonantes de transferência de energia, ou primeiramente ocorre a difusão espectral e, após alcançarem o estado final, éxcitons são suprimidos por centros não radiativos ressonantes? Se ambos processos ocorrem, qual é o percentual de participação de cada um no balanço energético final? A migração da excitação entre moléculas distribuídas aleatoriamente é descrita corretamente por uma equação de difusão? O que ocorre com estes processos quando introduzimos um pequeno ordenamento ao sistema em questão? A tentativa de resposta a estas questões, mesmo que parcial, será objetivo deste projeto.

O entendimento destes processos e as respostas a estas questões são importantes na definição de novas estratégias para o aumento da eficiência dos mesmos. Para isso, o domínio das técnicas de preparação de filmes orgânicos é de importância fundamental. A fabricação de compósitos poliméricos, através de técnicas de deposição em camadas, oferece um excelente controle de propriedades finais do filme, como espessura e ordenamento molecular, permitindo a implementação de uma arquitetura molecular. Dentre as várias técnicas empregadas, a técnica de automontagem, (layer by layer -LBL), tem se tornado bastante atrativa pelo excelente nível de controle estrutural que oferece e por sua simplicidade experimental. 


\subsection{Efeito da separação entre cadeias}

Nesta seção, promovemos o controle do processo migratório, em polímeros conjugados, por meio da separação gradativa dos segmentos conjugados de PPV, com um polímero inerte em uma mistura sólida. Este controle se deve ao fato da taxa transferência da excitação eletrônica entre segmentos conjugados ser dependente da distância relativa entre eles.

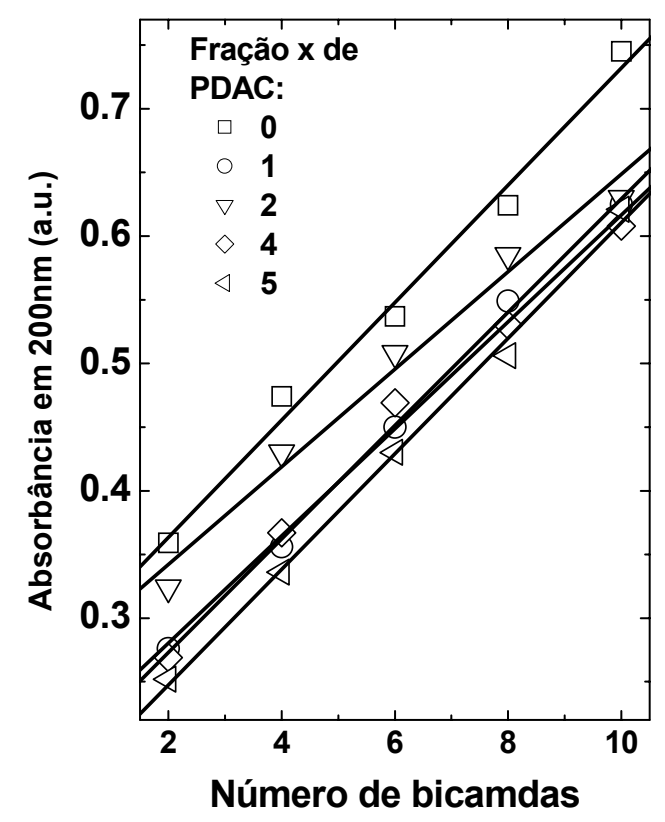

Figura 5.1.1 Taxa de deposição do PTHT/PDAC, solução catiônica, e DBS, solução aniônica.

O comportamento linear da variação da intensidade da absorbância, em 220nm (nesse comprimento de onda há estados absorsivos do PTHT), em função do número de bicamadas, Figura 5.1.1, indica que cada 
bicamada possui praticamente a mesma quantidade de material adsorvido para as frações volumétricas de PDAC utilizadas, ou seja, a espessura por bicamada não é alterada com a diluição. De acordo com o trabalho de Célio Aécio Medeiros Borges [11], o sinal de absorbância, em 200 nm, deve se basicamente ao DBS incorporado por bicamada.
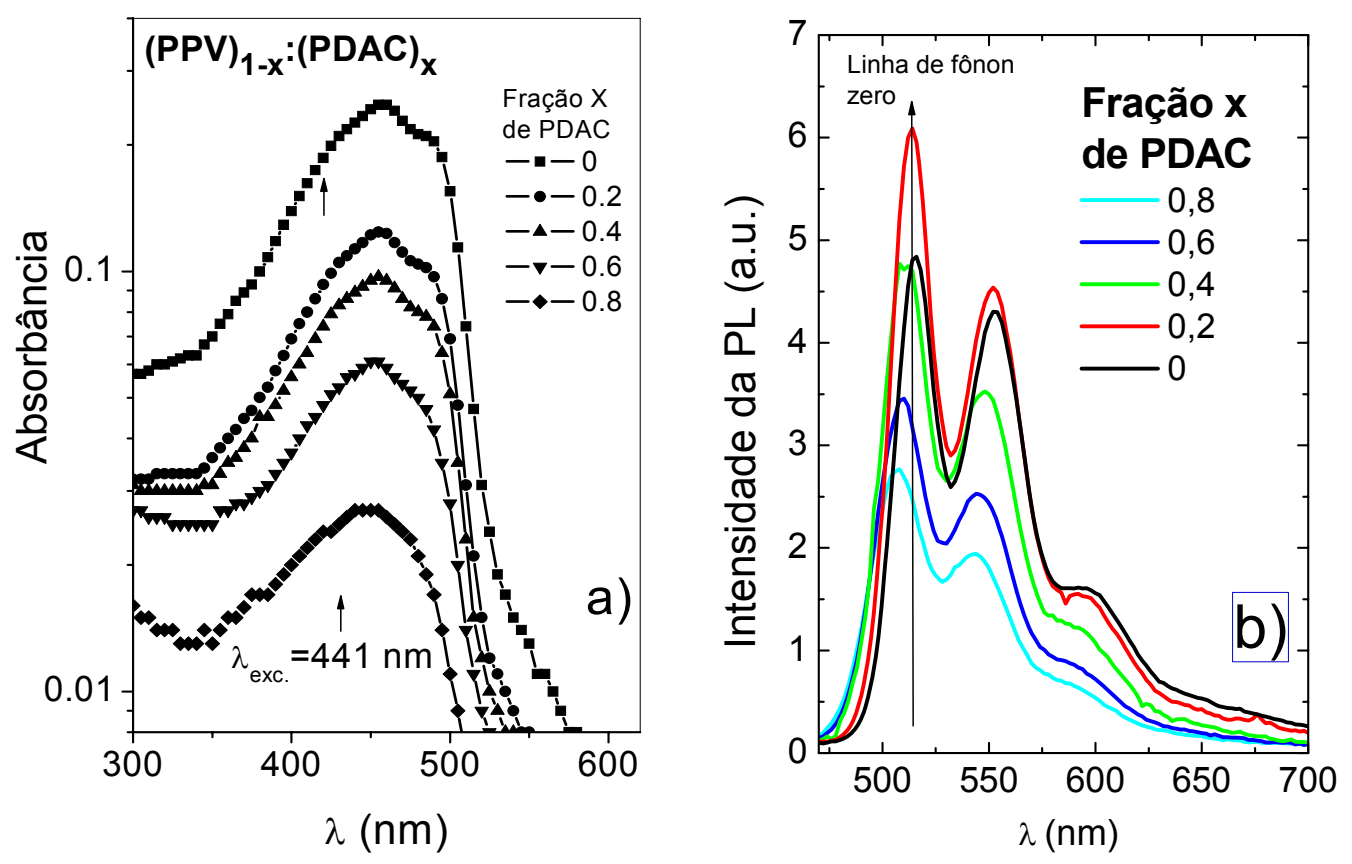

Figura 5.1.2 a) Logaritmo da absorbância e (b) luminescência em função da fração $x$ de PDAC na mistura (PPV) $)_{1-\mathrm{x}}(\text { PDAC })_{\mathrm{x}}$.

As Figura 5.1.2a) e b) mostram medidas de absorbância e luminescência, respectivamente, para filmes automontados, a partir de uma mistura formada por frações volumétricas do material precursor do polímero luminescente PPV, o (cloreto de xilideno tetrahidrotiofeno) ou (PTHT)1-x e o polímero poli(hidrocloreto de alilamina), ou (PDAC)x. Após a diluição, em solução, a uma dada fração volumétrica $\mathrm{x}$, filmes ultrafinos destes polímeros 
catiônicos foram automontados (10 bicamadas) com o ânion de cadeia longa dodecilbenzeno sulfônico, DBS. O DBS, neste caso, atua como camada aniônica para a deposição do policátion PTHT e, ao mesmo tempo, ocorre a troca com o contraíon $\mathrm{Cl}^{-}$do PTHT, o que permite a realização do processo de conversão a baixas temperaturas. O tempo de deposição de cada monocamada foi de 30 segundos. Assim, o PTHT foi convertido em PPV após tratamento térmico, por 30 minutos, a $110^{\circ} \mathrm{C}$.

Identificamos o efeito da diluição das cadeias de PPV em PDAC, na Figura 5.1.2a), através do decréscimo da intensidade da absorbância da banda conjugada do PPV (posicionada entre 400 e $500 \mathrm{~nm}$ ) com o aumento da fração $x$ de PDAC no filme. Utilizamos a escala logarítmica, nesta figura, para evidenciar os pequenos valores da absorbância com o aumento de x. Assim, verificamos que a forma espectral da banda conjugada do PPV não é modificada de forma significativa, indicando que o PPV não é alterado com a diluição em PDAC. A intensidade da absorbância cai cerca de 9 vezes no intervalo $0 \leq \mathrm{x} \leq 8$. Como esperávamos, existe uma correspondência de 1 para 1 entre a fração de diluição do PTHT e o decréscimo na absorbância: uma diluição de 9 vezes produz uma diminuição de um fator 9 na intensidade da absorbância. Já a luminescência (Figura 5.1.2b)) não decresce na mesma proporção, ou seja, a intensidade da linha de fônon zero decresce apenas duas vezes para as diluições consideradas. Este resultado sugere que a eficiência de emissão do PPV está sendo alterada com a separação das cadeias.

A Figura 5.1.3a) compara melhor a intensidade da absorbância no comprimento de onda do laser de He-Cd de excitação (441 nm) e a 
eficiência de emissão do PPV, definida como a razão da intensidade integrada da luminescência pelo valor da absorbância em 441 nm, em função de x. É interessante notarmos que, apesar da queda da absorção no comprimento de onda de excitação $(441 \mathrm{~nm})$, a eficiência de emissão do PPV aumenta com a diluição do PPV em PDAC. Neste caso, a eficiência de emissão do PPV aumenta 9 vezes quando a fração de diluição do PPV em PDAC varia no intervalo $0<x<9$. Este comportamento é praticamente o mesmo para dois valores (baixo e alto) do peso molecular do PDAC.

Atribuímos este aumento da eficiência de emissão do PPV à mudança da taxa de transferência de energia com a diluição. Como foi visto, com os filmes estirados, esta taxa é muito alta para os filmes sem diluição e é responsável por processos de despolarização, observados nos filmes de PPV estudados neste trabalho. Conseqüentemente, a excitação eletrônica sofre inúmeras transferências entre segmentos conjugados de PPV, durante o processo de relaxação energética, até encontrar um segmento longo, onde decai radiativamente. Neste processo de múltiplas transferências, a probabilidade de encontrar centros supressores de luminescência é alta, o que reduz a probabilidade do processo radiativo final. No caso das amostras diluídas, a taxa de transferência diminui e, conseqüentemente, a migração diminui. Isto reduz a probabilidade da excitação de encontrar um centro nãoradiativo, o que aumenta, portanto, a eficiência da emissão nestes filmes. 

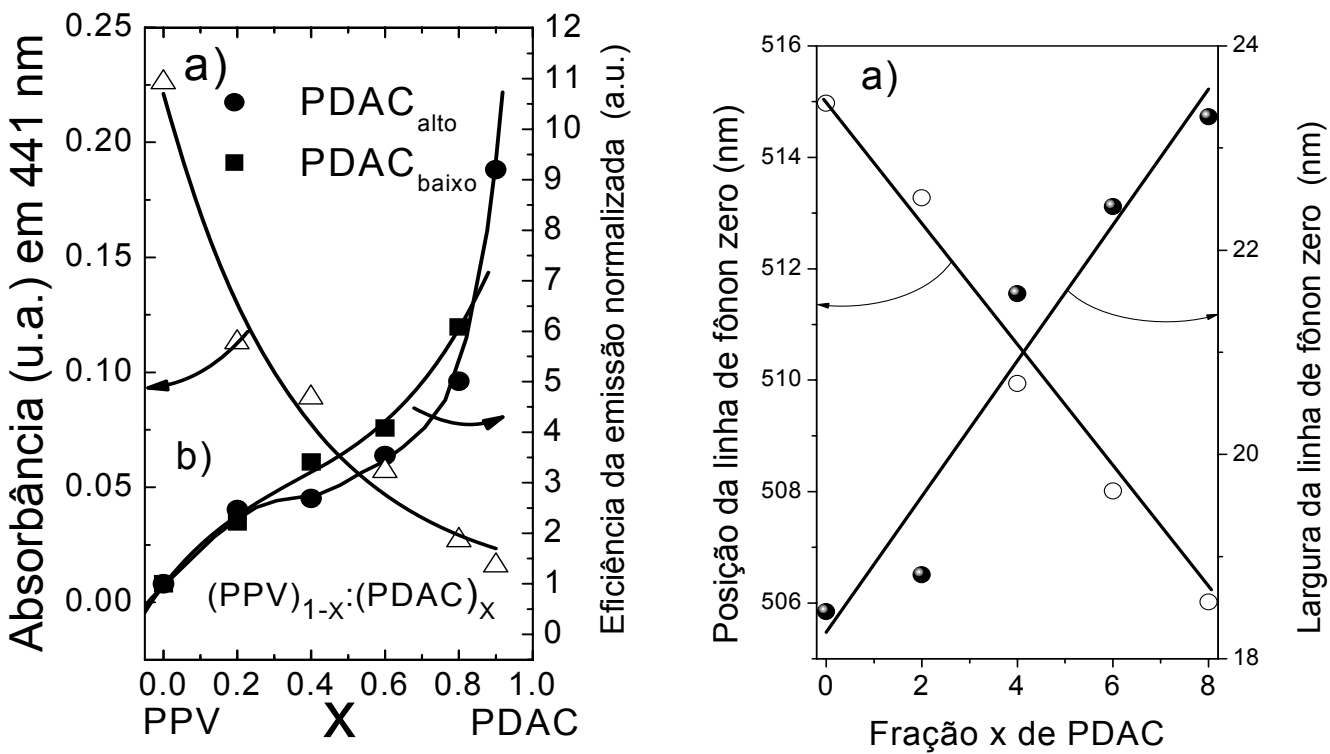

Figura 5.1.3 a) Intensidade da absorbância no comprimento de onda do laser de HeCd de excitação (441 nm) e a eficiência de emissão do PPV, definida como a razão da intensidade integrada da luminescência pelo valor da absorbância em $441 \mathrm{~nm}$, em função da fração $x$ de PDAC em filmes de PPV. b) A mesma dependência para a posição e largura da linha de fônon zero da emissão do PPV.

A Figura 5.1.3b) mostra a dependência da posição e largura da linha de fônon zero (por volta de $510 \mathrm{~nm}$ ) com a variação da fração de PDAC no filme. Vemos que os espectros de luminescência alargam e deslocam se para altas energias, com o aumento da fração x, ou seja, da separação entre as cadeias de PPV. O alargamento e o deslocamento espectral da luminescência não se devem a mudanças, por exemplo, no decréscimo do tamanho de conjugação do PPV ou interações dos segmentos conjugados desse material com a matriz de PDAC. Este resultado pode ser confirmado primeiramente pelos espectros de absorbância na Figura 5.1.2, pois estes variam muito pouco para o intervalo de diluição $0 \leq x \leq 8$. Na seção 5.2 , veremos que os espectros de luminescência deslocam-se muito pouco em 
relação a grandes variações nos espectros de absorbância. Isto se deve ao eficiente processo de difusão espectral (migração seguido de relaxação de energética) em polímeros conjugados. Desta forma, o deslocamento para o azul e o alargamento com o aumento da fração de PDAC estão associados ao fato da separação das cadeias diminuir a taxa de transferência de energia entre cadeias, o que aumenta a probabilidade de emissão de segmentos de menor tamanho de conjugação. Estes fenômenos serão tratados mais adiante.

Medidas de excitação seletiva da luminescência (PLE) podem dar informação dos processos envolvidos na relaxação energética dos portadores fotoexcitados. As Figura 5.1.4a) e b) comparam espectros de PLE e absorbância, em função da fração $x$ de PDAC, nos filmes estudados acima. Fixamos o comprimento de onda de detecção na primeira réplica de fônon do espectro de luminescência (estrutura vibracional em $550 \mathrm{~nm}$ ). A Figura 5.1.4a) mostra o espectro de absorção do PPV, sem diluição $(x=0)$, para efeito de comparação das mudanças da linha espectral. Fizemos a normalização dos espectros na máxima intensidade para melhor visualização.

Ao contrário dos espectros de absorbância (Figura 5.1.4b), a forma de linha espectral da PLE sofre grandes modificações. Em primeiro lugar, os espectros de excitação apresentam uma estrutura característica, na região de baixo comprimento de onda (em torno de $480 \mathrm{~nm}$ ), cuja intensidade cai com o aumento da fração de PDAC. Além disso, o maior peso espectral (maior banda do espcetro) da PLE aumenta para pequenos comprimentos de onda à medida que a diluição aumenta. A medida de excitação seletiva é 
geralmente mais complexa que as medidas de absorção. Além de ser proporcional às transições ópticas envolvidas na absorção, a PLE fornece informação sobre a dinâmica da relaxação energética dos portadores de carga e dos processos envolvidos entre os estados de absorção e os estados emissivos.
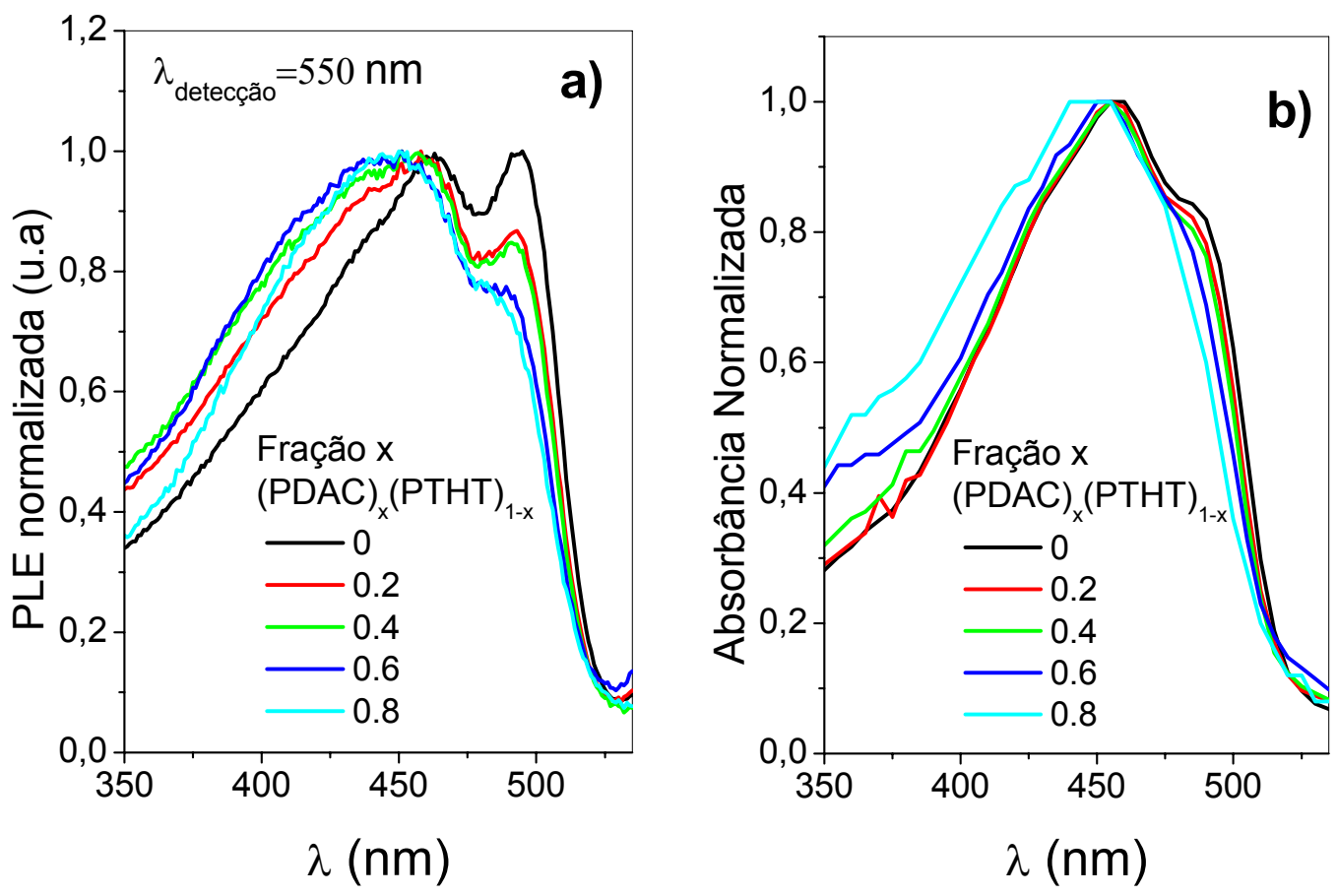

Figura 5.1.4. Espectros de a) PLE e b) absorbância em função da fração $x$ de PDAC. $O$ espectro de absorção do PPV, sem diluição $(x=0)$ (círculos abertos), é mostrado na figura a) para efeito de comparação.

A Figura 5.1.5 exibe a diferença entre espectros de PLE e de absorção para cada fração de PDAC, $\mathbf{x}$, nos filmes estudados nesta seção. A mesma figura mostra o espectro de absorção do PPV (círculos), sem diluição $(x=0)$, para efeito de comparação. Espectros de excitação seletiva seriam coincidentes com os de absorção se os processos envolvidos na relaxação 
energética fossem suprimidos. Neste caso a diferença entre os espectros seria nula.

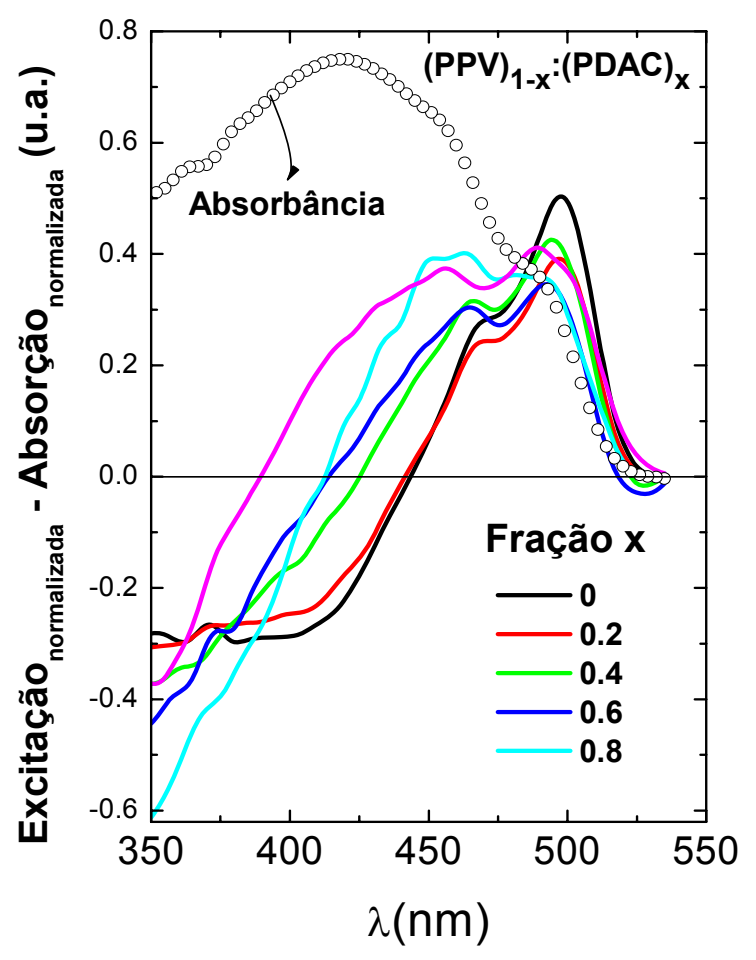

Figura 5.1.5. Diferença entre o espectro de excitação (PLE da Figura 5.1.4a) e o espectro de absorbância Figura 5.1.4b) para as amostras contendo diferentes frações de PDAC.

No entanto, a Figura 5.1.5 mostra que os segmentos conjugados de PPV são eficientemente excitados na região espectral de comprimentos de onda entre $480 \mathrm{~nm}$ e $520 \mathrm{~nm}$, ou seja, na borda de absorção de baixa energia. Este efeito é mais evidente para as curvas correspondentes a $x=0$, 0,2 e 0,4 partes de PDAC, do que para as demais. Este intervalo de energia reporta se a transições ópticas envolvendo de segmentos conjugados do PPV de grau de conjugação grande. O decréscimo da intensidade absorbância, com o aumento do comprimento de onda, sugere que esta região espectral também corresponde a segmentos conjugados longos de 
baixa densidade. Isto permite que a excitação seletiva selecione segmentos conjugados com diferentes separações intercadeia nessa região espectral, porque a densidade de segmentos longos decresce com o aumento do comprimento de onda de excitação. Esta separação dos segmentos conjugados se reflete no aumento da intensidade da PLE para os filmes com pequena diluição (x pequeno). Como já vimos para estes filmes, a eficiência de emissão é baixa devido à grande migração da energia entre cadeias. Com a excitação seletiva, promovemos a separação dos segmentos conjugados à medida que aumentamos o comprimento de onda de excitação. Como a separação entre cadeias reduz o processo de migração, a eficiência de emissão deve aumentar nessa região espectral para os sistemas moleculares de alta densidade. Já os filmes contendo alta diluição das cadeias de PPV não apresentam este aumento evidente da PLE.

A diferença entre os espectros de PLE e absorbância, Figura 5.1.5, mostra uma brusca queda na região de comprimentos de onda abaixo de 480nm, chegando a valores negativos (absorbância maior que a PLE). Isto significa que parte dos portadores de carga gerados abaixo de $480 \mathrm{~nm}$, são suprimidos por processos não radiativos durante a difusão espectral e não participam da emissão nos segmentos longos. Esta evidência é corroborada pelo aumento da parte positiva, da diferença entre os espectros de PLE e absorbância, na região de baixas energias (Figura 5.1.5) à medida que a fração de PDAC nos filmes aumenta. Este aumento se reporta à redução do processo de migração energética e ao conseqüente aumento da eficiência da luminescência com o aumento da diluição do PPV. 
Medidas em função da temperatura da amostra dão indícios da natureza dos processos supressores da luminescência. A Figura 5.1.6 mostra a intensidade integrada normalizada da luminescência (na temperatura de $4 \mathrm{~K}$, para melhor visualização) de filmes contendo $\mathbf{x}=\mathbf{0 , 9}$; 0,8 e 0,0 de fração volumétrica de PDAC. A intensidade da amostra contendo $x=0,9$ é praticamente independente da temperatura no intervalo de 4 a $260 \mathrm{~K}$. No entanto, a intensidade da luminescência cai com o aumento da temperatura para amostras pouco diluídas. No caso do PPV puro, a intensidade decai 2,5 vezes. Este resultado demonstra que a excitação é suprimida por processos de natureza extrínseca (centros supressores como defeitos) que são ativados pela temperatura durante a difusão espectral. Processos extrínsecos, tais como centros de carbonila, estão presentes e atuam como centros supressores cuja eficácia depende da temperatura [1]. Com a separação das cadeias, os processos de transferência de energia são eliminados e, com isso, a excitação não alcança estes centros supressores. 


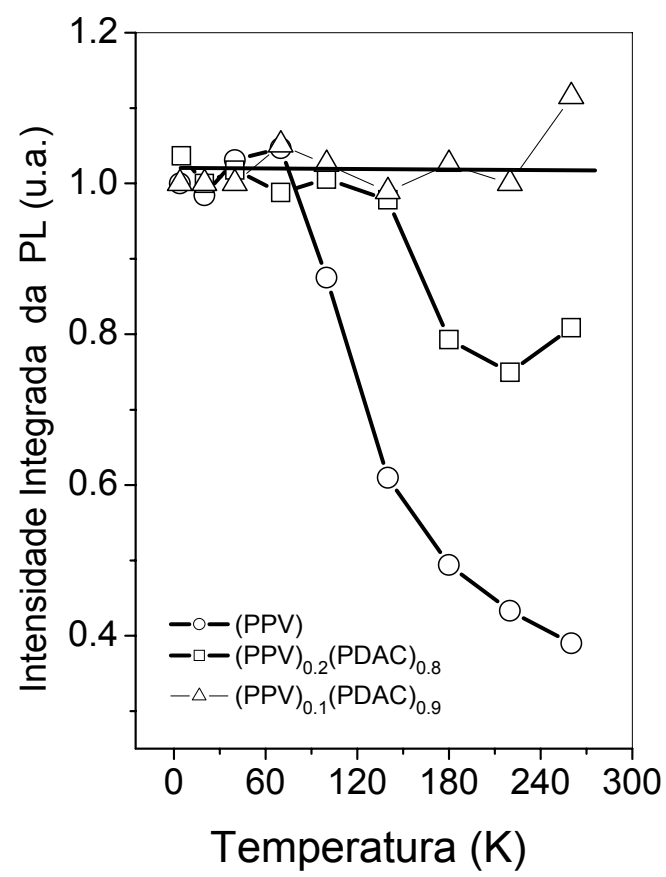

Figura 5.1.6 Intensidade integrada da luminescência (normalizada em $4 \mathrm{~K}$ para melhor visualização) de filmes contendo 10, 20 e $100 \%$ de PPV.

A diluição das moléculas de PPV, em uma matriz inerte, suprime os processos intercadeia. No entanto, a transferência intracadeia ainda está ativada. Como a intensidade da luminescência não decai com a temperatura para os filmes com alto valor de diluição, podemos inferir dos resultados exibidos que os processos intracadeia não são eficientes para transferir a excitação até centros supressores no intervalo de temperaturas estudado (4 a $300 \mathrm{~K})$. Medidas de luminescência em moléculas isoladas [25] demonstram que as taxas de transferências intracadeias são pequenas e comparáveis com aquelas dos processos radiativos.

Em resumo, o alargamento e deslocamento da luminescência observado para as amostras contendo maior separação das cadeias (valores altos de $\mathrm{x}$ ), indicam que segmentos moleculares menores estão participando 
da emissão final. Ou seja, os processos de transferência de energia intercadeia são responsáveis pela diminuição da eficiência da luminescência nos filmes poliméricos, uma vez que provocam a difusão espectral. Este processo de relaxação energética induz grande parte dos decaimentos radiativos nos segmentos longos de PPV e, ao mesmo tempo, maior probabilidade de aprisionamento da excitação nos sítios de extinção energética. 


\subsection{Efeito da separação ao longo da cadeia}

O aumento da eficiência, à custa da separação das cadeias, na blenda $(\mathrm{PPV})_{1-\mathrm{x}} /(\mathrm{PDAC})_{\mathrm{x}}$, pelo polímero espaçador PDAC, seção 5.1, atribuímos à redução da transferência de energia intercadeia, o que reduz a probabilidade da excitação ser suprimida por processos não radiativos. No entanto, restam os processos de transferência intracadeia, haja vista que a difusão espectral se faz também ao longo da cadeia. Além do fato de que o enovelamento das cadeias pode promover que dois segmentos de PPV, pertencentes à mesma cadeia, posicionem se, lado a lado, como se fossem de cadeias distintas que participam dos processos de TE. Para avaliarmos a contribuição dos processos inter e intracadeia, na relaxação energética dos polímeros conjugados, fizemos o estudo do efeito da separação dos segmentos conjugados ao longo da cadeia, analisando as propriedades de emissão do copolímero PPV-PTHT. Mostramos, na seção 3.4, que a incorporação aleatória de determinada concentração de DBS, em solução de PTHT, privilegia um comprimento de conjugação médio $n$, específico para os segmentos conjugados de PPV. Quanto menor for n, maior será a separação dos segmentos de PPV, por segmentos de PTHT não conjugados, ao longo da cadeia. Nesta seção, vamos utilizar o copolímero (PPV)n(PTHT)m para produzir as condições tais que processos de transferência de energia intracadeia sejam reduzidos. 

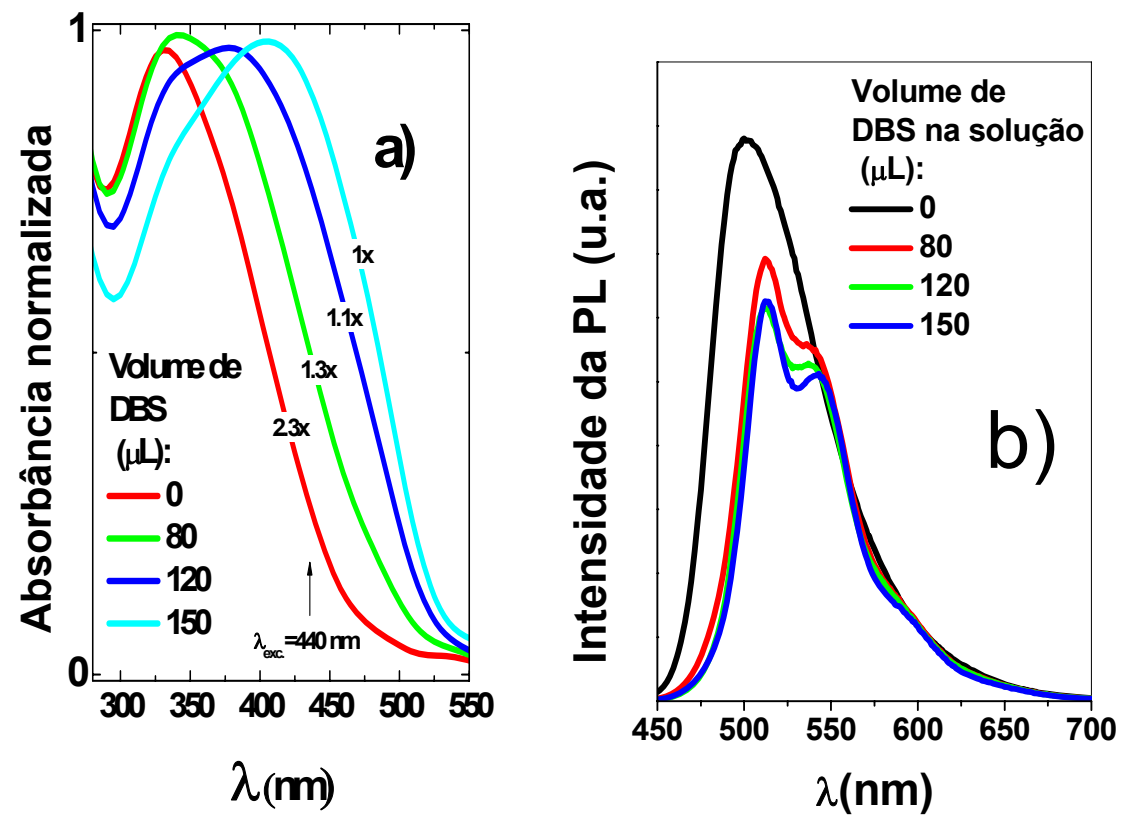

Figura 5.2.1. (a) Absorbância e (b) espectros de luminescência em função do volume de DBS em solução de do polieletrólito precursor do PPV, PTHT.

A Figura 5.2.1a) e Figura 5.2.1b) mostram, respectivamente, os espectros de absorbância e de luminescência do copolímero (PPV)n(PTHT)m obtido de filmes automontados do polímero precursor, o poli(cloreto de xilideno tetrahidrotiofeno) ou PTHT, contendo diferentes volumes de DBS. Após a incorporação de DBS, na solução de PTHT, filmes ultrafinos destes polímeros catiônicos foram automontados (10 bicamadas) com o poliânion, PSS. O PTHT:DBS/PSS foi convertido em PPV após tratamento térmico por 15 minutos, à $110^{\circ} \mathrm{C}$, sob vácuo.

Como já observamos, o efeito da incorporação do DBS pode ser visto na Figura 5.2.1a), através do expressivo deslocamento espectral de $\Delta \lambda=75$ nm $(0,75 \mathrm{eV})$ da absorbância da banda conjugada do PPV em direção ao azul, com o aumento do volume de DBS, $0 \mu \mathrm{L}$ à $150 \mu \mathrm{L}$, na solução de PTHT. Apesar da queda na absorbância, no comprimento de onda de 
excitação $(440 \mathrm{~nm})$, vemos que a intensidade da luminescência do PPV aumenta, Figura 5.2.1b), ao passo que o volume de DBS, em solução, diminui (menor tamanho de conjugação das cadeias). Isto indica que a eficiência da emissão foi alterada pela separação dos segmentos conjugados ao longo da cadeia de PPV. Além disso, observamos que os espectros de emissão sofrem um alargamento e um deslocamento espectral para o azul. Porém este deslocamento é de apenas $12 \mathrm{~nm}(0,058 \mathrm{eV})$, muito menor em relação àquele produzido na absorbância. Isso significa, a excitação é transferida eficientemente para os poucos segmentos de PPV de alta conjugação para depois decair radiativamente na região espectral acima de $500 \mathrm{~nm}$

A razão da intensidade integrada da luminescência pelo valor da absorbância, no comprimento de onda de excitação em 441 nm (eficiência de emissão), é mostrada na Figura 5.2.2, em função do volume de DBS na solução de PTHT. Vemos que a eficiência de emissão aumenta 4 vezes, com o aumento da separação dos segmentos conjugados do PPV (diminuição do volume de DBS no PTHT). Este aumento se deve a dois fatores: (i) a diminuição dos processos de transferência intracadeia (processos intercadeia não foram eliminados nessas amostras, ver próxima seção) e (ii) contribuição da emissão dos segmentos conjugados menores que antes não emitiam, pois atuavam somente nos processos intermediários de TE para os segmentos ainda maiores. Este último fato promove o alargamento e o deslocamento espectral observados na Figura 5.2.1b). Os dois fatores de aumento da eficiência não podem ser separados, nos experimentos acima, e serão tratados mais detalhadamente na próxima 
seção. Contudo, nos filmes de maior volume de DBS, na solução de PTHT

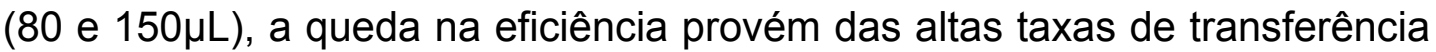
intra e intercadeias, que conduzem a excitação às moléculas menos energéticas e aos centros supressores.

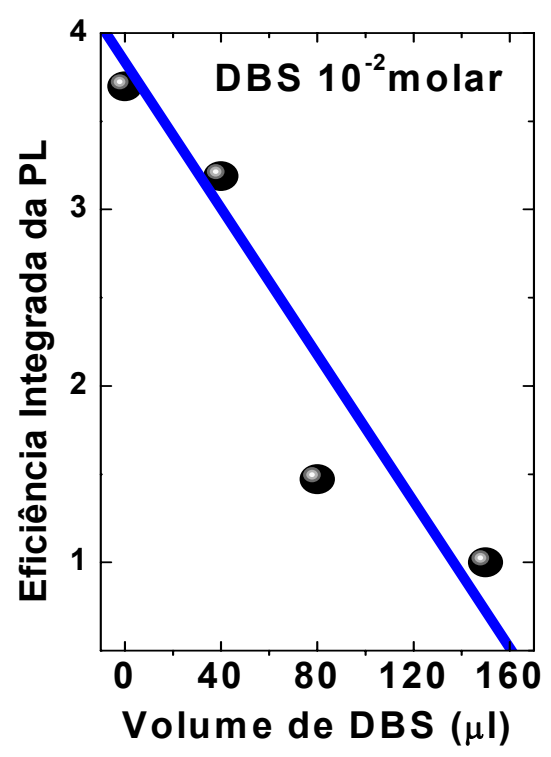

Figura 5.2.2. Eficiência Integrada da PL em função do volume de DBS na solução de PTHT.

Os espectros de PLE normalizados, Figura 5.2.3a), mostram o mesmo deslocamento espectral monotônico para o azul observado na absorbância (Figura 5.2.1a)), à medida que diminui o volume de DBS incorporado, em solução. Porém, os espectros de PLE mostram-se, com um peso espectral mais evidente, na região próxima à borda da banda de absorção (região acima de $425 \mathrm{~nm}$ ), para as amostras contendo maior volume de DBS. Este comportamento pode ser visto na Figura 5.2.3b), que mostra a diferença entre espectros de PLE e de absorção para cada volume de DBS utilizado na produção dos filmes estudados nesta seção. Isto indica um aumento da 
eficiência dos segmentos de maior energia. Advindo do fato de a excitação selecionar sítios de maior energia, que estão em pequena concentração, ou seja, maior separação, na região da lacuna de energia. A queda da diferença entre a PLE e a absorbância para altas energias se deve à atuação de processos não-radiativos que competem com os processos de relaxação energética intermediários e processos radiativos finais.

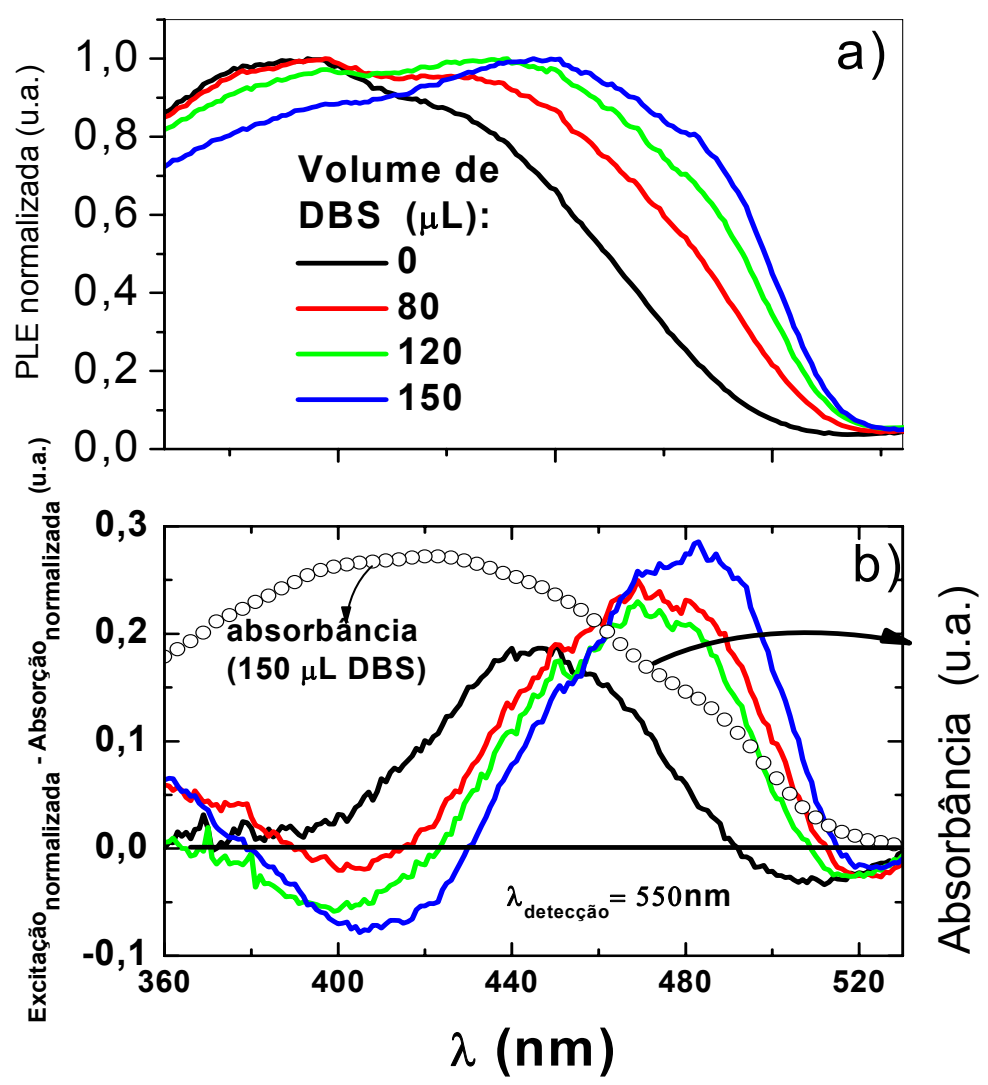

Figura 5.2.3. (a) PLE normalizada e (b) diferença entre o espectro de excitação (PLE da figura a) e o espectro de absorbância (da figura 5.2-1a), em função do volume de DBS em solução de do polieletrólito precursor do PPV, PTHT. 0 espectro de absorbância (círculos) de uma amostra preparada com $150 \mu$ le dBS é mostrado para efeito de comparação. 
$\mathrm{Na}$ Figura 5.2.3b), o deslocamento relativo entre os espectros provém das diferentes taxas de transferência de energia, por sua vez influenciadas pelas estruturas distintas do copolímero presente em cada amostra. $\mathrm{O}$ filme contendo $0 \mu \mathrm{L}$ de DBS tem sua maior contribuição espectral localizada no intervalo de 390 a 490nm. Este fenômeno procede da distribuição de segmentos, neste filme, que está deslocada para os pequenos comprimentos dos segmentos conjugados. Para os filmes de maior conjugação, existe um expressivo aumento da eficiência da luminescência na região de maiores comprimentos de onda, comprovando o efeito da separação dos segmentos emissores pela excitação. Além disso, o experimento demonstra que o esqueleto do copolímero apresenta grandes segmentos não conjugados de PTHT, entre dois segmentos conjugados de PPV. O PTHT, neste caso, funciona como separador para a transferência de energia intracadeia.

O fato da difusão espectral ser alterada pela separação intracadeia, responde à questão sobre o alargamento dos espectros de emissão das amostras com pequenas concentrações de DBS, Figura 5.2.1b). Ou seja, parte da excitação passa a decair, em segmentos conjugados menores de PPV, quando a difusão espectral é limitada, deslocando e alargando o espectro para as altas energias. Outra parte da excitação alcança eventuais segmentos maiores que emitem nos grandes comprimentos de onda.

A Figura 5.2.4 mostra a dependência com a temperatura da luminescência do PPV na estrutura do copolímero $(P P V)_{n}(P T H T)_{m}$, para volumes de DBS de $0 \mu \mathrm{L}$ e $150 \mu \mathrm{L}$. Isto corresponde a dois diferentes comprimentos do segmento conjugado, (PPV) n. 
O filme $0 \mu \mathrm{L}$ de DBS possui, em média, maior quantidade de segmentos menores de PPV, que são distanciados, no esqueleto do copolímero, por grandes segmentos de PTHT. Esta característica estrutural atenua os processos de transferência de energia intracadeia. Já no filme de $150 \mu \mathrm{L}$ DBS, as restrições para os processos inter e intracadeia são menores, ou seja, as taxas de transferência de energia são maiores, o que favorece o processo de migração da excitação.

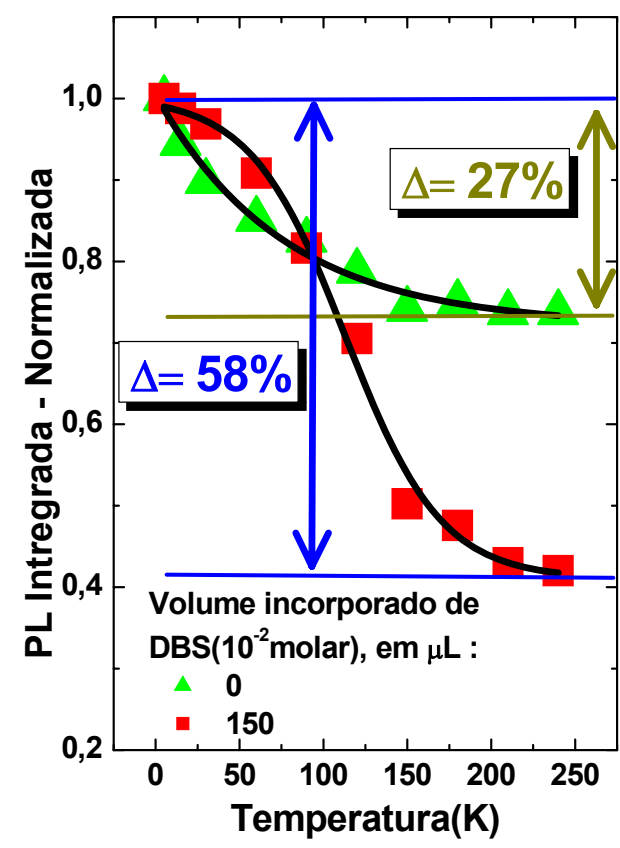

Figura 5.2.4 Fotoluminescência integrada em função da temperatura para os volumes de DBS na solução de PTHT de $0 \mu \mathrm{L}$ e de $150 \mu \mathrm{L}$.

Confirmamos novamente, segundo análise da Figura 5.2.4, que a temperatura atua como ativador de centros de extinção da energia. É visto pelo aumento da intensidade da luminescência, à medida que diminuímos a temperatura. Se fizermos o caminho inverso, veremos uma queda de $27 \%$ na intensidade da luminescência, conforme a temperatura aumenta para a 
amostra de $0 \mu \mathrm{L}$ de DBS. Para o filme de $150 \mu \mathrm{L}$ de DBS, a queda da intensidade da emissão é de $58 \%$. Nestes filmes, os segmentos de PPV estão mais próximos ao longo da cadeia, a ponto de favorecer alta migração por TE, o que aumenta a probabilidade de parte da excitação ser suprimida por canais de decaimento não radiativo. O mesmo processo de migração é reduzido, para a amostra de $0 \mu \mathrm{L}$ de DBS, induzindo menor variação da intensidade da luminescência com a temperatura. 


\subsection{Separações Simultâneas Intracadeia e Intercadeia}

Sondamos os efeitos sobre a luminescência quando realizadas as duas modalidades de separação dos segmentos conjugados em um filme: (i) a separação intercadeia, feita pelo polímero espaçador PDAC, e (ii) a separação intracadeia, proporcionada pela incorporação do sal orgânico DBS que dá origem ao copolímero $(\mathrm{PPV})_{\mathrm{n}}(\mathrm{PTHT})_{\mathrm{m}}$. Os filmes de PPV desta seção foram preparados por automontagem a partir de uma solução catiônica contendo frações de PTHT, DBS e PDAC e de uma solução aniônica contendo PSS. Variações da fração de PDAC, x, e do volume de DBS incorporado, na solução catiônica, produziram juntamente a separação intra e intercadeia. O filme precursor (PTHT:DBS:PDAC)/PSS foi convertido em PPV após tratamento térmico por 15 minutos, à 110 oC, sob vácuo.

Os espectros de absorbância, luminescência e PLE dos filmes com separação simultânea intracadeia e intercadeia exibem as mesmas propriedades relacionadas à forma de linha e à relaxação energética já apresentadas nas seções anteriores. Logo, analisaremos, nesta seção, somente as propriedades e os efeitos dessa estrutura molecular embasados nos ganhos de eficiência da emissão e deslocamento da linha de zero fônon.

O quadro da Figura 5.3.1 compara os valores da eficiência (números absolutos em evidência) da luminescência conseguidos à medida que provocamos a separação inter e intracadeia. No eixo das abscissas 
encontram-se os volumes de DBS utilizados e o eixo das ordenadas referese a dois valores extremos de frações volumétricas de PDAC, ou seja, $x=0$ (amostra não diluída) e x=0,9 (amostra com diluição entrecadeia). As setas indicam o sentido em que há um aumento de eficiência da luminescência com a separação molecular. Como anteriormente, verifica-se o aumento da eficiência de emissão para todos os casos de separação molecular tratados (veja sentido das setas).

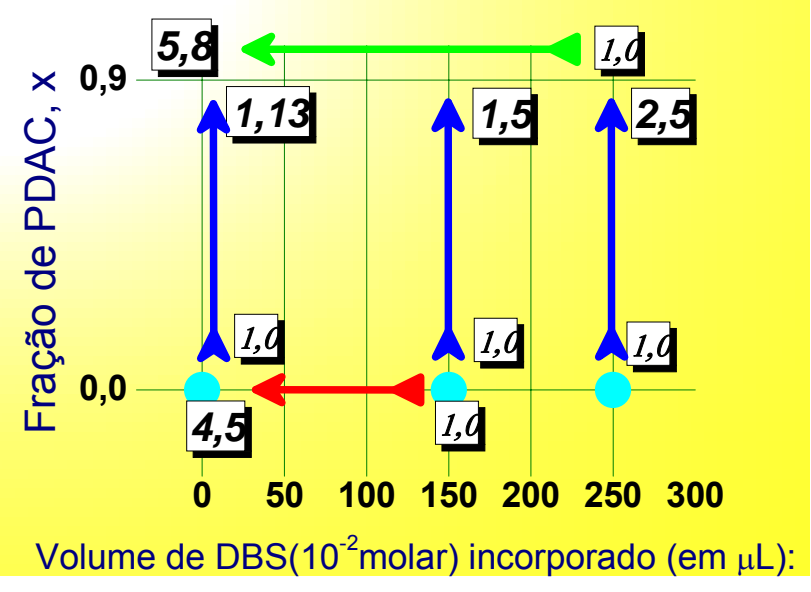

Figura 5.3.1 Ganho de eficiência da PL ao se atenuarem os processos de transferência de energia inter e intracadeia. As amostras de que extraímos os dados têm como solução aniônica: PSS, e catiônica: PTHT/DBS/PDAC, ambas aquosas.

Os valores relativos de aumento da eficiência exibidos não são comparáveis aos conseguidos nas seções 5.1 e 5.2, uma vez que a engenharia molecular adotada, neste estudo, difere das anteriores, tendo como solução aniônica PPS, que não demonstra o mesmo controle sobre o comprimento de conjugação do DBS utilizado nos estudos posteriores.

A seta vermelha, sobre o eixo de fração de PDAC, $\mathbf{x}=\mathbf{0}$, mostra o efeito que a obstrução parcial da transferência intracadeia causa na luminescência final. Esta seta remete à diminuição dos segmentos médios 
de PPV e aumento dos segmentos de PTHT no copolímero (sem que tenhamos promovido a separação intercadeia). Neste caso, o ganho de eficiência deve se ao fato de separarmos, no esqueleto do copolímero (PPV)n(PTHT)m, os segmentos de PPV com os segmentos não conjugados de PTHT. Assim como a seta verde exibe o aumento de 5,8 vezes da eficiência ao promovermos a separação intracadeia, diminuição do volume de DBS de 250 a $0 \mu \mathrm{L}$, em uma série de filmes com $x=0,9$ de PDAC. As setas azuis indicam o efeito da separação entre cadeias para diferentes valores de separação intercadeia (diferentes volume de DBS).

Comparando-se as setas azuis, o decréscimo do ganho da eficiência com o aumento da separação intracadeia (decréscimo do volume de DBS) indica que esta separação sozinha já é bastante efetiva (ganho de 4,5 sobre o eixo das abscissas). Por outro lado, a separação intracadeia de amostras com alta separação entre cadeias (seta verde) produz um grande aumento da eficiência de emissão, sugerindo que os processos de TE ao longo da cadeia contribuem eficientemente para a relaxação energética da excitação eletrônica nos polímeros conjugados.

As separações inter e intracadeia do segmento conjugado, no mesmo filme, principalmente atenuam a taxa de TE, ou seja, reduzem o processo de migração da excitação e, conseqüentemente, diminui a probabilidade da mesma alcançar centros supressores de energia. Portanto, a separação inter e intracadeia induzem o aumento da eficiência da emissão, haja vista que nos filmes mais diluídos a queda na intensidade da absorbância não acompanha àquela na intensidade da emissão. 
Como vimos acima, a TE é extremamente eficiente tanto para processos intercadeia, como para processos intracadeia. Este resultado é compartilhado por trabalhos recentes envolvendo espectroscopia de uma única molécula $[26,27]$. Estes trabalhos mostram que, em uma comparação entre TE inter- e intracadeia, em polímeros conjugados, a migração da excitação intracadeia possui menor uma menor taxa de probabilidade do que a intercadeia (pico segundos), ou seja, ocorre em tempos maiores (décimos de ns), contudo dentro do tempo de vida da excitação.

Os dados das seções anteriores mostram que a migração inter- e intracadeia são tão eficientes que, após inúmeras transferências de energia, TE, a excitação é capaz de relaxar a energia e encontrar os segmentos conjugados longos, onde decai radiativamente, ou defeitos que a suprimem. Isto pode ser visto pelo pequeno deslocamento espectral da luminescência em relação à absorção (seção 2.10). No entanto, os mesmos dados mostram que com a separação, estes processos são limitados, o que pode ser visto pelo aumento da eficiência da luminescência, bem como pelo alargamento e pelo deslocamento espectral. 

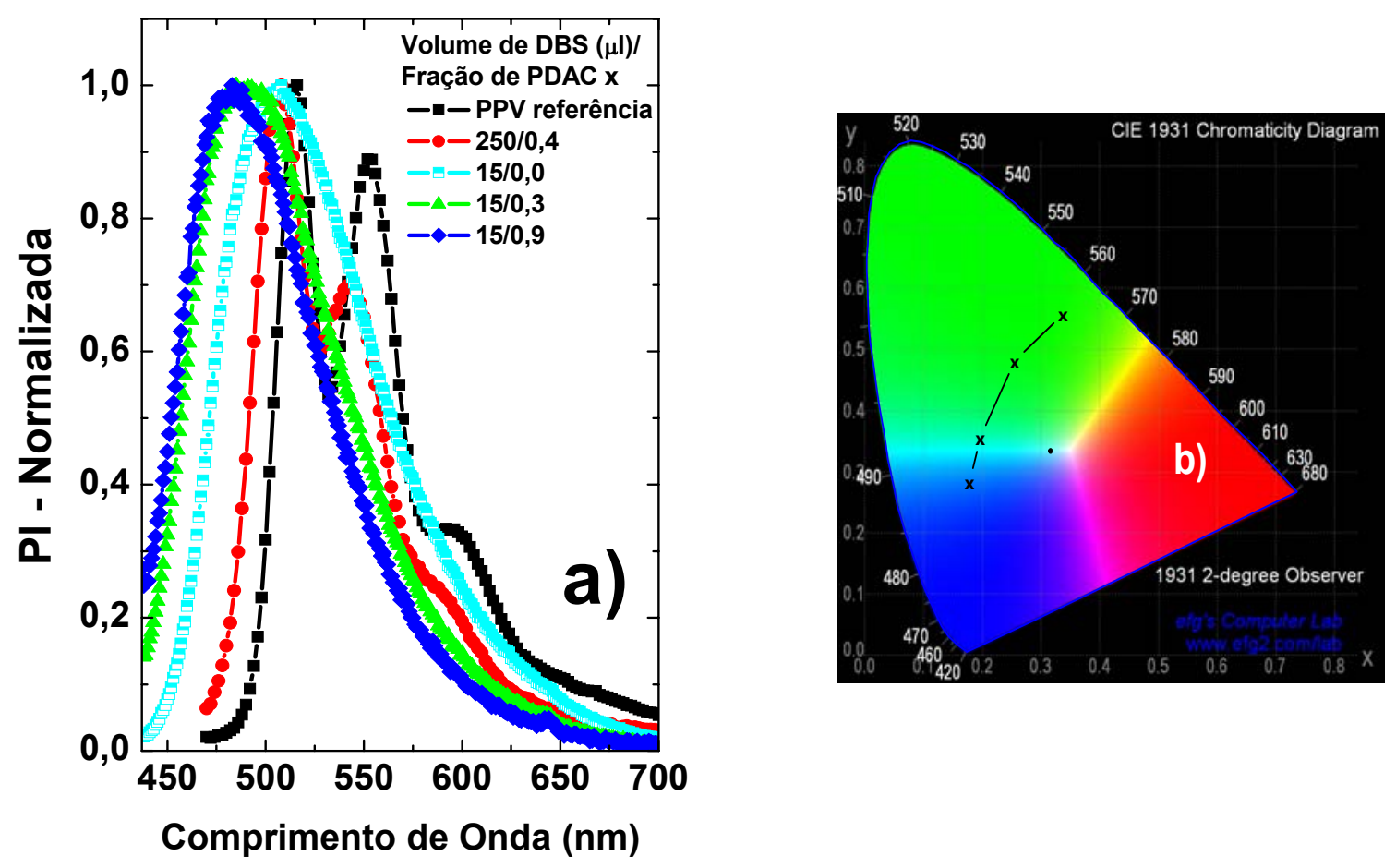

Figura 5.3.2 a) Lunimescência normalizada em função das separações dos segmentos de PPV, através do separador PDAC e pela seleção do comprimento da molécula conjugada mediante incorporação de DBS. b) triângulo de cores, em que se tem o grau de pureza da cor, apresentamos o deslocamento da banda de emissão conforme se separam as cadeias.

No entanto, o processo de migração só pode ser efetivamente controlado se ambas as separações forem feitas simultaneamente. Isto pode ser visto na Figura 5.3.2a), que mostra o efeito da separação simultânea intra- e intercadeia. Os resultados da Figura 5.3.2a) mostram tanto um deslocamento espectral quanto um alargamento da forma de linha, ambos provocados pela separação dos segmentos de PPV. Observa-se que o deslocamento é ainda maior para o azul quando temos as duas separações no filme estudado. Isto significa que os segmentos menores de PPV (maior 
energia), que antes participavam apenas dos processos intermediários de relaxação energética durante a TE, agora, apresentam-se nos processos finais de recombinação radiativa, isto explica tanto o deslocamento para o azul, quanto o alargamento espectral. Porém, como a distribuição de comprimentos dos segmentos de PPV obedece a uma 'Gaussiana' [28], seção 2.2, e mesmo que tenhamos segmentos pequenos, em maior número, ainda segmentos grandes são alcançados pela excitação no estado final, alargando o espectro de emissão.

Na Figura 5.3.2 b), apresentamos, o deslocamento do comprimento médio espectral (definido como a média ponderada dos comprimentos de onda) das emissões da Figura 5.3.2a) através do diagrama cromático. Vemos claramente que o comprimento de onda médio se desloca do verdeamarelado para o azul-esverdeado à medida que separamos os segmentos de PPV. Este resultado é a primeira demonstração de emissão do PPV no azul e da importância dos processos de TE na forma de linha espectral de polímeros conjugados. 


\subsection{Efeito da separação molecular na polarização da emissão}

$\mathrm{Na}$ seção 4.2, vimos que filmes automontados apresentam um alto grau de polarização da luminescência $\left(\mathbf{P}_{\|} / \mathbf{P}_{\perp}>\mathbf{3}\right)$ devido a um pequeno ordenamento molecular na direção do escoamento da água durante a preparação pelo método de automontagem. Nesta seção, estudamos a origem da alta polarização nestas amostras através da separação molecular nessas amostras. Analisamos a luz emitida por estes filmes através de um analisador (polarizador linear) conforme o procedimento experimental mostrado na seção X.Xx.

Verificamos a anisotropia na luminescência em três amostras que apresentavam diferentes características:

1. Filmes de PPV de alto grau de conjugação (250 $\mu$ de DBS) diluídos no polímero opticamente inerte PDAC. Aqui variamos a proporção de PDAC na solução de PPV, o que corresponde uma diluição Intercadeia dos segmentos conjugados.

2. Filmes de PPV com grau de conjugação intermediário (150 $\mu$ de DBS) e também variamos a proporção de PDAC em solução.

3. Filme de referência de PPV depositado pelo método "spincasting", que apresentam alto grau de desordem.

A Figura 5.4.1 compara as medidas de polarização em função do ângulo que o analisador (polarizador) faz com a direção da luz de excitação 
(paralela à direção de escoamento da água) para uma amostra 'spincasting' e outra preparada por automontagem. Percebemos que para os filmes automontados, razão $\mathrm{P}_{/ /} / \mathrm{P}_{\perp}=4,5$ (maior que 3), indicando o alto grau de organização molecular. Já nos filmes casting, $P_{/ /} / P_{\perp}=1,5$ (menor que 3), sugerindo que a TE redistribui a polarização inicial pela luz incidente polarizada para outras direções no plano da amostra, correspondendo a um processo de despolarização.

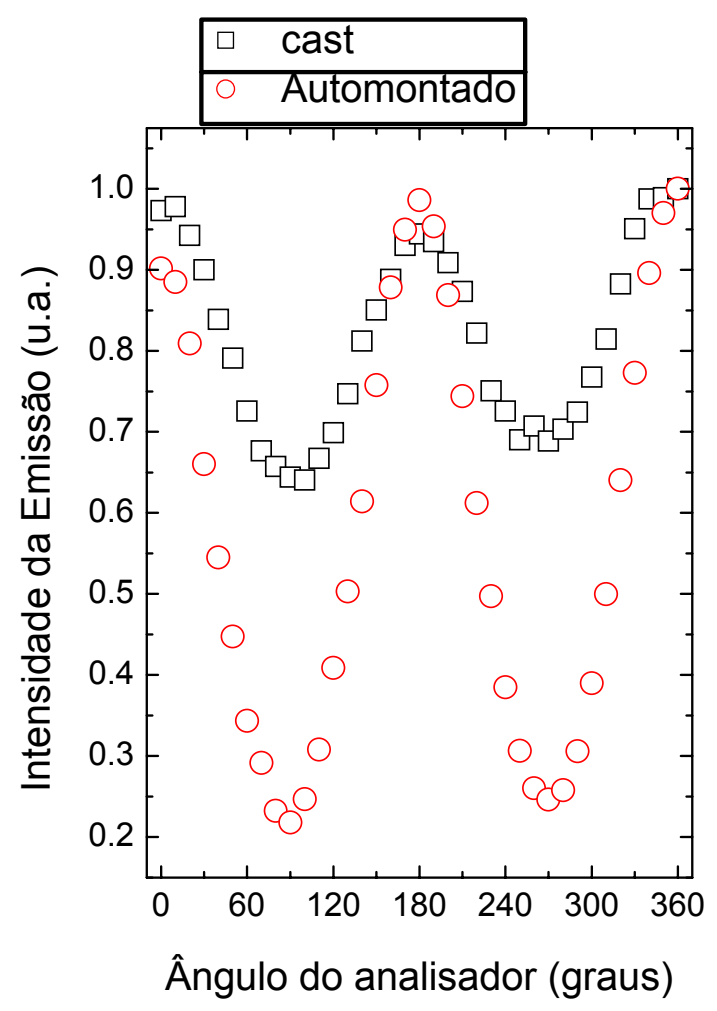

Figura 5.4.1 Medidas de Polarização de filmes construídos pelos métodos de automontagem e spincasting, em função do posicionamento do analisador (polarizador) em relação a polarização da luz de excitação.

$\mathrm{Na}$ seção 4.3., demonstramos que os processos de TE são responsáveis pelo alto grau de polarização da luz emitida em filmes spincast de PPV sobre teflon com pequeno grau de ordenamento molecular. Como 
filmes automontados apresentam uma alta polarização da luminescência devido à TE, esta deve ser alterada com a separação dos segmentos conjugados.

A Figura 5.4.2 mostra a dependência da polarização da luminescência $\mathbf{P}_{\| / /} \mathbf{P}_{\perp}$, em função da fração $\mathbf{x}$ de PDAC, na solução precursora de PTHT, para dois filmes contendo cada 150 e $250 \mu$ ld DBS, respectivamente.

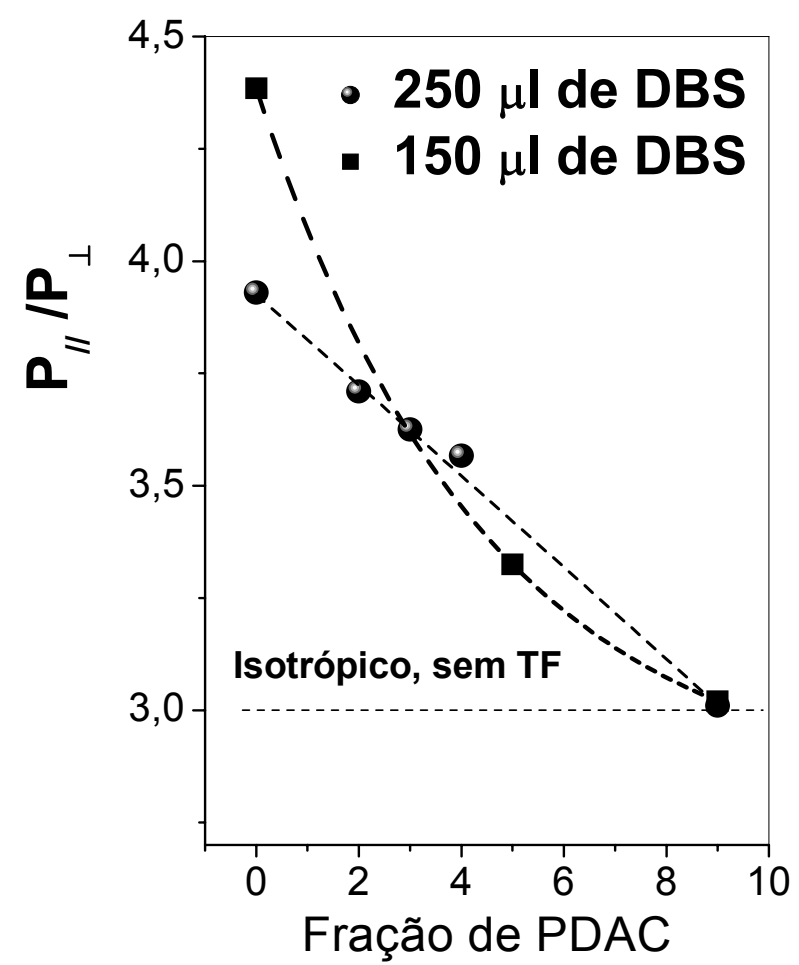

Figura 5.4.2 Razão $P_{/ /} / P_{\perp}$ da Intensidade da luz emitida paralelamente $\left(P_{/ /}\right)$e perpendicularmente $\left(P_{\perp}\right)$ à direção de polarização da luz do laser de excitação.

Vemos pela Figura 5.4.2 que a polarização da luminescência diminui com o aumento da diluição para os dois casos considerados, atingindo a razão $\mathrm{P}_{/ /} / \mathrm{P}_{\perp}=3$ esperada para uma distribuição isotrópica de segmentos conjugados para altas frações de PDAC. No caso de baixa diluição, a TE transfere a excitação eletrônica dos segmentos conjugados desordenados 
para segmentos ordenados que participam da emissão (processo final) $\circ$ que produz luminescência com alta polarização. No caso de alta diluição, a TE é suprimida pela separação molecular, o que faz com que o decaimento radiativo da excitação ocorra em segmentos conjugados desordenados isotrópicos excitados pela luz polarizada incidente. Este resultado mais uma vez demonstra que processos de TE são responsáveis pela alta polarização da luminescência em filmes que apresentam uma pequena ordem molecular, corroborando os resultados obtidos para amostras de PPV sobre teflon com pequeno grau de estiramento.

A pequena anisotropia molecular dos filmes automontados gera a polarização da luminescência através da TE. A separação molecular produzida pelo PDAC na Figura 5.4.2 reduz a migração intercadeia, reduzindo o grau de polarização ao valor esperado sem a presença de TE. Portanto, concluímos que nos filmes com baixíssima anisotropia, os processos de TE intercadeia são predominantes e responsáveis pela migração da excitação dos segmentos conjugados desordenados (curtos) para os segmentos conjugados ordenados (longos). Acreditamos que estes processos intercadeia sejam responsáveis pela inversão e aumento da polarização nos filmes de PPV sobre teflon na região de baixo grau de estiramento $(\mathrm{L} / \mathrm{Lo}<1,4)$. Com o aumento do estiramento $(\mathrm{L} / \mathrm{Lo}>1,4)$ ocorre $\mathrm{o}$ desenovelamento das cadeias do PPV. Desta forma, é de esperamos que, neste caso, os processos intracadeia sejam favorecidos por este desenovelamento, concorrendo com os processos intercadeia na migração das excitações. 
Capítulo 6

6. Conclusão 
Nosso objetivo inicial para o presente trabalho consistiu em estudar: (i) a influência do ordenamento molecular no estado de polarização da luz emitida pelos filmes poliméricos de poli ( $p$-fenileno vinileno) (PPV) e (ii) os tipos de mecanismos de transporte de energia, Transferência de Energia Intracadeia e Intercadeia, que ocorrem entre os segmentos conjugados de PPV.

Afirmamos primeiramente, as metodologias adotadas, para a construção dos filmes finos: (i) método SA ou automontagem LbL e (ii) método 'spincast', promoveram o crescimento de filmes homogêneos o que nos garantiu a reprodutibilidade dos resultados. Os substratos: Teflon, quartzo e vidro se adequaram, aos objetivos de cada experimento, permitindo colhermos os espectros advindos puramente do PPV. Além disso, o substrato de Teflon possibilitou, por meio de suas propriedades físicas: térmicas e de elasticidade, as medidas sob estiramento.

No estudo de filmes não estirados, sobre Teflon, através de cálculos, embasados na teoria descrita na Introdução Teórica, concluímos que os filmes de PPV 'spincast' são isotrópicos. Ao detalharmos os espectros de fotoluminescência, vemos que a TE constitui uma propriedade de alta 
relevância. Pois atribuímos a despolarização da luminescência dos filmes 'spincast' ao fato de que a TE redistribui a excitação aos estados finais emissivos, localizados em segmentos desordenados de PPV. Contudo, em uma mesma forma de análise, para os filmes LbL, verificamos certa anisotropia axial na emissão, sobre o eixo de imersão, adquirida do seu processo de fabricação. Por outro lado, percebemos que uma pequena anisotropia, na rede polimérica, faz com que a luz emitida seja polarizada, ou seja a TE canaliza a excitação até os segmentos conjugados de PPV orientados.

No estudo de filmes com baixo grau de estiramento, sobre Teflon, concluímos que, suportados nos cálculos da seção Introdução Teórica, filmes de PPV 'spincast', cuja isotropia é intrínseca, apresentam, mesmo que para pequenos estiramentos uniaxiais, alta polarização da luminescência sobre o eixo de estiramento. A partir dos cálculos teóricos encontramos a distribuição angular média dos segmentos de PPV orientados pelo estiramento. A TE é responsável por direcionar eficientemente a excitação, mesmo de moléculas orientadas perpendicularmente ao estiramento, àquelas orientadas sobre o eixo de estiramento. No caso de filmes LbL, sob pequenos estiramentos, encontramos os mesmos efeitos dos filmes 'spincast', entretanto, a anisotropia residual da técnica de fabricação, satura a polarização da luminescência, à medida que o grau de estiramento aumenta.

Nos filmes diluídos com PDAC entendemos que, quando a separação intercadeia supera a distância máxima permitida para a que haja TE, a migração da excitação para os segmentos conjugados longos e para os centros supressores fica, praticamente, limitada, o que contribui sobremaneira para o 
aumento da eficiência da luminescência, alargamento e deslocamento espectrais.

Para os filmes em que induzimos a separação intracadeia, através da incorporação seletiva de volumes de DBS, verificamos: (i) que transferência de energia ao longo das cadeias também contribuem efetivamente no transporte da excitação em polímeros conjugados e (ii) que a separação intracadeia impede parcialmente a energia de excitação de desintegrar-se em centros supressores. Além disso, estas duas afirmações explicam o aumento da eficiência da luminescência, alargamento e deslocamento espectrais.

Aliamos as duas modalidades de diluição inter e intracadeia, no mesmo filme, e constatamos a capacidade de modularmos a banda de emissão através da separação inter e intracadeia simultâneas.

Vimos também que a migração intercadeia é responsável pela despolarização da luminescência. 


\section{Referências Bibliográficas}


1. MARletTA, A., Processos ópticos de semi-orgânicos à base de Polímeros emissores de Luz., 2001, Tese (Doutorado). Instituto de Física de São Carlos, Universidade de São Paulo.

2. MARLETTA, A., Propriedades ópticas de semicondutores orgânicos à base de polímeros emissores de luz., São Carlos, 2001, 221,Tese (Doutorado), Instituto de Física de São Carlos,, Universidade de São Paulo - USP

3. SERVICE, R.F., Organic light emitters gain longevity. Science. 273(5277): p. 878-880, 1996

4. ALONSO, M.F., E., Fundamental University Physics: Quantum

and Statistical Physics. Vol. Volume III: Addison-Weley Pulishing Company, 1968

5. LU, Y., Solitons and Polarons in Conducting Polymers. World Scientific, Singapora, 1987.

6. $\quad$ PEIERLS, R.E., Quantum Theory of Solids: Oxford University Press, 1955

7. FRIEND, R.H.B., D.D.C.; TOWNSEND, T.D., Photo-excitation in conjugated polymers. Phys.D: Appl.Phys. 20: p. 1367-1384, 1987

8. SU, W.P.S., J.R.; HEEGER, A. J., Solitons excitations in Polyacetylene. . Phys. Rev.B22. erratum, 28: p. 1138, 1983.

9. SU, W.P.S., J.R.; HEEGER, A. J., Solitons in Polyacetylene. Phys. Rev.Lett.,. 42: p. 1698, 1979.

10. CHANDROSS, M., et al., Excitons in Poly(Para-Phenylenevinylene). Physical Review B. 50(19): p. 14702-14705, 1994

11. BORGES, C.A.M., Processos radiativos e não radiativos em polímeros conjugados emissores de luz., São Carlos, 2001, Dissertação (Mestrado), Instituto de Física de São Carlos, Universidade de São Paulo.

12. GUILLET, J., Polymer photophysics and photochemistry: An introduction to the study of photoprocesses in macromolecules.: Cambridege University Press, 1985

13. FOERSTER, T.H., Discussion of the Faraday Society. 27: p. 7-17, 1959

14. YAMAZAKI, I., N. TAMAI, and T. YAMAZAKI, Electronic Excitation Transfer in Organized Molecular Assemblies. Journal of Physical Chemistry. 94(2): p. 516-525, 1990

15. BACCHIOCCHI, C. and C. ZANNONI, Energy transfer in condensed systems - The effect of phase organization. Chemical Physics Letters. 268(56): p. 541-548, 1997 
16. NISHIJIM.Y, Y. ONOGI, and T. ASIA, Fluorescence Method for Studying Molecular Orienatation in Polymer Solids. Journal of Polymer Science Part C-Polymer Symposium,(15PC): p. 237-\&, 1966

17. NORDEN, B., Applications of Linear Dichroism Spectroscopy. Applied Spectroscopy Reviews. 14(2): p. 157-248, 1978

18. IRVINE, P.A. and P. SMITH, Development of the Axial Young Modulus with Draw Ratio of Flexible-Chain Polymers. Macromolecules. 19(1): p. 240-242, 1986

19. DIRIX, Y., T.A. TERVOORT, and C. BASTIAANSEN, Optical-Properties of Oriented Polymer Dye Polarizers. Macromolecules. 28(2): p. 486-491, 1995

20. KERN, W., Purifying Si and SiO2 surfaces with hydrogen peroxide. Semiconductor International. v. 94, 1984

21. HENDERSON, B. and G.F. IMBUSCH, Optical Spectroscopy Of Organic Solids: Oxford Science Publication, 1989

22. DECHER, G. and J.D. HONG, Buildup of Ultrathin Multilayer Films by a Self-Assembly Process .2. Consecutive Adsorption of Anionic and Cationic Bipolar Amphiphiles and Polyelectrolytes on Charged Surfaces. Chemistry Chemical Physics. 95(11): p. 1430-1434, 1991

23. MARLETTA A., Mat. Res. Soc. Symp. Proc. 560: p. 309, 1999

24. MARLETTA, A., et al., Rapid conversion of poly(p-phenylenevinylene) films at low temperatures. Advanced Materials. 12(1): p. 69-+, 2000

25. C.A.M., B., Processos radiativos e não radiativos em polímeros conjugados emissores de luz, São Paulo, 2002, Doutorado, Instituto de Física de São Carlos, Universidade de São Paulo.,

26. J. G. MÜLLER, U.L., G. RASCHKE, M. ANNI, U. SCHERF, J. M. LUPTON, AND FELDMANN, Linewidth-Limited Energy Transfer in Single Conjugated Polymer Molecules. Phys. Rev.Lett.,. 91: p. 267403-1a4, 2003

27. M.M. -L. GRAGE, P.W.W., A. RUSECKAS, T. PULLERITS, W. MITCHELL AND P. L> BURN, I. D. W. SAMUEL, V. SUNDSTRÖM, Conformational disorder and energy migration in MEH-PPV with partially broken conjugation. Journal of Chemical Physics. 118(16): p. 7644 a 7650, 2003

28. CHANG, R., et al., Experimental and theoretical investigations of absorption and emission spectra of the light-emitting polymer MEH-PPV in solution. Chemical Physics Letters. 317(1-2): p. 142-152, 2000 